\title{
Rational Design of High Performance Conjugated Polymers for Organic Solar Cells
}

\author{
Huaxing Zhou, ${ }^{\dagger}$ Liqiang Yang, ${ }^{\ddagger}$ and Wei You*, ${ }^{\dagger}$, \\ ${ }^{\dagger}$ Department of Chemistry, University of North Carolina at Chapel Hill, Chapel Hill, North Carolina 27599-3290, United States \\ ${ }^{\ddagger}$ Curriculum in Applied Sciences and Engineering, University of North Carolina at Chapel Hill, Chapel Hill, \\ North Carolina 27599-3287, United States
}

\begin{abstract}
The research on the polymer-based solar cells (PSCs) has attracted an increasing amount of attention in recent years because PSCs pose potential advantages over mainstream inorganic-based solar cells, such as significantly reduced material/fabrication costs, flexible substrates, and light weight of finished solar cells. The research community has made great progress in the field of bulk heterojunction ( $\mathrm{BHJ}$ ) polymer solar cells since its inception in 1995. The power conversion efficiency (PCE), a key parameter to assess the performance of solar cells, has increased from $1 \%$ in the 1990 s to over $8 \%$ just recently. These great advances are mainly fueled by the development of conjugated polymers used as the electron-donating materials in BHJ solar cells. In this Perspective, we first briefly review the progress on the design of conjugated polymers for polymer solar cells in the past 16 years. Since a conjugated polymer can be arbitrarily divided into three constituting components-the conjugated backbone, the side chains, and the substituents-we then focus on the rational design of conjugated polymers by separately discussing the influence of each component on the physical and photovoltaic (PV) properties of these polymers. Special attention is paid to the design of donoracceptor type low-band-gap polymers because this approach is prevailing in the literature with its unique features. In doing so, we strive to extract useful rules for the rational design of conjugated polymers with predictable properties. We conclude by proposing future research opportunities to achieve even higher PCEs for PSCs.
\end{abstract}

\section{INTRODUCTION}

1.1. Background. Polymer solar cells (PSC) have attracted an increasing amount of attention in the research community due to the potential advantages of PSC over inorganic-based solar cells, including low cost, light weight, and fast/cheap rollto-roll production. ${ }^{1-7}$ Typically, p-type semiconductor (i.e., electron DONOR, such as conjugated polymers) and n-type semiconductor (i.e., electron ACCEPTOR, such as fullerene derivatives) are blended in a bulk heterojunction (BHJ) configuration as the core component for PSC. ${ }^{3}$ The interpenetrated network of $\mathrm{BHJ}$ offers two advantages: (a) it minimizes the traveling distance of excitons (electron-hole pair generated upon light absorption) to the DONOR/ACCEPTOR (D/A) interface and concurrently maximizes the $\mathrm{D} / \mathrm{A}$ interfacial area, thereby ensuring the exciton dissociation at the $\mathrm{D} / \mathrm{A}$ interface to generate maximum free charge carriers; (b) it offers charge transport pathways to facilitate the charge collection at electrodes, completing the conversion of the photon energy to electrical energy (i.e., photovoltaic effect). In a complete BHJ solar cell, the active layer is sandwiched between a transparent anode (typically tin-doped indium oxide, ITO) and a metal cathode (Figure 1). Additionally, a thin layer of poly $(3,4-$ ethylenedioxythiophene)-poly(styrenesulfonate) (PEDOT: PSS) is generally applied in between the ITO and the active layer to improve the electrical contact between the ITO and the active layer and to adjust energy levels. ${ }^{8}$

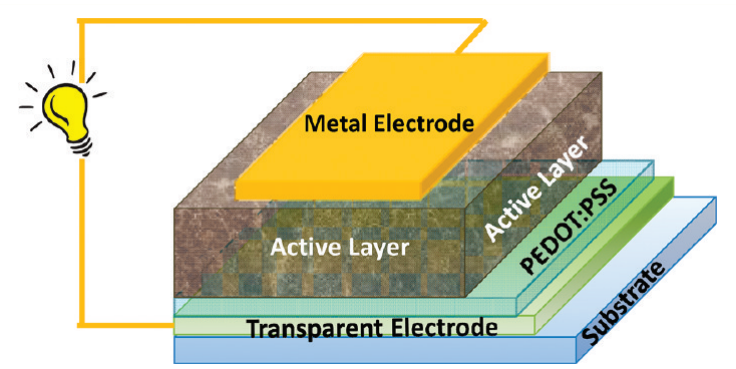

Figure 1. Schematic illustration of the structure of a typical bulk heterojunction polymer solar cell device.

The power conversion efficiency (PCE) of polymer solar cells has improved rapidly from below $1 \%$ to over $8 \%$ in the past 16 years. ${ }^{9}$ This impressive accomplishment is mainly achieved by the molecular engineering of the structure of conjugated polymers (as the DONOR materials), ${ }^{10-12}$ assisted by limited successes in derivatizing the fullerenes (as the electron ACCEPTOR). ${ }^{12-18}$

Because of the limited solubility of buckminsterfullerene $\left(\mathrm{C}_{60}\right)$ in common organic solvents, a fullerene derivative, [6,6]phenyl-C61-butyric acid methyl ester $\left(\mathrm{PC}_{61} \mathrm{BM}\right)$, has been used as

Received: July 18, 2011

Revised: November 11, 2011

Published: January 11, 2012 
a standard and efficient ACCEPTOR material in PSC. The photoinduced charge transfer from the conjugated polymer to $\mathrm{PC}_{61} \mathrm{BM}$ occurs quantitatively on the picosecond time scale with exciton dissociation rate near unity, ${ }^{3}$ a unique feature inherited from the original $\mathrm{C} 60 .{ }^{19}$ Although some other high performance fullerene derivatives have also been developed over the years, ${ }^{12-18,20}$ the relatively cheap and commercially available $\mathrm{PC}_{61} \mathrm{BM}$ is still widely applied as the standard ACCEPTOR material. In recent years, $\mathrm{PC}_{71} \mathrm{BM}, \mathrm{C}_{70}$ analogue of $\mathrm{PC}_{61} \mathrm{BM}$, was used in some research groups to increase PCE because of its better light absorption in the visible region. ${ }^{15}$ In this Perspective, we will focus on the rational design of conjugated polymers under the assumption that $P C_{61} B M / P C_{71} B M$ is used as the electron $A C C E P T O R$. The seemingly narrow topic of conjugated polymer-based solar cells in fact covers a much wider range of active research thrusts, ranging from materials synthesis, physical chemistry (e.g., exciton behavior and morphological study of active layers), to device physics and involves multiple disciplines (chemistry, physics, and engineering). Therefore, interested readers should refer to other related reviews to grasp a more comprehensive picture of the extremely active and productive field of polymer solar cells..$^{10,12,21-33}$ Finally, to avoid confusion, donor and acceptor are generally referred to as building units for the design of polymers, while DONOR and ACCEPTOR with all letters capitalized are reserved to represent the DONOR polymer and ACCEPTOR (e.g., fullerene) in the BHJ blend, respectively.

1.2. A Brief History of the Development of Conjugated Polymers for Polymer Solar Cells. The rather short history of $\mathrm{BHJ}$ solar cells can be roughly divided into three phases from the perspective of the conjugated backbones of DONOR polymers. Phase one centered on poly(phenylene vinylene)s (PPV), such as poly[2-methoxy-5-(2'-ethylhexyloxy)1,4-phenylenevinylene] (MEH-PPV) and poly[2-methoxy-5-(3',7'dimethyloctyloxy)-1,4-phenylenevinylene] (MDMO-PPV). Power conversion efficiency as high as $3.3 \%$ was achieved in PPV-based $\mathrm{BHJ}$ solar cells with $\mathrm{PC}_{61} \mathrm{BM}$ as the ACCEPTOR material, mainly through the application of chlorinated solvents to tune active layer morphologies. ${ }^{34,35}$ A high open-circuit voltages $\left(V_{\text {oc }}\right)$ up to $0.82 \mathrm{~V}$ was obtained as a result of the relatively low highest-occupied molecular orbital (HOMO) energy level of $-5.4 \mathrm{eV}$ of MDMOPPV; however, the large band gap of MDMO-PPV limited the short-circuit current density $\left(J_{\mathrm{sc}}\right)$ to $5-6 \mathrm{~mA} / \mathrm{cm}^{2}$. Therefore, in phase two, a smaller-band-gap polymer, regioregular poly(3hexylthiophene) (rr-P3HT), was thoroughly investigated. ${ }^{27}$ P3HT-based $\mathrm{BHJ}$ devices provide a noticeably higher current density (over $\left.10 \mathrm{~mA} / \mathrm{cm}^{2}\right)$, attributed to its lower band gap $(1.9 \mathrm{eV})$ as well as to its increased $\pi$-stacking and crystallinity which yields a higher hole mobility. ${ }^{36-38}$ Upon optimization of the active layer morphology via thermal ${ }^{38}$ or solvent annealing, ${ }^{39}$ an impressive PCE of $5 \%$ was achieved. ${ }^{27,40}$ Unfortunately, the high $\mathrm{HOMO}(-5.1 \mathrm{eV})$ energy level of $\mathrm{P} 3 \mathrm{HT}$ has restricted the $V_{\text {oc }}$ to $\sim 0.6 \mathrm{~V}$ in its related $\mathrm{BHJ}$ solar cells with $\mathrm{PC}_{61} \mathrm{BM}$ as the ACCEPTOR, which consequently limits the overall efficiency.

Presently in phase three, numerous polymer backbones have been reported. High $V_{\text {oc }}$ over $1 \mathrm{~V},{ }^{41-43}$ high $J_{\mathrm{sc}}$ over $17.3 \mathrm{~mA} / \mathrm{cm}^{25}$, and fill factor $(F F)$ over $70 \%^{44,45}$ have been demonstrated in different polymer-based $\mathrm{BHJ}$ solar cells. If all these impressive values could be combined in one polymer solar cell, it would give a PCE as high as $12 \%$ ! However, due to the interplay of polymer properties such as energy levels and band gap and their correlation with $V_{\mathrm{oc}}$ and $J_{\mathrm{sc}}$ highest $V_{\mathrm{oc}}$ and highest $J_{\mathrm{sc}}$ cannot be concurrently obtained. ${ }^{46}$ In order to achieve the highest possible PCE, one needs to carefully balance the $V_{\mathrm{oc}}$ and $J_{\mathrm{sc}}$ via judicious control over physical properties of a conjugated polymer (i.e., in pursuit of "ideal polymers").

1.3. Required Properties for Ideal Polymers. To design ideal polymers as the DONOR in polymer-based $\mathrm{BHJ}$ solar cells with high PCE $\left(\mathrm{PCE}=V_{\text {oc }} \times J_{\text {sc }} \times F F / P_{\text {in }}\right)$, the following issues need to be carefully addressed.

a. Open-Circuit Voltage $\left(V_{o c}\right)$. $V_{\mathrm{oc}}$ is tightly correlated with the energy level difference between the HOMO of the DONOR polymer and the LUMO of the ACCEPTOR (e.g., $\left.\mathrm{PC}_{61} \mathrm{BM}\right){ }^{47}$ In theory, polymers with low-lying HOMO levels would exhibit higher $V_{\text {oc }}$. However, the HOMO level of the DONOR polymer cannot go too low. This is because generally a minimum energy difference of $\sim 0.3 \mathrm{eV}$ between the LUMO energy levels of the DONOR polymer and the ACCEPTOR is required to facilitate efficient exciton splitting and charge dissociation. When $\mathrm{PC}_{61} \mathrm{BM}$ with a LUMO level of $-4.2 \mathrm{eV}$ is used as the ACCEPTOR, the lowest possible LUMO level of the DONOR polymer would be near $-3.9 \mathrm{eV}$. Continuously lowering the HOMO level of the DONOR polymer would inevitably enlarge the band gap of the polymer, diminishing the light absorbing ability of the DONOR polymer (thereby a low $J_{\mathrm{sc}}$ ). The origin of $V_{\mathrm{oc}}$ is still under intense debate, and recent data indicate that $V_{\mathrm{oc}}$ is decided by a couple of other factors besides just the HOMO level of the polymer. ${ }^{48,49}$ Furthermore, bulkiness of side chains, interchain distances, and morphology of active layer have also been demonstrated to have a noticeable effect on the $V_{\text {oc }}{ }^{50}$

b. Short-Circuit Current $\left(J_{s c}\right)$. The theoretical upper limit for $J_{\text {sc }}$ of any excitonic solar cell is decided by the number of excitons created during solar illumination. Ideally, the absorption of the active layer should be compatible with the solar spectrum to maximize the exciton generation. Since $\mathrm{PC}_{61} \mathrm{BM}$ has a poor absorption in the visible and near-IR region where most of the solar flux is located, the DONOR polymer has to serve as the main light absorber. Roughly $70 \%$ of the sunlight energy is distributed in the wavelength region from 380 to $900 \mathrm{~nm}^{51}$ hence, an ideal polymer should have a broad and strong absorption in this range, which requires the polymer band gap to be $1.4-1.5 \mathrm{eV}$. A narrower band gap polymer could absorb more light, which would increase the $J_{\text {sc }}$ however, continuing to lower the band gap would require an increase of the HOMO level of the DONOR polymer (since the LUMO level cannot be lower than $-3.9 \mathrm{eV}$ with $\mathrm{PC}_{61} \mathrm{BM}$ as the ACCEPTOR for efficient exciton splitting and charge dissociation $)^{21}$ and would reduce the $V_{\mathrm{oc}}$.

If one assumes a fill factor of 0.65 , an external quantum efficiency of $65 \%$, and an optimal morphology, one can approximate the overall PCE from the optical band gap and the LUMO/HOMO of the DONOR polymer in a polymer: $\mathrm{PC}_{61} \mathrm{BM} \mathrm{BHJ}$ solar cell (Figure 2$){ }^{47}$ It is clearly seen that a PCE of $10 \%$ can be achieved by an "ideal" polymer with an optimal band gap of $1.5 \mathrm{eV}$ and a HOMO level around $-5.4 \mathrm{eV}$.

Though the experimentally determined $V_{\text {oc }}$ can be very close to the predicted value based on the measured HOMO level of the polymer, the actual $J_{s c}$ extracted from a polymer solar cell is usually significantly lower than the theoretical $J_{\mathrm{sc}}$ due to a number of loss mechanisms (e.g., monomolecular or bimolecular recombination) during the charge generation, transport, and extraction. 22,51 Thus a few other desirable features need to be included to mitigate these losses, such as high molecular weight, high charge mobility, and optimized active layer morphology, all of which will help improve the actual $J_{\text {sc }}$.

c. Fill factor (FF). From a semiconductor photovoltaic device point of view, a high $F F$ requires a small series resistance $\left(R_{\mathrm{s}}\right)$ and a large shunt resistance $\left(R_{\mathrm{sh}}\right),{ }^{52}$ both of which are 


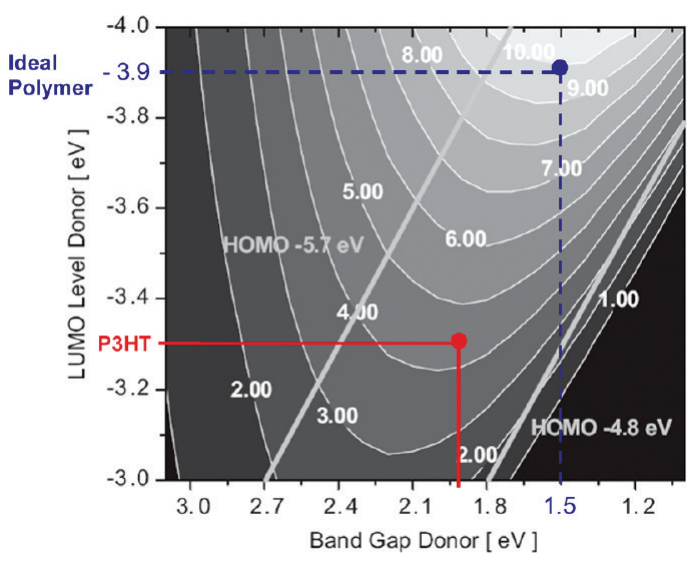

Figure 2. Calculated energy-conversion efficiency of P3HT and an "ideal" polymer, assuming FF and IPCE at 65\%. Reprinted with permission from ref 47. Copyright 2006 Wiley-VCH Verlag GmbH \& Co. KgaA.

significantly impacted by the morphology of the polymer/ fullerene blend. Thus, the morphology of the active layer should be optimized to promote charge separation and favorable transport of photogenerated charges in order to maximize the $F F$ and the attainable $J_{\text {sc }}$.

Finally, besides high PCE, solution processability (offered by side chains) and long-term stability of polymer solar cells (related with both materials and encapsulation) are of equal importance for future application and commercialization.

In short, the properties desired for a high performance polymer are (1) good solubility, (2) high molecular weight, (3) HOMO level around $-5.4 \mathrm{eV}$, (4) LUMO level around $-3.9 \mathrm{eV}$, (5) high hole mobility, (6) optimal morphology, and (7) long-term stability.

\section{MOLECULAR ENGINEERING OF CONJUGATED POLYMERS FOR POLYMER SOLAR CELLS}

2.1. Structural Features of Conjugated Polymers: A Bird's Eye View. A typical conjugated polymer used as the electron DONOR in polymer solar cells is illustrated in Scheme 1.

Scheme 1. Illustration of a Typical Conjugated Polymer for Polymer Solar Cells

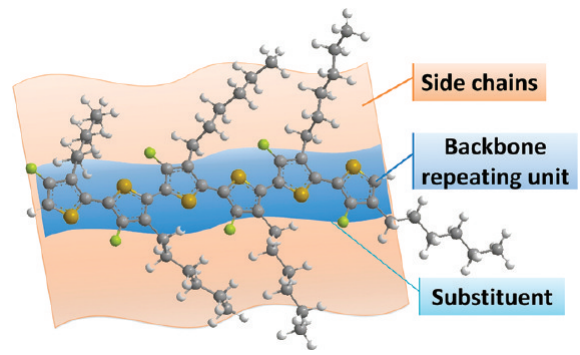

Generally, a conjugated polymer can be arbitrarily divided into three constituting components: the conjugated backbone, the side chains, and the substituents. The conjugated backbone is the most important component because it dictates most of the PSC-related physical properties of the conjugated polymer, such as energy levels, band gap, and inter/intra molecular interactions. Hundreds of different backbones have been reported so far; ${ }^{10-12}$ however, the design of polymer backbones has been quite empirical. As a result, the discovery of high performance polymers is rather serendipitous. Therefore, the rational design of conjugated backbone (i.e., the repeating units) is of utmost importance in the further development of polymer solar cells.

On the other hand, side chains play a crucial role in improving the molecular weight, solubility, and processability of conjugated polymers. Furthermore, these side chains can adjust intermolecular interactions and allow proper mixing with $\mathrm{PC}_{61} \mathrm{BM}$ to form the desired morphology. However, these insulating side chains also dilute the chromophore density and disturb $\pi$-stacking of polymer backbones, which could thwart the light absorption and charge transport. In addition, improper attachment of side chains may introduce steric hindrance and twist the conjugated backbone, which could lead to a large band gap, low charge carrier mobility, and poor photovoltaic properties. Finally, there are increasing evidence showing that the shape and length of side chains have noticeable impact on the photovoltaic properties of conjugated polymers.

Lastly, substituents (such as F and $\mathrm{CN}$ ) are generally used as fine-tuning methods to tweak the physical properties of conjugated polymers, particularly the electronic properties (energy levels, band gap, mobility, etc.). Since photovoltaic properties of conjugated polymers are very sensitive toward their electronic properties, sometimes substituents can have important influence on the photovoltaic performance of related conjugated polymers.

2.2. Rational Design of Conjugated Polymer Backbones. All reported conjugated backbones for PSC can be arbitrarily classified into a few categories based on the constitution of the repeating unit, namely (a) homopolymer, (b) donoracceptor polymer, (c) quinoid polymer, and (d) other types of polymers, as shown in Figure 3.

The repeating unit of the homopolymer usually consists of a single aromatic unit or fused aromatics. The physical properties of these polymers are largely determined by the intrinsic properties of the constituting single or fused aromatics, with appreciable contribution from steric hindrance between these repeating units. Thus, most of the homopolymers have large band gaps $(>1.9 \mathrm{eV})$, which limit the light absorption of these materials. In addition, very often the aforementioned steric hindrance forces the adjacent repeating units off the desired coplanarity of these units, negatively impacting the band gap and the crystallinity of the polymer, thereby diminishing photovoltaic properties of related $\mathrm{BHJ}$ devices. ${ }^{40,53,54}$ The best polymer of this type is the regioregular P3HT with PCE over 5\% after thorough optimizations. ${ }^{27,38,40}$

On the other hand, it is fairly easy to construct low-band-gap polymers with tunable energy levels via the donor-acceptor (D-A) approach. The repeating unit of $\mathrm{D}-\mathrm{A}$ polymers comprises of an electron-rich "donor" moiety and an electrondeficient "acceptor" moiety. The internal charge transfer between the "donor" and the "acceptor" moieties leads to the observed low band gap. ${ }^{55}$ This strategy was first proposed in $1993^{56,57}$ and best illustrated by Tour et al. by using a copolymer of 3,4-aminothiophene and 3,4-nitrothiophene to reach a band gap of $1.0 \mathrm{eV}$, as shown in Figure $3 .^{58}$ The internal charge transfer (ICT) intrinsic with the $\mathrm{D}-\mathrm{A}$ structure leads to more desirable doublebond characteristic between repeating units. Therefore, the conjugated backbone adopts a more planar configuration to facilitate the $\pi$-electrons delocalization along the conjugated backbone, leading to a smaller band gap. One unique feature of the $\mathrm{D}-\mathrm{A}$ polymers is that the HOMO and LUMO energy levels are largely localized on the donor moiety and the acceptor moiety, respectively (though HOMO is more delocalized along the D-A structure). ${ }^{33,59}$ This feature offers an important advantage of individually tuning the band gap and energy levels of the conjugated polymer. For example, a smaller band gap can 
a)

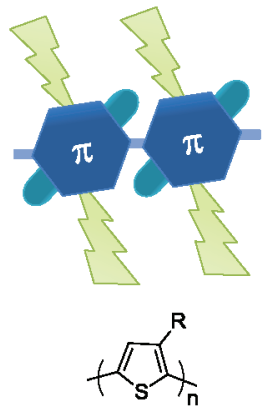

b)

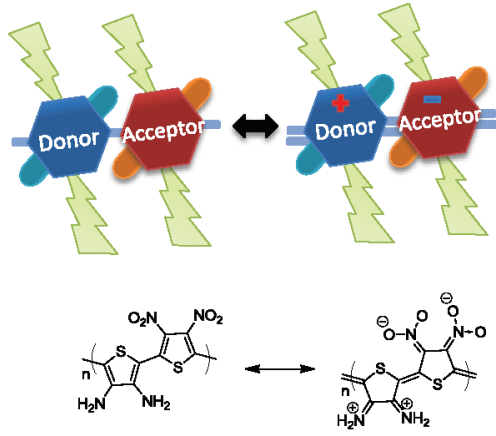

c)

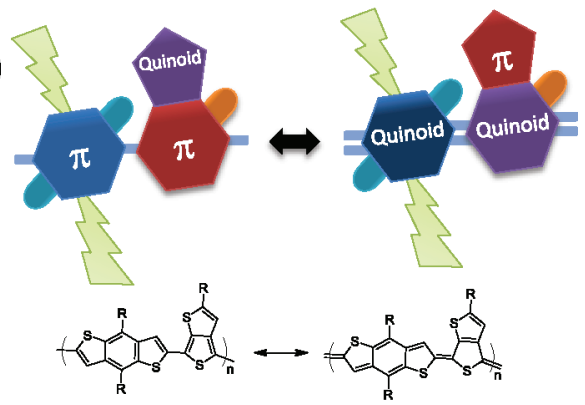

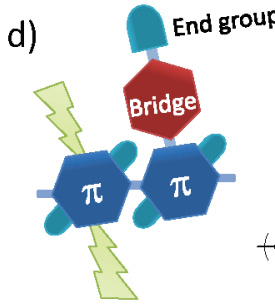
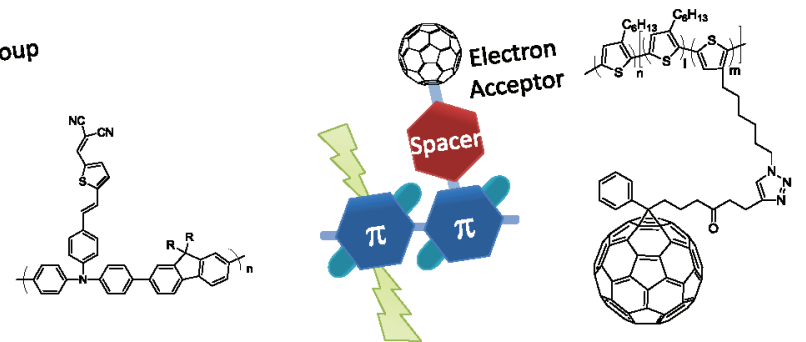

Figure 3. Different types of conjugated polymers with representative structures: polymer; (d) other types.

be obtained by copolymerizing a more electron-rich donor moiety and a more electron-deficient acceptor moiety, whereas the HOMO and LUMO levels can also be adjusted by varying the electrondonating ability of the donor moiety and the electron affinity of the acceptor moiety. ${ }^{59}$ Most of the conjugated polymers for PSC reported so far are based on this D-A concept, with several of them showing over $7 \%$ efficiency in their $\mathrm{BHJ}$ cells. ${ }^{45,60-63}$

"Quinoid" polymers employ a different approach to effectively lower the band gap. Typically two aromatic units are fused in a particular geometry to take advantage of the larger value of resonance energy of the first aromatic unit (e.g., benzene, $1.56 \mathrm{eV}$ ) over the second unit (e.g., thiophene, $1.26 \mathrm{eV}$ ), so that the second aromatic unit (e.g., thiophene) tends to dearomatize to adopt a quinoid structure. Since the quinoid resonance form is lower in energy than the aromatic form, stabilizing the quinoid form will effectively reduce the band gap of related conjugated polymers. Figure 4 shows a few successful
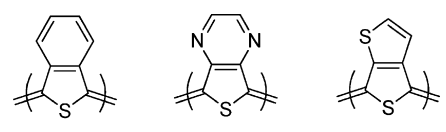

quinoid structure

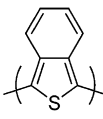

(a)

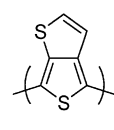

(c)

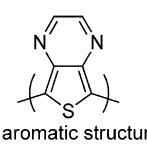

(b)
Figure 4. Aromatic and quinoid forms of poly(benzo[c]thiophene) (a), poly(thieno $[3,4-b]$ pyrazine $(b)$, and poly(thieno[3,4-b]thiophene) (c). Reprinted with permission from ref 7. Copyright 2010 American Chemical Society.

examples, including poly(benzo[c]thiophene $)\left(E_{\mathrm{g}}=1.1 \mathrm{eV}\right){ }^{64}$ poly(thieno[3,4 $b]$ pyrazine $\left(E_{\mathrm{g}}=0.95 \mathrm{eV}\right),{ }^{65}$ and poly(thieno[3,4 $b]$ thiophene) $\left(E_{\mathrm{g}}=0.8-0.9 \mathrm{eV}\right) .{ }^{66,67}$ The major drawback of these fused systems lies in their relatively high-lying HOMO energy levels, which explains that low-band-gap copolymers synthesized by alternating these prequinoid monomers with other aromatic rings such as thiophenes and fluorenes showed low $V_{\text {oc }}$ in $\mathrm{BHJ}$ solar cells. ${ }^{68-73}$ Further engineering the substituents on these conjugated backbone can lower the HOMO levels, ${ }^{74-77}$ thereby leading to impressive efficiency numbers (over $7 \%$ ). ${ }^{74,78}$

Rather than inserting electron-deficient acceptor moieties into the conjugated backbone to lower the band gap, the bridge polymer attaches them as the pendant groups to the backbone, aiming to optimize the absorption and conserve/promote the isotropic charge transport without any interruption by these acceptor moieties. ${ }^{79,80}$ There are only a few examples of these bridge polymers with limited success. ${ }^{79-81}$ One challenge for this type of polymers is the understanding and control of the active layer morphology.

The so-called "double-cable" approach was designed with the hope of "building in" well-defined nanostructure/morphology, rather than going through an arduous struggle in controlling the morphology in typical $\mathrm{BHJ}$ cells of polymer/fullerene blends. This "double-cable" design covalently links electron acceptors such as fullerenes (ACCEPTOR cable) to electron DONORS such as the conjugated backbones (DONOR cable). The advantages of this design include (i) a larger DONORACCEPTOR interfacial area when compared with a typical BHJ structure, (ii) absence of undesirable large phase separation, (iii) relatively stable morphology, and (iv) variation of the chemical structures of the DONOR and the ACCEPTOR and length of the spacer between them, allowing to fine-tune the electronic interaction among the double-cable components. ${ }^{82,83}$ Several materials of this "double-cable" design have been demonstrated in polymer solar cells. ${ }^{84-89}$ However, the PCE of such devices is still at a very low level, likely due to fast recombination of opposite charges, ineffective interchain charge transport, and low ACCEPTOR content. ${ }^{90,91}$

Because of the aforementioned advantages, the versatility in design, and the popularity of the $\mathrm{D}-\mathrm{A}$ polymers, we will focus on the design of donor-acceptor polymers in this Perspective.

2.3. A "Weak Donor-Strong Acceptor" Approach toward Ideal Polymers. As discussed in section 1.3, the ideal 
conjugated polymer for $\mathrm{BHJ}$ solar cells should have a low-lying HOMO energy level to ensure a high $V_{\text {oc }}$ and a narrow band gap to maximize the $J_{\mathrm{sc}}$. Because the $\mathrm{D}-\mathrm{A}$ polymers offer the unique feature of almost independently tuning the energy levels and the band gap, a "weak donor-strong acceptor" strategy has been proposed to maintain a low HOMO energy level via the "weak donor" and to result a narrow band gap by employing a "strong acceptor" via ICT (Figure 5). ${ }^{59}$ In addition, the charge

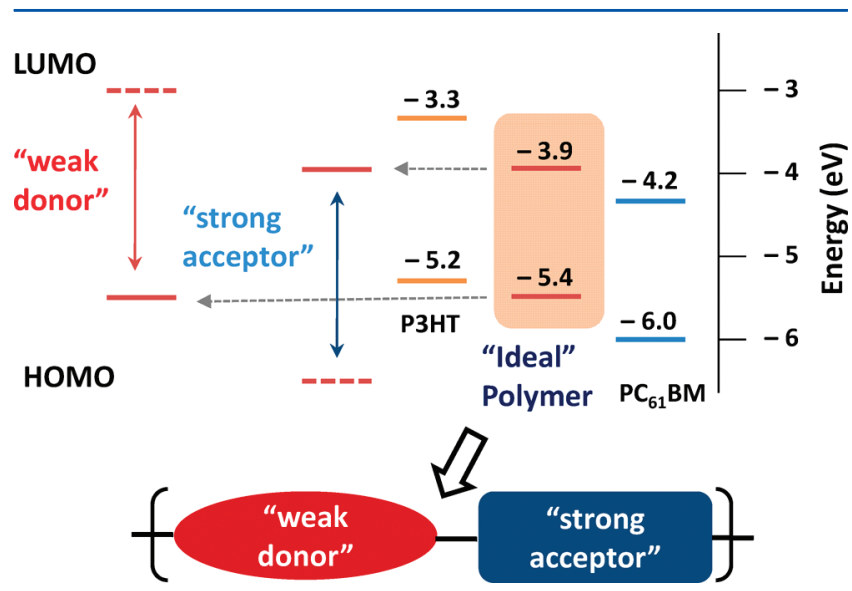

Figure 5. "Weak donor-strong acceptor" concept and energy levels. Adapted with permission from ref 59. Copyright 2010 American Chemical Society.

mobility, molecular interaction, and stability of a conjugated polymer can also be optimized by appropriate backbone design.

In the following sections, we will categorize various electrondonating units and electron-accepting units from the literature based on their structural features. The goals are to (a) summarize structure-property relationships of these units, and (b) identify principles that can facilitate future designs.

2.3.1. Selection of Donor Units. To design a suitable donor unit, first and foremost is to control its electron-donating ability, which has a large impact on the HOMO level and the band gap of conjugated polymers. Fused conjugated units are generally employed, since an appropriate fusion of a few single aromatic units can not only tune the electronic properties but also impact the charge mobility and intermolecular interactions of related conjugated polymers.

2.3.1.1. Fused Three Rings: Control over the Energy Levels. Figure 6a summarizes a few fused conjugated units with three rings. For example, fluorene is one of the most popular donor units used in D-A polymers for PSC due to a few notable features of the polyfluorenes, such as good thermal and chemical stability, high charge carrier mobility, and high absorption coefficients. In addition, the synthesis and alkylation of fluorene unit are readily accessible. ${ }^{95-98}$ Furthermore, the central fused five-membered ring structure of the fluorene eliminates the otherwise severe steric hindrance of adjacent benzene units. Also, the alkyl chains are usually anchored on the 9-position of the fluorene, which does not add any a)
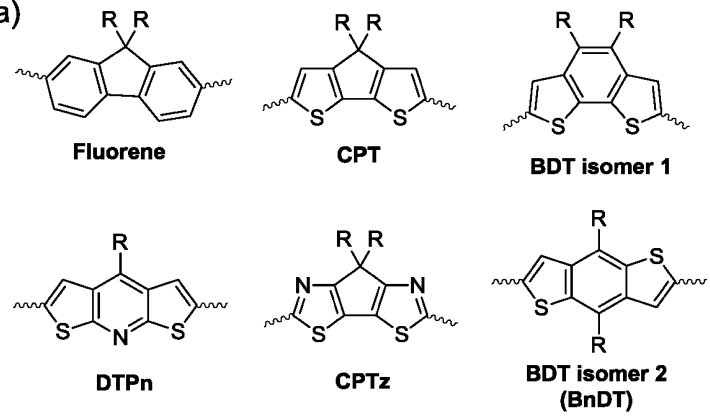

b)
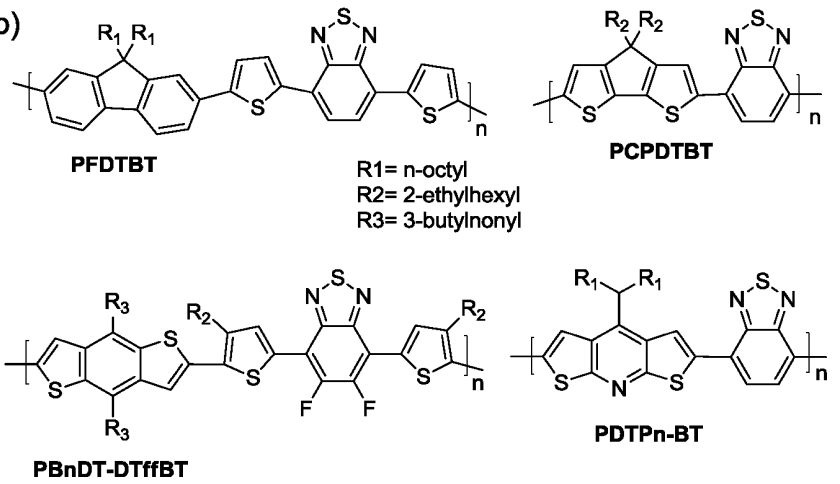

Figure 6. (a) Examples of fused-three-ring donor units. (b) Chemical structures of related copolymers.

additional steric hindrance. All these lead to a planar backbone of fluorene-related conjugated polymers, improving the intermolecular interaction and stacking of conjugated polymers.

Electronically, the fluorene unit is a very weak electron donor because of the relatively electron-deficient benzene units. ${ }^{99}$ Therefore, most fluorene-based conjugated polymers have low HOMO levels around $-5.5 \mathrm{eV} .^{74,100-103}$ As a result, $V_{\text {oc }}$ of polyfluorene-based $\mathrm{BHJ}$ solar cells are generally around $1 \mathrm{~V}$ (Table 1). ${ }^{100,102}$ However, these polymers usually have relatively large band gaps, which are not ideal for efficient light harvesting. To address this band-gap challenge, the thiophene analogue of the fluorene, cyclopentadithiophene (CPT) unit by fusing two thiophene units, was developed. ${ }^{104}$ The CPT unit is much more electron-rich than the fluorene; thus, the ICT between the CPT donor unit and the acceptor unit is much stronger, leading to a significantly decreased band gap of related polymers (e.g., $1.4 \mathrm{eV}) .^{.04-106}$ The $J_{\text {sc }}$ of CPT-based polymers can reach up to $\sim 17 \mathrm{~mA} / \mathrm{cm}^{2}$ by optimizing the morphology with additives, which is among the highest $J_{s c}$ in polymer solar cells. ${ }^{5,93}$ Unfortunately, the electron-rich nature of the CPT raises the $\mathrm{HOMO}$ of CPT-based polymers to around $-5.2 \mathrm{eV}$; therefore, a small $V_{\mathrm{oc}}$ is generally observed $(0.5-0.6 \mathrm{~V})$.

Comparison between the fluorene and the CPT leads to the conclusion that a weak donor with electron-donating ability in between CPT and fluorene would be desirable toward the ideal polymer of both a low HOMO energy level and a narrow band gap. One natural choice is to fuse the benzene unit and the thiophene unit, such as the BDT unit (and its isomers). Both

Table 1. Summary of Band Gaps, HOMO Levels, and Photovoltaic Properties of Conjugated Polymers in Figure 6b

\begin{tabular}{|c|c|c|c|c|c|c|c|}
\hline polymer & band gap $(\mathrm{eV})$ & HOMO $(\mathrm{eV})$ & $V_{\mathrm{oc}}(\mathrm{V})$ & $J_{\mathrm{sc}}\left(\mathrm{mA} / \mathrm{cm}^{2}\right)$ & FF & PCE (\%) & ref \\
\hline PFDTBT & 1.9 & -5.7 & 1.04 & 4.66 & 0.46 & 2.2 & 92 \\
\hline PCPDTBT & 1.4 & -5.3 & 0.62 & 16.2 & 0.55 & 5.5 & 93 \\
\hline PBnDT-DTffBT & 1.7 & -5.5 & 0.91 & 12.91 & 0.61 & 7.2 & 61 \\
\hline PDTPn-BT & 2.1 & -5.6 & 0.31 & 0.75 & 0.37 & 0.09 & 94 \\
\hline
\end{tabular}


a)

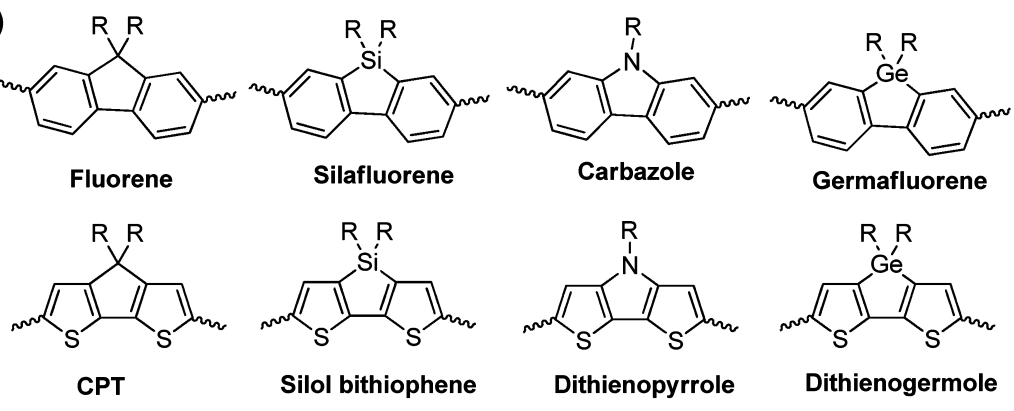

b)
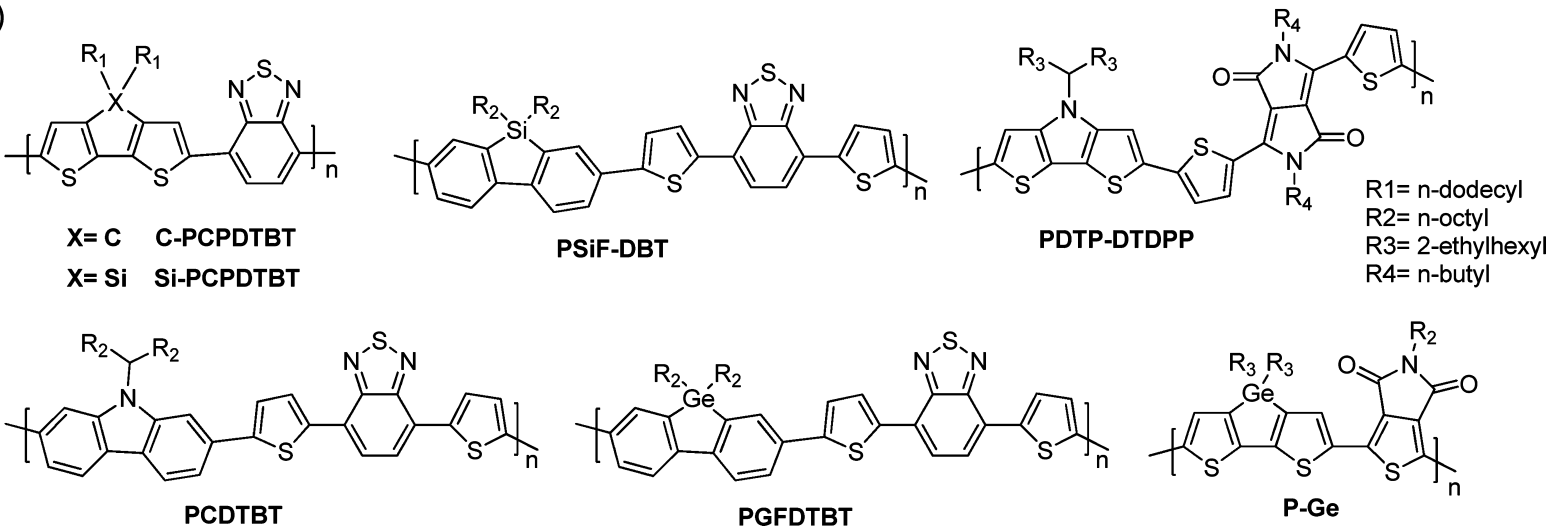

Figure 7. (a) Structures of donor units fused by bridging atoms. (b) Chemical structures of related copolymers.

Table 2. Summary of Band Gaps, HOMO Levels, and Photovoltaic Properties of Conjugated Polymers in Figure $7 \mathrm{~b}$

\begin{tabular}{lccccccc}
\multicolumn{1}{c}{ polymer } & band gap $(\mathrm{eV})$ & HOMO $(\mathrm{eV})$ & $V_{\text {oc }}(\mathrm{V})$ & $J_{\mathrm{sc}}\left(\mathrm{mA} / \mathrm{cm}^{2}\right)$ & $F F$ & PCE $(\%)$ & ref \\
Si-PCPDTBT & 1.4 & -5.3 & 0.57 & 17.3 & 0.61 & 5.9 & 5 \\
C-PCPDTBT & 1.3 & -5.3 & 0.37 & 15.5 & 0.48 & 5 \\
PSiF-DBT & 1.82 & -5.4 & 0.90 & 9.5 & 0.51 & 5.4 & 109 \\
PDTP-DTDPP & 1.13 & -4.90 & 0.38 & 14.87 & 0.48 & 2.7 & 110 \\
PCDTBT & 1.9 & -5.5 & 0.88 & 10.6 & 0.66 & 6.1 & 4 \\
PGFDTBT & 1.8 & -5.6 & 0.79 & 6.9 & 0.51 & 2.8 & 111 \\
P-Ge & 1.69 & -5.6 & 0.85 & 12.6 & 0.68 & 7.3 \\
\hline
\end{tabular}

BDT isomers have a benzo core in the center and two flanking thiophene rings. BDT units offer two advantages: the necessary alkylation (to improve the solubility of resulting polymers) can be fulfilled on the center benzene ring, and the two flanking thiophene units render much less steric hindrance with adjacent acceptor units, leading to a more planar backbone. The differences of the isomers are on the linking position of these three subunits and symmetry of the molecule (to be discussed later in section 2.3.1.4). Both of the isomers exhibit weaker electron-donating ability compared with that of the CPT. Therefore, the HOMO levels of some BDT-based polymers are closer to the ideal HOMO energy level. ${ }^{6,45,61,107}$ Together with a relatively narrow band gap, a few BDT-based polymers have demonstrated PCE over $6 \%$ in their BHJ cells. ${ }^{45,61,107}$ Particularly, BHJ PV devices based on PBnDT-DTffBT has been shown with a $V_{\mathrm{oc}}$ around $0.9 \mathrm{~V}$ and a $J_{\mathrm{sc}}$ over $12 \mathrm{~mA} / \mathrm{cm}^{2}$, leading to a PCE over $7 \%{ }^{61}$

Further decreasing of electron-donating ability of the donor unit can be realized by changing the benzo unit to the pyridine unit or switching thiophene units to thiazole units as exemplified in Figure 6. Polymers based on both of the units show significantly decreased HOMO levels. ${ }^{94,108}$ However, dithienopyridine (DTPn)-based polymers exhibit decreased $V_{\text {oc }}$ along with decreased $J_{\text {sc }}$ due to their larger band gaps. Possible reasons are non-ideal polymer $-\mathrm{PC}_{61} \mathrm{BM}$ interaction and poor exciton dissociations. ${ }^{94}$

Further tuning of the electron-donating ability and other physical properties of these donor units can be achieved via modifying specific atoms of the donor units (Figure 7 and Table 2).

Replacing the center (the only $\mathrm{sp}^{3}$ ) carbon atom of the CPT unit with silicon has been thoroughly studied by Brabec and co-workers. ${ }^{112,113}$ Since carbon and silicon have similar electron negativity and outer layer electronic structure $\left(\mathrm{s}^{2} \mathrm{p}^{2}\right), \mathrm{CPT}$ and silol dithiophene have a similar electron-donating ability. This explains the fact that HOMO levels and band gaps of the Sibridged polymer (Si-PCPDTBT) and the C-bridged polymer (PCPDTBT) are nearly identical. However, the larger silicon atom and the longer $\mathrm{C}-\mathrm{Si}$ bond modify the geometry of the fused dithiophene unit, allowing a better stacking of the polymer backbone. This helps improve hole and electron mobilities of Si-PCPDTBT/PC ${ }_{71} \mathrm{BM}$ blend, a factor of $2-3$ higher than those of the PCPDTBT/ $\mathrm{PC}_{71} \mathrm{BM}$ blend. Further indication for the better stacking of Si-PCPDTBT can be found from the absorption spectra of polymer thin films. In spite of similar band gaps between Si-PCPDTBT and PCPDTBT, a strong aggregation peak is present around $750 \mathrm{~nm}$ in the case of Si-PCPDTBT. This is confirmed by grazing incidence X-ray study (Figure 8). A pronounced diffraction peak at 5.2 (17 ̊), typical for alkyl chains separating the backbones, and a weak 


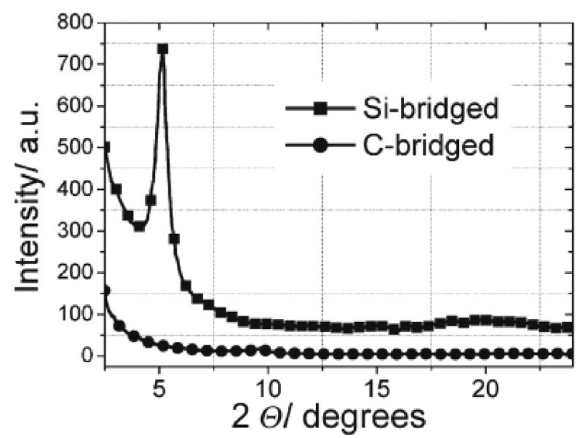

Figure 8. Diffractometry images of films of pristine silicon-bridged (squares) and carbon-bridged polymer deposited on quartz substrates. Reprinted with permission from ref 112. Copyright 2010 Wiley-VCH Verlag GmbH \& Co. KgaA.

peak at around $20^{\circ}$ corresponding to the backbone $\pi-\pi$ stacking are observed in thin films of Si-PCPDTBT. These data support a much ordered stacking of backbone and side chains of Si-PCPDTBT. Importantly, this enhanced aggregation reduces the formation of charge-transfer complexes ${ }^{114}$ and increases the formation of free charge carriers. Thus, this seemingly small change from carbon to silicon leads to pronounced increases on both the $V_{\text {oc }}$ (from 0.37 to $0.57 \mathrm{~V}$ ) and the $J_{\mathrm{sc}}$ (from 15.5 to $17.3 \mathrm{~mA} / \mathrm{cm}^{2}$ ) under the same processing condition, with a PCE of $5.9 \%$ achieved for $\mathrm{Si}$ PCPDTBT (vs $2.7 \%$ for PCPDTBT). ${ }^{5}$

However, changing the bridging atom of the fluorene from carbon to silicon has a strong effect on the electron-donating ability and energy levels of related polymers (PFDTBT vs PSiF-DBT). ${ }^{109}$ Furthermore, silafluorene-based polymers have higher electroluminescent efficiency, thermal stability, and slightly larger hole mobility. ${ }^{15}$ Therefore, a larger $J_{\text {sc }}$ has been demonstrated with a little drop on $V_{\text {oc }}$ and a PCE over $5 \%$ has been realized for a silafluorene-based polymer. ${ }^{109}$

On the other hand, pyrrole is much more electron-rich than the cyclopentadiene (the center structural unit of the CPT). By replacing the bridging carbon atom of the $\mathrm{CPT}$ unit with a nitrogen atom, the resulting dithienopyrrole unit should have a stronger electron-donating ability than that of the CPT. ${ }^{116}$ This leads to a more pronounced ICT between the dithienopyrrole and the acceptor unit; therefore, a decreased band gap is generally observed for dithienopyrrole-based polymer when compared with those of CPT-based D-A polymers. The FET mobility of dithienopyrrole-based polymers is slightly increased due to an enhanced polymer chain planarity and chain-chain interaction. ${ }^{117}$ However, because of the electron-rich nature of the dithienopyrrole, the HOMO levels of dithienopyrrole-based polymers are elevated to around $5.0 \mathrm{eV},{ }^{110,116,118}$ which would lead to significantly decreased $V_{\text {oc }}$ and environmental instability of related solar cells. In addition, since only one side chain is allowed on the $\mathrm{N}$ atom, a long and bulky alkyl chain is required to render reasonable solubility in common organic solvents. In general, these long and bulky side chains have negative impacts on the PV properties (further discussion will be provided in section 2.5.2). Nevertheless, a high $J_{\mathrm{sc}}$ of $14.87 \mathrm{~mA} / \mathrm{cm}^{2}$ and a respectable total efficiency of $2.7 \%$ were demonstrated for a dithienopyrrole-based polymer in its $\mathrm{BHJ}$ solar cells with $\mathrm{PC}_{71} \mathrm{BM}$, despite a $V_{\mathrm{oc}}$ of just $0.4 \mathrm{~V}^{110}$

However, substituting the center carbon in the fluorene unit with a nitrogen (i.e., converting the fluorene into the carbazole) received more success for a number of reasons. First, since fluorene unit itself is relatively electron-deficient (compared with the CPT), the addition of an electron-donating nitrogen would slightly increase the electron density of the resulted carbazole unit. Therefore, the HOMO energy levels of carbazole-based $\mathrm{D}-\mathrm{A}$ polymers would increase, closer to the ideal HOMO level (Figure 5). Second, the polycarbazoles have been successfully used in polymer LED ${ }^{119}$ and FET, ${ }^{120}$ demonstrating excellent p-type transport properties. Third, the carbazole unit is fully aromatic and not too electron rich, offering a decent chemical and environmental stability. ${ }^{121}$ Therefore, it is not surprising that a carbazole-based polymer (PCDTBT) has been demonstrated with a $V_{\text {oc }}$ of $0.88 \mathrm{~V}$, a $J_{\text {sc }}$ of $10.6 \mathrm{~mA} / \mathrm{cm}^{2}$, and an impressive $F F$ around $66 \%$, leading to an overall PCE over $6 \%$ in its $\mathrm{BHJ}$ cells with $\mathrm{PC}_{71} \mathrm{BM}^{4}$

Other hetreoatoms have also been explored as the bridging atoms (Figure 7). For example, germafluorene-containing polymers have been reported. ${ }^{111}$ Germanium is in the same group (group 14 on the periodic table) with $\mathrm{C}$ and $\mathrm{Si}$, but with a larger radius. The optical band gap and the HOMO level of polygermafluorene are similar to those of poly(silafluorene)s, indicating a similar electron-donating ability of the germalfuorene. Interestingly, polymers based on germafluorene do not show as good PV performance as poly(silafluorene)s, largely because of a decreased $V_{\text {oc }}$ in spite of lower HOMO levels than these of poly(silafluorene)s. Similarly, dithienogermole with $\mathrm{Ge}$ as the bridging atom was also reported by Amb et al. ${ }^{62}$ Similar energy levels and band gaps were reported for silol-dithiopheneand dithienogermole-based copolymers. Both copolymers exhibit great photovoltaic properties with PCEs over $6 \%$ in inverted $\mathrm{BHJ}$ solar cells with $\mathrm{PC}_{71} \mathrm{BM}$ as the acceptor.

2.3.1.2. High Level of Fusion: Ladder Type Donors. Inspired by the success of fused three rings, high level of fusion of the aromatic units on the conjugated backbone has also been actively explored because it can facilitate $\pi$-electron delocalization to increase the effective conjugation length, offering an effective method to reduce the band gap, in addition to controlling energy levels (Figure 9). ${ }^{122,123}$ Moreover, the resulting coplanar geometries and rigid structures can suppress the rotational disorder around interannular single bonds and lower the reorganization energy, which in turn can enhance the charge mobility. ${ }^{124-126}$ This high level of fusion can be achieved by either covalently fastening adjacent aromatic units in the backbone (i.e., ladder type) or by fusing three or more aromatic units into an enlarged conjugated $\pi$ unit. However, excessively strong interchain $\pi-\pi$ stacking interactions arising from this high degree of coplanarity could make the conjugated polymers insoluble and unprocessable. ${ }^{127}$

For example, the poly(fluorene) and the poly(CPT) discussed above can be considered as fused poly(phenylene) and poly(thiophene), respectively. Besides the benefits such as band gap reduction and charge mobility enhancement, the symmetry of these alkylated fused thiophene units eliminates any possible regioregularity issue of poly(3-alkylthiopene)s, which could decrease effective $\pi$-conjugation of the conjugated backbone. ${ }^{53,54}$

The higher level of fusion can help increase environment stability of related polymers and fix possible isomerization of conjugated polymer backbones. For example, in the poly(phenylenevinylene) (PPV), the photo-oxidation via $[2+2]$ cycloaddition of excited-state singlet oxygen and vinylene group would result in an irreversible chain scission with consequent reduction of the conjugation length and a blue-shifted absorption. ${ }^{130,131}$ To address the issue of the easy oxidation of the vinyl linkage, Song et al. cyclized the vinylene group with 
a)<smiles>[R]c1cc(-c2sc(C)cc2[R])sc1C</smiles>

polythiophene fragment<smiles>[R]C1([R])c2cc(C)sc2-c2sc(C)cc21</smiles>

CPT<smiles>[R]c1cc(/C=C/c2cc([R])c(C)cc2[R])c([R])cc1C</smiles>

PPV fragment<smiles>[R]C1([R])C2=C(c3ccc(C)cc31)C([R])([R])C21Cc2cc(C)ccc21</smiles>

ININE<smiles></smiles><smiles></smiles>

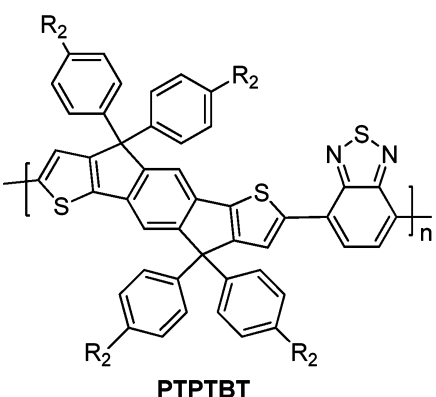

Figure 9. (a) Chemical structures of ladder-type donor units. (b) Chemical structures of related copolymers.

b)

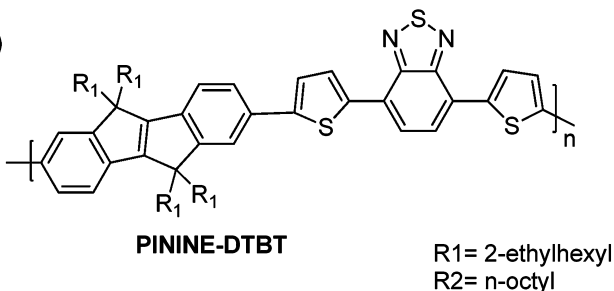

Table 3. Summary of Band Gaps, HOMO Levels, and Photovoltaic Properties of Conjugated Polymers in Figure 9b

\begin{tabular}{lccccccc}
\multicolumn{1}{c}{ polymer } & band gap $(\mathrm{eV})$ & HOMO $(\mathrm{eV})$ & $V_{\mathrm{oc}}(\mathrm{V})$ & $J_{\mathrm{sc}}\left(\mathrm{mA} / \mathrm{cm}^{2}\right)$ & $F F$ & PCE $(\%)$ & ref \\
PININE-DTBT & 1.84 & -5.45 & 0.47 & 5.93 & 0.43 & 1.88 & 128 \\
PTPTBT & 1.57 & -5.36 & 0.85 & 11.2 & 0.67 & 6.41 & 129 \\
\hline
\end{tabular}

adjacent benzene units using two 5-membered rings with carbon as the bridge. ${ }^{128}$ This conversion of PPV into ININE copolymers would prevent backbone scission by singlet oxygen. Thus, polymers containing ININE show significantly enhanced UV-vis and PL stability after irradiation with white light in air.

More ladder-type donor units by fusing three or more adjacent units have been developed (Figure 9). ${ }^{43,132-138}$ In addition to the advantages mentioned above for these fused systems, these laddertype systems may additionally lead to broader, more intense absorption bands which will result in enhanced solar light harvesting. Furthermore, for every repeating unit in the ladder-type donor containing polymers, there are more positions to attach solubilizing chains, which may provide a better solution processability of the related polymers. ${ }^{43}$ Some typical ladder-type donor units are summarized in Figure 9. All the constructing subunits are just benzene and thiophene rings. With different bridging atoms, the electronic properties of these ladder-type donors can be adjusted as discussed above. The highest PCE over 6\% with a high $V_{\text {oc }}$ of $0.85 \mathrm{~V}$ has been achieved by a conjugated polymer containing ladder-type donor unit TPT with a low HOMO level of $5.36 \mathrm{eV}$ (Table 3). ${ }^{129}$

2.3.1.3. High Level of Fusion: Fused Conjugation over Three or More Aromatic Units. Another method to achieve the high level of fusion is to fuse three or more aromatic units into an enlarged conjugated unit with extended $\pi$-conjugation (Figure 10). Similar to ladder type systems, these extended $\pi$-conjugation systems feature enforced planarity and more effective $\pi$-electron delocalization, which can lead to broader light absorption and improve $\pi-\pi$ interactions between polymer chains in thin solid films to enhance the charge carrier mobility. ${ }^{140}$ In addition, the HOMO energy levels of related polymers can be tuned through adjusting the fused aromatic moieties within these polycyclics.

For example, replacing the benzene core of benzodithiophene (BDT isomer 1) with a more electron-deficient naphthalene core leads to the naphthalenedithiophene (NDT isomer 1). NDT-based polymers exhibit both small band gaps and low HOMO levels. ${ }^{141}$ Noticeably, a NDT-based polymer (PNDT-DTPyT) exhibited a large $J_{\mathrm{sc}}$ of $14.16 \mathrm{~mA} / \mathrm{cm}^{2}$ and a decent $V_{\text {oc }}$ of $0.71 \mathrm{~V}$, with a PCE of $6 \%$ in its BHJ solar cells (Table 4). ${ }^{107}$ To further decrease the electron-donating ability of the donor unit for a deeper HOMO level, dithienoquinoxaline (QDT) with a more electron-deficient quinoxline core was designed. Indeed, QDT-based polymers exhibited enhanced $V_{\text {oc }}$ but smaller $J_{s c}$ in related $\mathrm{BHJ}$ solar cells due to decreased HOMO levels but concomitantly larger band gaps when compared with those of NDT analogues. ${ }^{46,107,141}$ In another example, quadrathienonaphthalene (QTN) with an even larger pancake-like $\pi$-conjugation prompts better electron delocalization, molecular interaction, and hole mobility. Therefore, the QTN-based polymers exhibit smaller band gaps and slightly decreased HOMO levels. The homopolymer of QTN has a band gap of $2.0 \mathrm{eV}$, and an efficiency over $2 \%$ was demonstrated. ${ }^{139}$

Besides cyclic extension of the conjugation, linear extension on the donor unit has also been explored to adjust energy levels and enhance molecular interaction and charge mobility. However, there are only a few reported cases due to synthetic difficulties of these units (structures on the second row of Figure 10a). ${ }^{142-146}$ Further, it is quite a challenge to attach solubilizing chains on these linearly extended aromatic systems. Nevertheless, some unique properties of this type of donor units do exist. For example, these donor units have very stiff backbones, long 
Table 4. Summary of Band Gaps, HOMO Levels, and Photovoltaic Properties of Conjugated Polymers in Figure 10b

\begin{tabular}{|c|c|c|c|c|c|c|c|}
\hline polymer & band gap $(\mathrm{eV})$ & HOMO $(\mathrm{eV})$ & $V_{\text {oc }}(\mathrm{V}) \exp$ & $J_{\mathrm{sc}}\left(\mathrm{mA} / \mathrm{cm}^{2}\right)$ & $F F$ & PCE (\%) & ref \\
\hline PNDT-DTPyT & 1.53 & -5.36 & 0.71 & 14.16 & 0.62 & 6.2 & 107 \\
\hline PQDT-DTPyT & 1.56 & -5.50 & 0.75 & 13.49 & 0.55 & 5.6 & 107 \\
\hline HMPQTN & 2.00 & -5.39 & 0.72 & 5.69 & 0.50 & 2.06 & 139 \\
\hline
\end{tabular}

a)<smiles>[R]c1c([R])c2cc(C)sc2c2sc(C)cc12</smiles>

BDT isomer 1<smiles>[R]c1c2cc(C)sc2c([R])c2cc(C)sc12</smiles>

BDT isomer 2<smiles>[R]c1cc2c3cc(C)sc3c3cc(C)sc3c2cc1[R]</smiles>

NDT isomer 1<smiles>[R]c1c2cc(C)sc2cc2c([R])c3cc(C)sc3cc12</smiles>

NDT isomer 2<smiles>[R]c1nc2c3cc(C)sc3c3sc(C)cc3c2nc1[R]</smiles>

QDT<smiles>[R]c1cc2c(s1)=c1c=2c2cc([R])sc2c2c3cc([Z])sc3c3sc(C)cc3c12</smiles>

QTN

b)

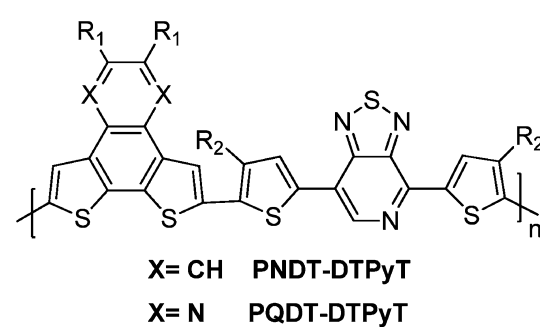<smiles>[R9]c1cc2c3cc([R3])sc3c3c4cc(C(C)(C)C)sc4c4sc(C)cc4c3c2s1</smiles>

$\mathrm{R} 1=\mathrm{n}$-octyl

$\mathrm{R} 2=$ 2-ethy|hexyl

R3= 2-hexyldecyl<smiles>[R]c1c2cc3cc(C)sc3cc2c([R])c2cc3sc(C)cc3cc12</smiles>

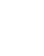


a)

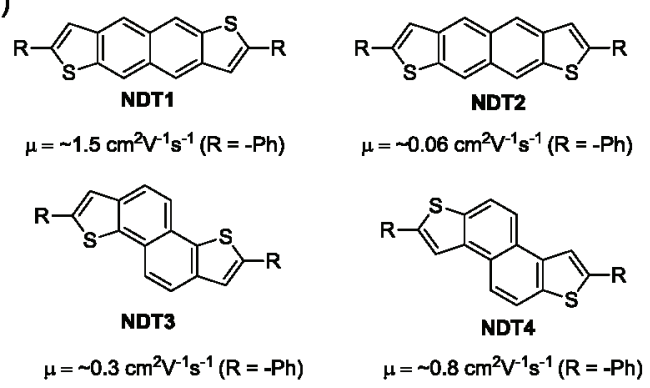

c)
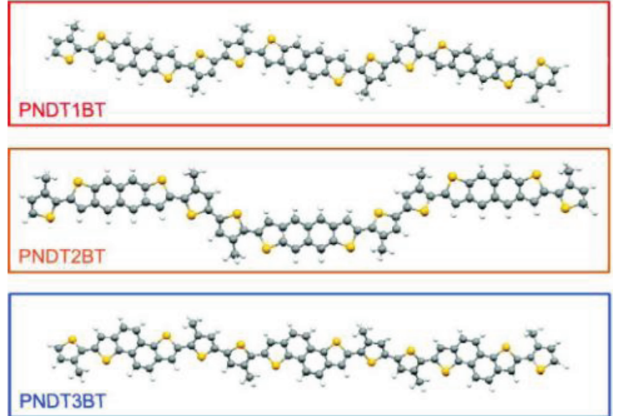

b)

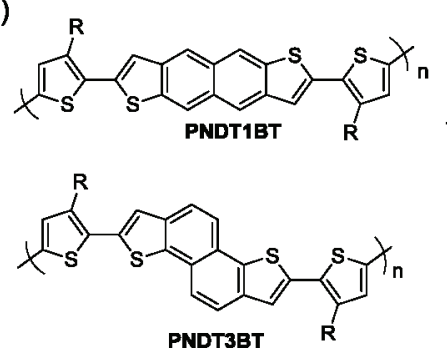

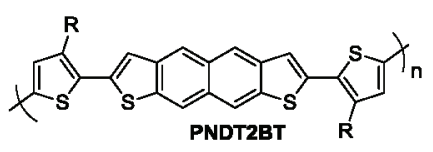

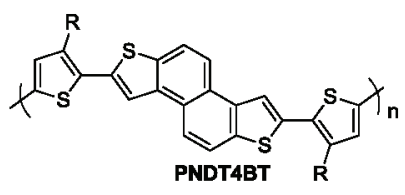

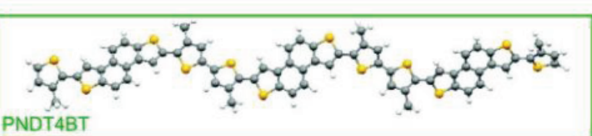

Figure 12. (a) Four isomeric naphthodithiophenes: naphtho[2,3-b:6,7- $\left.b^{\prime}\right]$ dithiophene (NDT1), naphtho[2,3-b:7,6- $\left.b^{\prime}\right]$ dithiophene (NDT2), naphtho[1,2-b:5,6- $\left.b^{\prime}\right]$ dithiophene (NDT3), and naphtho[2,1-b:6,5- $\left.b^{\prime}\right]$ dithiophene (NDT4). (b) Chemical structures of the naphthodithiophenebased semiconducting polymers. (c) Optimized backbone structures of the polymers PNDT1BT, PNDT2BT, PNDT3BT, and PNDT4BT. The side chains were replaced with methyl groups to simplify the calculation. Reprinted with permission from refs 150 and 151 . Copyright 2011 American Chemical Society.

Lower HOMO levels are also observed in polymers containing angular-shaped NDTs. In addition, stacking of polymer chains is much stronger in polymers containing NDTs of centrosymmetry than in polymers with NDTs of axis symmetry. However, the mobility of polymers are affected by other factors than just the shape and symmetry of the donor unit (NDT). ${ }^{150}$ A different mobility rank was summarized for these polymers containing NDT and two thiophene units (PNDT3BT $>$ PNDT4BT $>$ PNDT1BT $>$ PNDT2BT). This difference in mobility rank between the polymers and NDT molecules can be related to the curvature of the backbone of these polymers. As shown in Figure 12, though NDT1 has a linear shape and NDT3 has an angular shape, the PNDT3BT could adopt a pseudostraight-shaped backbone (rather than a zigzag-shaped one in the case of PNDT1BT), which would lead to an effective packing of PNDT3BT into most highly ordered structure among all these four polymers, thereby the highest mobility. Similar results were reported by Müllen and co-workers, who also studied the impact of the shapes and curvature of the molecules on mobilities. ${ }^{152,153}$

To conclude this discussion on the donor units, Figure 13 shows an empirical electron-donating ability trend of representative donor units. This donor unit trend is based on the comparison of oxidation potentials and band gaps of polymers with identical acceptor units. Due to the influences of other factors, such as steric hindrance and significant differences on $\pi$-stacking, this trend may vary. Generally, a "weak donor" with moderate electron donating ability is needed to create polymers with ideal HOMO levels around $-5.4 \mathrm{eV}$. High mobility, proper intermolecular interaction, enhanced $\pi$-electron delocalization, and bonding geometry also need to be taken into consideration in order to design high performance conjugated polymers.

2.3.2. Design of Acceptor Units. Similar to the donor units, the acceptor units are of equal importance in controlling the energy levels and band gaps of conjugated polymers. However, compared with the great variety of donor units reported (e.g., a few successful examples discussed in previous section), the design and synthesis of functional acceptors only received moderate success. Nevertheless, several novel acceptor units have been developed, which contributed significantly to the enhanced photovoltaic performance of related polymers.

Perhaps the most commonly employed acceptor unit is the 2,1,3-benzothiadiazole (BT). Because of its strong electronaccepting ability and commercial availability, BT has been very popular in constructing low-band-gap conjugated polymers. $^{93,104,154}$ Moreover, these two $\mathrm{N}$ atoms in the thiadiazole ring could possibly form hydrogen bonding with adjacent units (e.g., the hydrogen atom on the thiophene ring), leading to a more planar backbone. With all these good features, many polymers with a BT acceptor unit have shown low band gaps and good photovoltaic properties. ${ }^{5,104,154}$ The best example comes from a conjugated polymer copolymerizing dithienosilole ( $\mathrm{Si}$ PCPDTBT) with the BT unit, which exhibited a band gap of $1.37 \mathrm{eV}$ and thereby a $J_{\mathrm{sc}}$ of $17.3 \mathrm{~mA} / \mathrm{cm}^{2}$, with a PCE up to $5.9 \%$ in its $\mathrm{BHJ}$ devices.

Adding one thienyl group on both sides of the BT converts BT into di-2-thienyl-2,1,3-benzothiadiazole (DTBT) (Figure 14), 4,41,42,109,155-157 which has a few more advantages when compared with the original BT unit. First, the two flanking thienyl units relieve the otherwise possibly severe steric hindrance between the BT unit and donor aromatic units (especially when benzene based aromatics are used). ${ }^{128}$ Thus, the synthesized donor-acceptor polymers adopt more planar structures, thereby reducing the band gap by enhancing the $\mathrm{D}-\mathrm{A}$ conjugation. In addition, a more planar conjugated backbone facilitates the chain-chain interactions among polymers in the solid state, improving the charge carrier (usually hole) mobility. Second, while the electron-accepting BT unit maintains the low band gap, the two electron-rich, flanking thienyl units would help improve the hole mobility, since thiophene-based polymers (such as P3HT) have shown noticeably high hole mobility. ${ }^{158}$ Third, the 


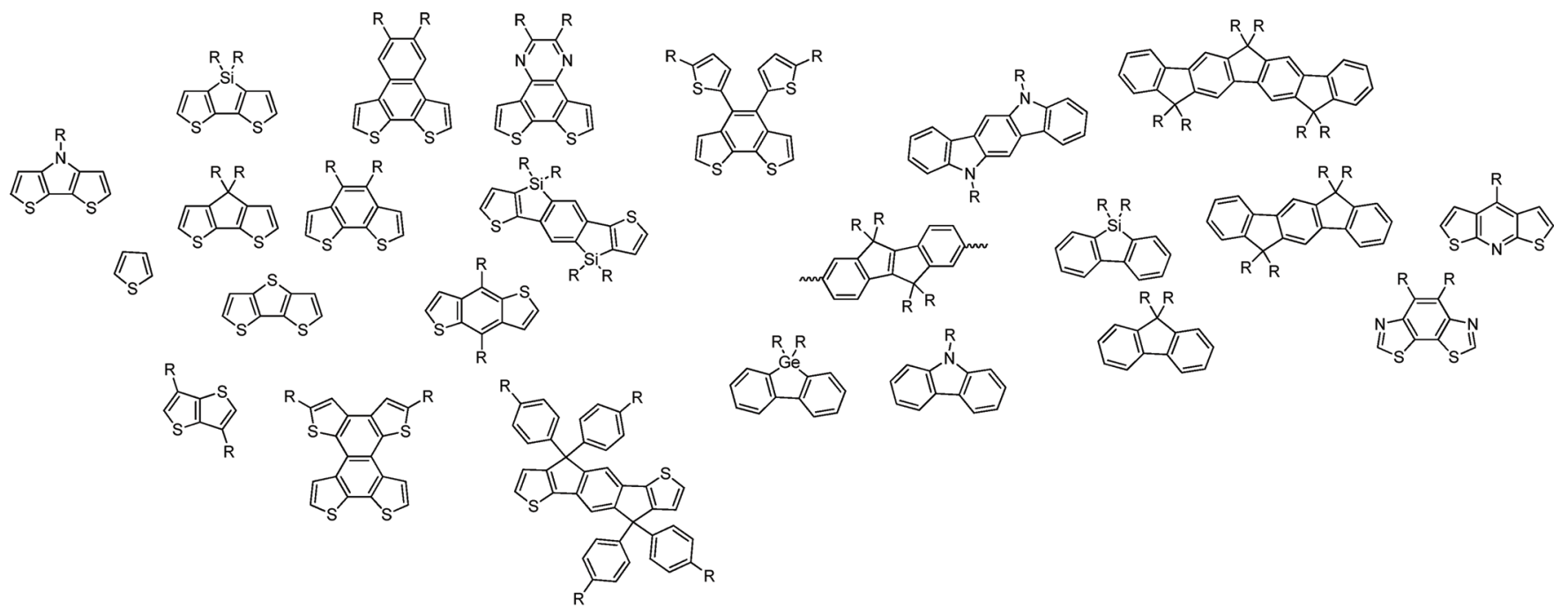

\section{Decreasing Electron Donating Ability (empirical)}

Figure 13. An empirical chart showing the relative electron-donating ability of various donor units.

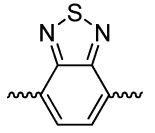

BT

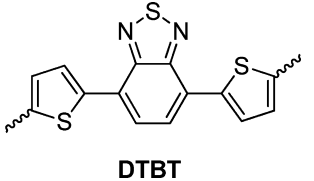

DTBT
Figure 14. Chemical structures of BT and DTBT acceptor units.

BT unit has limited positions for addition of solubilizing chains or substituents, and attaching these units would likely introduce steric hindrance. To this end, these flanking thienyl units can provide more possible positions for further modification of electronic properties and solubility of conjugated polymers, with minimal steric hindrance involved if properly introduced. ${ }^{159}$ However, due to the electron-rich nature of these thienyl units, in some cases, the two flanking thienyl units slightly increase the HOMO levels of the conjugated polymers when compared with BT-based polymers. ${ }^{128,132}$

Similar to the design of donor units (Figure 7), the electron affinity of acceptors can also be fine-tuned by varying specific atoms. Figure 15 lists a series of such units which can be treated as structurally related with the BT. For example, replacing the sulfur atom of the BT unit with a nitrogen atom, the electronaccepting ability of the triazole is significantly reduced when compared with that of the BT. It is because the lone pair on the middle nitrogen atom of the triazole unit is more basic than the lone pairs on the sulfur of the BT and is more easily donated into the triazole ring, making it relatively electron-rich when compared with the original BT. Thus, conjugated polymers incorporating triazole unit usually show a larger band gap around $2.0 \mathrm{eV}$ (Table 5). ${ }^{45}$ On the other hand, the electron-accepting ability of the quinoxaline $(\mathrm{Qx})$ is in between the triazole and BT. One advantage of $\mathrm{Qx}$ is that it can be alkylated to improve the solubility of conjugated polymers without introducing steric hindrance. ${ }^{160}$ In addition, alkylated benzo units can be introduced to the periphery of the Qx instead of alkyl chains, which provides additional control to adjust molecular interactions and may increase $V_{\text {oc }}$ and charge mobility. ${ }^{161,162}$ Benzoxadiazole (BX), the oxygen containing analogue to the BT unit, has very similar electron-accepting ability to that of BT. Thus, polymers containing the BX unit have very similar HOMO and LUMO levels to those of BTbased analogues. Interestingly, these BX-based polymers usually do not perform as well as these BT-based analogues, possibly due to lower mobilities of these BX-containing polymers. ${ }^{106,156,163}$ Lastly, the selenium analogue of the BT unit, 2,1,3-benzoselenadiazole (BSe), demonstrates many interesting properties in photoelectronic devices. ${ }^{160,164}$ In general, BSebased polymers exhibit smaller band gaps and lower HOMO and LUMO levels (from CV). ${ }^{69,165,166}$ However, the photovoltaic properties of BSe-based polymers are restricted by the weak absorption of the active layer and the imbalance in the hole and electron transport of the active layer which may result from bad morphology.

In most of the high performance $\mathrm{D}-\mathrm{A}$ conjugated polymers reported, close to ideal HOMO energy levels were achieved (e.g., $-5.4 \mathrm{eV}$ ), which lead to an observed open-circuit voltage $\left(V_{o c}\right)$ as high as $0.92 \mathrm{~V} .^{6,45,61}$ However, very often the band gaps of these materials are still larger than the proposed $1.5 \mathrm{eV}$ of ideal polymers, resulting in mediocre short-circuit currents $\left(J_{s c}\right)$. In order to further improve the efficiency, a smaller band gap is needed to achieve a higher $J_{\text {sc }}$ while the low HOMO energy level should still be maintained (for a high $V_{\text {oc }}$ ). According to the proposed approach of "weak donor-strong acceptor", one should incorporate "strong acceptors" with large electron deficiency in the conjugated backbone to lower the LUMO levels, thereby decreasing the band gap of related polymers. We will elaborate on this concept by discussing several such strong acceptors.

One such example is the dithienylthiadiazolo[3,4-c]pyridine (DTPyT), which differs from the original DTBT by only one atom (Figure 16). Compared with benzene, pyridine is $\pi$-electron deficient. Therefore by replacing the benzene in the BT unit with pyridine, the new acceptor, thiadiazolo[3,4-c]pyridine (PyT), would be one such stronger acceptor. Polymers incorporating DTPyT unit were first reported by Leclerc et al., ${ }^{156}$ and their PV performances were then enhanced up to $6.3 \%$ by You et al. (Table 6$)^{107}$ by copolymerizing with "weak donors" to adjust energy levels and attaching solubilizing chains 
Table 5. Summary of Band Gaps, HOMO/LUMO Levels, and Photovoltaic Properties of Conjugated Polymers in Figure 15b

\begin{tabular}{lcccccccc}
\multicolumn{1}{c}{ polymer } & band gap $(\mathrm{eV})$ & HOMO $(\mathrm{eV})$ & LUMO $(\mathrm{eV})$ & $V_{\mathrm{oc}}(\mathrm{V})$ exp & $J_{\mathrm{sc}}\left(\mathrm{mA} / \mathrm{cm}^{2}\right)$ & $F F$ & PCE $(\%)$ & ref \\
PBnDT-HTAZ & 1.98 & -5.29 & -2.87 & 0.70 & 11.14 & 0.55 & 4.30 & 45 \\
PCDTQx & 2.02 & -5.46 & -3.42 & 0.95 & 3.0 & 0.56 & 1.8 & 156 \\
PCDTBT & 1.88 & -5.45 & -3.60 & 0.86 & 6.8 & 0.56 & 3.6 & 156 \\
PCDTBX & 1.87 & -5.47 & -3.65 & 0.96 & 3.7 & 0.60 & 2.4 & 156 \\
H11 & 1.52 & -4.88 & -3.33 & 0.55 & 1.05 & 0.32 & 0.18 & 69 \\
\hline
\end{tabular}
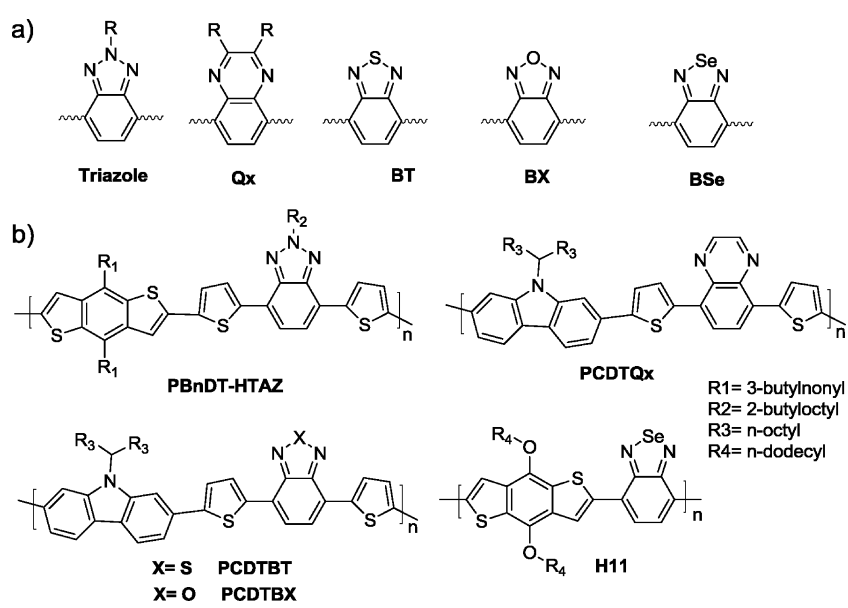

Figure 15. (a) Chemical structures of trizole, $\mathrm{Qx}, \mathrm{BT}, \mathrm{Bx}$ and BSe units. (b) Chemical structures of related copolymers.

to improve the molecular weight and the film morphology. All the DTPyT-containing polymers reported by You and coworkers showed noticeably reduced LUMO levels, slightly reduced HOMO levels, and thus smaller band gaps than those of their DTBT counterparts. The smaller band gap significantly improves the observed $J_{\mathrm{sc}}$ of the related $\mathrm{BHJ}$ devices, while the low HOMO energy level maintains the high $V_{\text {oc }}$. Therefore all three polymers (PNDT-DTPyT, PQDT-DTPyT, and PBnDT-DTPyT) achieved high efficiency numbers in their $\mathrm{BHJ}$ devices, demonstrating the great utility of DTPyT acceptor moiety in designing high performance solar cell materials.

Similarly, tetrazine $(\mathrm{Tz})$ which has a very high electron affinity has also been used as a strong acceptor to construct low-band-gap polymers with over $5 \%$ efficiency achieved. ${ }^{167}$ When incorporated into $\mathrm{D}-\mathrm{A}$ conjugated polymers, both HOMO and LUMO levels of Tz-based copolymers are lower than those of BT-based copolymers, indicating a stronger electron affinity of the $\mathrm{Tz}$ unit. Interestingly, the $\mathrm{Tz}$ unit shows more impact on HOMO levels than on LUMO levels, which is different from most acceptor units. This results in slightly broader band gaps of Tz-based polymers when compared with these of BT-based polymers.

Isoindigo is a symmetrical and perfect planar $\pi$-conjugated molecule consisting of two indolin-2-one units, which are strongly electron withdrawing. ${ }^{168,170,171}$ A few conjugated polymers based on isoindigo units possess near-ideal low HOMO levels around $-5.4 \mathrm{eV}$ and low LUMO levels around $-3.9 \mathrm{eV}$. However, relatively low PCE up to $3 \%$ was obtained, with a large $V_{\text {oc }}$ of $0.9 \mathrm{~V}$ but a low $J_{\mathrm{sc}}$ around $5 \mathrm{~mA} / \mathrm{cm}^{2} .{ }^{168}$ Further improvement can be anticipated by choosing proper donor units and side chains as well as by improving the active layer morphology.

Structurally similar to isoindigo, pyrrolo $[3,4-c]$ pyrrole-1,4dione (DPP) has also been used in a number of $\mathrm{D}-\mathrm{A}$ conjugated polymers in the past 3 years. ${ }^{1,44,118,169,172-176}$ Low band gaps around $1.3 \mathrm{eV}$ are generally obtained, which is beneficial for $J_{\text {sc }}$ however, HOMO levels of DPP-based polymers are significantly elevated when compared with those of their analogues with other acceptors, possibly due to these two flanking electron-donating thienyl units. Nevertheless, efficiency numbers as high as $5.5 \%$ were reported for DPP-based polymers. ${ }^{169,176}$

The thieno[3,4-c]pyrrole-4,6-dione (TPD) unit was recently intensively explored. The symmetric and planar structure of TPD could improve the electron delocalization, enhancing the polymer chain-chain interactions and increasing the hole mobility. Similar to DPP and isoindigo, electron-withdrawing amide groups render TPD a strong acceptor. It was first incorporated in BnDT-based copolymers by Leclerc and coworkers. ${ }^{177}$ The resultant copolymer not only has a small band gap (thereby a potentially high $J_{\mathrm{sc}}$ ), also maintains a low HOMO energy level of $-5.56 \mathrm{eV}$. Therefore a high $V_{\text {oc }}$ of $0.85 \mathrm{~V}$ was achieved in the $\mathrm{BHJ}$ device with $\mathrm{PC}_{71} \mathrm{BM}$ as the acceptor. Along with a $J_{\text {sc }}$ of $9.81 \mathrm{~mA} / \mathrm{cm}^{2}$ and a $F F$ of 0.66 , a PCE of $\sim 5.5 \%$ was obtained. It is particularly worth mentioning that Leclerc et al. obtained these impressive values from devices with an active area of $1.0 \mathrm{~cm}^{2}$. Achieving high efficiencies on devices of large area is advantageous for real world application of PSC because efficiencies obtained on areas smaller than $0.2-0.3 \mathrm{~cm}^{2}$ may become strongly substrate sizedependent, in addition to the possible overestimation of the $J_{s c}$ from a very small area device. Similar polymers with identical conjugated backbone but having different solubilizing chains were independently reported by Jen's group and Xie's group with PCEs varying from $3.42 \%$ to $4.79 \%$ after certain optimization. ${ }^{178,179}$ Fréchet and co-workers later did a detailed study on the impact of these side chains on the TPD-BDT copolymer. ${ }^{180}$ PCEs up to $6.8 \%$ were reported just by varying the side chains of the conjugated backbone. More recently, TPD-based polymers of efficiency as high as $7.3 \%$ were reported by Amb et al. and Tao and co-workers. ${ }^{60,62,63,181}$ In their studies, the TPD acceptor was copolymerized with fused bithiophene with different bridging atoms. All of these copolymers exhibit high PCEs over 6\% in $\mathrm{BHJ}$ solar cells, which indicates a great potential of TPD unit in constructing novel materials for PSC.

However, acceptors should not be too electron withdrawing. As discussed earlier, the LUMO of the conjugated polymer should be at least $0.3 \mathrm{eV}$ larger than the LUMO of the n-type material to facilitate efficient exciton dissociation. Too strong an acceptor in the D-A polymer would lead to too low a LUMO level and the inability to split excitons at the interface between the polymer and fullerenes. Thus, no photocurrent or extremely small $J_{\mathrm{sc}}$ would be observed. Several examples include benzo $\left[1,2-c: 4,5-c^{\prime}\right]$ bis $([1,2,5]$ thiadiazole $)($ BBTD $),{ }^{182}[1,2,5]$ thiadiazolo[3,4-g]quinoxaline, ${ }^{183,184}$ pyrazino[2,3-g]quinoxaline, ${ }^{185}$ and $[1,2,5]$ thiadiazole $[3,4-d]$ pyridazine. ${ }^{186}$

2.4. Substituents. Though the energy levels and band gap of a conjugated polymer are mainly determined by the selection of conjugated aromatic units (e.g., D and A in D-A polymers), 
Table 6. Summary of Band Gaps, HOMO/LUMO Levels, and Photovoltaic Properties of Conjugated Polymers in Figure 16b

\begin{tabular}{|c|c|c|c|c|c|c|c|c|}
\hline polymer & band gap $(\mathrm{eV})$ & HOMO (eV) & LUMO $(\mathrm{eV})$ & $V_{\mathrm{oc}}(\mathrm{V}) \exp$ & $J_{\mathrm{sc}}\left(\mathrm{mA} / \mathrm{cm}^{2}\right)$ & FF & PCE (\%) & ref \\
\hline PBnDT-DTPyT & 1.51 & -5.47 & -3.44 & 0.85 & 12.78 & 0.58 & 6.3 & 107 \\
\hline PCPDTTTz & 1.68 & -5.34 & -3.48 & 0.75 & 12.2 & 0.59 & 5.4 & 167 \\
\hline PTI-1 & 1.60 & -5.85 & -3.88 & 0.89 & 5.4 & 0.63 & 3.0 & 168 \\
\hline PDPPTPT & 1.53 & -5.35 & -3.53 & 0.80 & 10.3 & 0.65 & 5.5 & 169 \\
\hline $\mathrm{P}-\mathrm{Ge}$ & 1.69 & -5.6 & NA & 0.85 & 12.6 & 0.68 & 7.3 & 62 \\
\hline
\end{tabular}
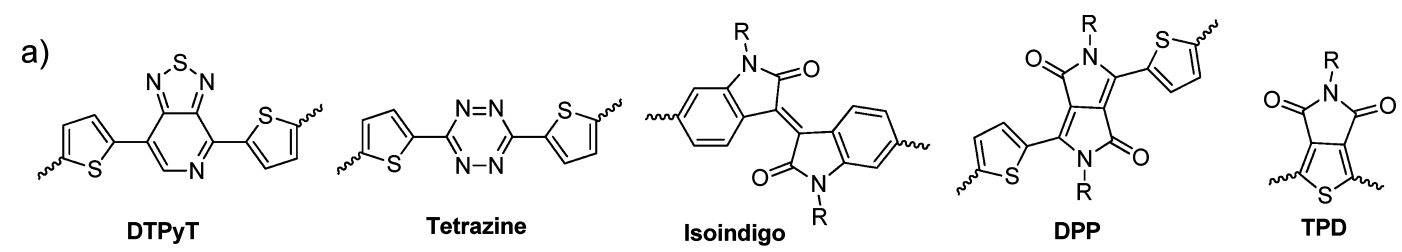

b)

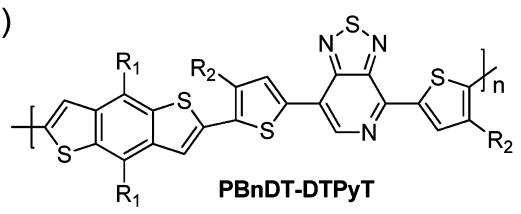

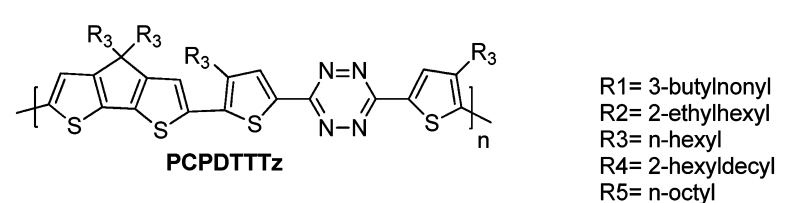<smiles>[R2]N1C(=O)/C(=C2/C(=O)N([R2])c3cc(C(C)(C)C)ccc32)c2ccc(-c3ccc(C)s3)cc21</smiles><smiles></smiles><smiles>[R6]N1C(=O)C2=C(C)SC(=C3c4sc(C)cc4[R]3([R20])[R2])C2C1=O</smiles>

Figure 16. (a) Chemical structures of some "strong acceptor" units. (b) Chemical structures of related copolymers.

substituents can be used to further tune energy levels, band gaps, molecular interaction, and even morphology.

Using archetypical PPV as the model polymer, the substituent effect on conjugated polymers was systematically studied by Bredas and Heeger with the valence effective Hamiltonian (VEH) method (Figure 17). ${ }^{187}$ Attaching

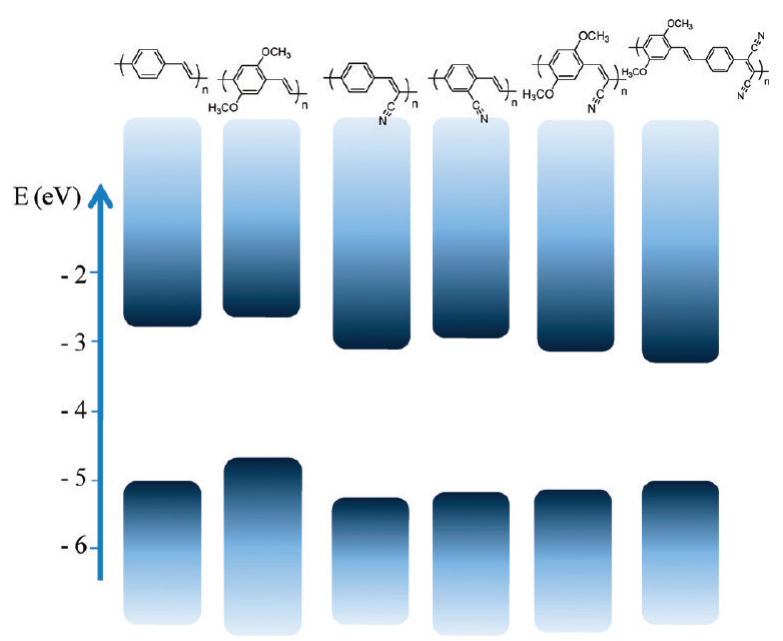

Figure 17. HOMO and LUMO of the compound investigated, relative to the work functions of calcium and aluminum. ${ }^{187}$

electron-donating methoxy groups to the benzene unit of the PPV would raise the HOMO energy level when compared with the original PPV (with similar LUMO level). This effect was also observed experimentally. ${ }^{188}$ When switching to the electron-withdrawing group (such as cyano), stabilization on both HOMO and LUMO levels would be expected. However, calculations found that the band gaps of the cyano PPVs would be larger than that of PPV because of the asymmetry in the stabilization of the HOMO and LUMO levels by the cyano substituent. Furthermore, the position of the cyano (either on the phenylene or on the vinylene) affects the energy levels and band gap. When cyano was added on the vinylene, the calculated LUMO level was noticeably lower than that of the analogue with cyano on the phenylene, with less difference on the HOMO energy levels. The authors attributed this effect to the different number of $\pi$-electrons on the vinylene and phenylene. Since vinylene unit only has two $\pi$-electrons whereas phenylene unit has six, substitution on the vinylene would introduce a relatively larger perturbation to the conjugated backbone, further lowering the LUMO level. All these results presented above indicate that electron-donating substituents (such as methoxy) would have a more significant impact on the HOMO level, while electron-withdrawing ones (such as cyano) would affect more strongly on the LUMO level. Therefore, by attaching both methoxy group and cyano group on the phenylene and the vinylene part of PPV, respectively, the resulting polymer exhibited a similar HOMO level with that of the methoxy PPV and a similar LUMO with that of the cyano PPV, leading to a significantly decreased band gap. ${ }^{189}$ This result is in good agreement with the proposed "weak donor-strong acceptor" strategy to design ideal polymers. $^{59}$

Another interesting substituent is the fluorine. Fluorine is the smallest electron-withdrawing group with a van der Waals radius of $1.35 \AA$ and a Pauling electronegativity of 4.0. Fluorinated organic molecules exhibit a series of unique features such as great thermal and oxidative stability, ${ }^{190}$ elevated resistance to degradation, ${ }^{191}$ enhanced hydrophobicity, and 
high lipophobicity in perfluorinated substances. ${ }^{192}$ In addition, these fluorine atoms often have a great influence on inter- and intramolecular interactions via $\mathrm{C}-\mathrm{F} \cdots \mathrm{H}, \mathrm{F} \cdots \mathrm{S}$, and $\mathrm{C}-\mathrm{F} \cdots \pi_{\mathrm{F}}$ interactions. ${ }^{191,193}$ Applying fluorine substitution in the D-A polymers was investigated by You and co-workers in two recent studies. ${ }^{45,61}$ In one report, they added two fluorine atoms to the commonly employed benzothiadiazole (BT), converting BT into fluorinated benzothiadiazole (ffBT) (Figure 18). ${ }^{61}$ The

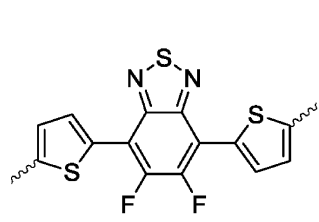

DTfBT

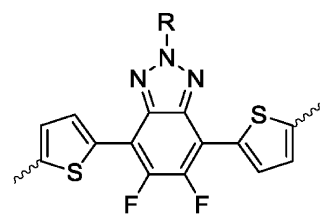

FTAZ<smiles>[R]OC(=O)c1sc2c(-c3cc4c(O[R])c5sc(C)cc5c(F)c4s3)sc(C([Y])C)c2c1[R]</smiles><smiles></smiles>

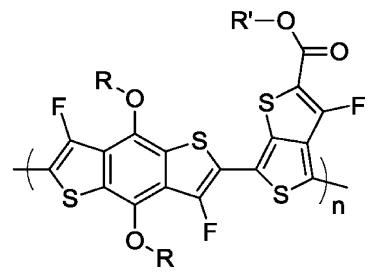

Figure 18. Chemical structures of fluorine atom containing acceptor units and conjugated polymers.

ffBT-based polymer showed decreased HOMO and LUMO levels but a similar band gap when compared with those of its nonfluorinated analogue. Preliminary PV tests on $\mathrm{BHJ}$ devices demonstrated both increased $V_{\mathrm{oc}}(0.91 \mathrm{~V})$ and $J_{\mathrm{sc}}\left(12.9 \mathrm{~mA} / \mathrm{cm}^{2}\right)$. Together with an also enhanced fill factor of 0.61 , an impressive PCE of $7.2 \%$ was thus obtained without special treatments. In another related study, BnDT-based copolymers (PBnDT-FTAZ) with 5,6-difluoro- $2 H$-benzo[d][1,2,3] triazole (FTAZ) as the acceptor unit was synthesized. ${ }^{45}$ This polymer exhibited a medium band gap of $2.0 \mathrm{eV}$ when compared with that of the DTBT-based polymer due to the weaker electron affinity of the FTAZ unit. Surprisingly, in spite of a band gap of $\sim 2.0 \mathrm{eV}$, the $J_{\text {sc }}$ of PBnDT-FTAZ based BHJ solar cells could reach over $12 \mathrm{~mA} / \mathrm{cm}^{2}$ (depending upon the thickness of the active layer), which can be explained by the high molecular weight and the large hole mobility of PBnDT-FTAZ. The BHJ devices based on PBnDT-FTAZ consistently showed a higher FF and $J_{\mathrm{sc}}$ than those of devices based on the polymers without fluorine substituents (PBnDT-HTAZ) at comparable thicknesses. A peak PCE of 7.1\% was obtained in $\mathrm{BHJ}$ devices of PBnDT-FTAZ: $\mathrm{PC}_{61} \mathrm{BM}$ without annealing or any additives. Remarkably, PBnDT-FTAZ:PC ${ }_{61} \mathrm{BM}$ solar cells can still achieve over $6 \%$ efficiency even at an unprecedented thickness of $1 \mu \mathrm{m}$ (of the active layer).

Besides the study on the fluorine substituent effect in D-A polymers, the fluorine atom has also been applied in quinoid polymers. For example, $\mathrm{Yu}$ and co-workers studied a series of polymers based on fluorinated thienothiophene (TT). ${ }^{74,78,194,195}$ As expected, the substitution of electron-withdrawing fluorine onto the polymer backbone reduced the HOMO energy levels of polymers when compared with the nonfluorinated analogues. Furthermore, this structural modification optimized the polymers' spectral coverage of absorption and their hole mobility as well as their miscibility with $\mathrm{PC}_{71} \mathrm{BM}$. All these contributed to an enhanced polymer solar cell performance up to $7.4 \%$, which is one of the highest efficiencies within the literature reports. ${ }^{74,78}$ Further, using the original conjugated backbone (BnDT-TT) as the subject of study, Son et al. showed that the incorporation of the fluorine onto various positions of the polymer backbone significantly affected the performance of related solar cells (Figure 18). ${ }^{76}$ Depending upon which hydrogen of the conjugated backbone is substituted by the fluorine, PCE of corresponding $\mathrm{BHJ}$ devices can vary from $2.3 \%$ to $7.2 \%$. They also observed that fluorination of the $\mathrm{BnDT}$ unit lowered both the HOMO and LUMO levels of the conjugated polymer but widened the band gap. Finally, perfluorination of the polymer backbone led to a poor compatibility of the polymer with $\mathrm{PC}_{71} \mathrm{BM}$; thus, poor solar cell performance was observed. In addition, the authors found that perfluorination of the polymer backbone resulted in poor photochemical stability against singlet oxygen attack. $^{76}$ These interesting effects of substituents on physical properties of conjugated polymers are still under active investigation.

2.5. Side Chains. For conjugated polymers used in organic solar cells, solubilizing side chains are required to allow solution processability, which is the key feature for future low-cost mass production of these flexible solar cells. Without solubilizing chains, the conjugated backbone would adopt a more planar structure, thereby facilitating the chain-chain interactions among polymers and leading to unprocessable "bricks". In addition to imparting the solubility to conjugated polymers, side chains have been discovered to play important roles in certain key properties of conjugated polymers, such as molecular weight, inter- and intramolecular interactions, charge transport, and active layer morphology. ${ }^{50}$ In this section, these recently emerged understandings of the side-chain effect will be discussed, followed by the suggested guidelines of designing solubilizing chains.

2.5.1. Position. It is well-known that decorating the polymer backbone with side chains can effectively improve the solubility of the polymer, which is a crucial prerequisite toward achieving high molecular weight of the resulting conjugated polymer. However, substituting the small hydrogen atoms on these aromatic units with rather big alkyl or alkoxy chains often result in significant steric hindrance between these aromatic units on the conjugated backbone. For example, a computational simulation revealed that severe steric hindrance introduced by these alkyl/alkoxy chains on the DTBT would lead to a twisted conjugated backbone in polymers incorporating the substituted DTBT. ${ }^{196}$ Therefore, the hole mobilities of the polymers incorporating such substituted DTBT were noticeably lower than that of the polymer with unsubstituted DTBT, which accounted for a smaller $J_{\mathrm{sc}}$ in the former case. ${ }^{196}$ In an earlier study, the homopolymers of alkylated DTBT were prepared by Jayakannan et al. by varying alkyl chains on either 3- or 4-positions of the thienyl groups. ${ }^{197}$ Though relatively high molecular weight polymers were obtained, the steric hindrance introduced by these alkyl chains in these polymers led to much larger band gaps than that of the homopolymer of unsubstituted DTBT. ${ }^{198}$ Later, Wang et al. synthesized a series of internal donor-acceptor type of copolymers containing benzothiadiazole (BT) and four thiophenes incorporating side 
chains on different position as shown in Figure 19. ${ }^{199}$ Despite indentical alkyl side chains, the positions where these alkyl side
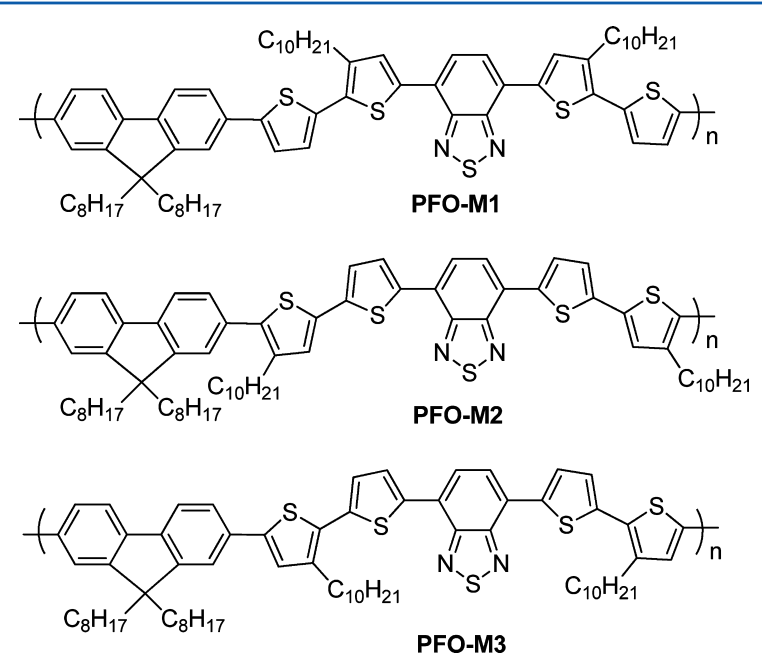

Figure 19. Chemical structures of PFO-M1, PFO-M2, and PFO-M3.

chains are attached to different thiophene rings have significant influence on the physical properties and photovoltaic performance of resulting polymers. Positioning these alkyl chains close to the fluorene renders large steric hindrance during polymerization, which results in a significantly lower molecular weight of PFO$\mathrm{M} 2$ and consequently a poor PV performance of related $\mathrm{BHJ}$ cells when compared with $1.82 \%$ for PFO-M1 and $2.63 \%$ for PFO-M3 based BHJ solar cells.

Most recently, You and co-workers systematically investigated what effect the side-chain positions had on the optical, electrochemical, and photovoltaic properties of conjugated polymers using PBDT-DTBT as the model polymer (Figure 20). ${ }^{159}$

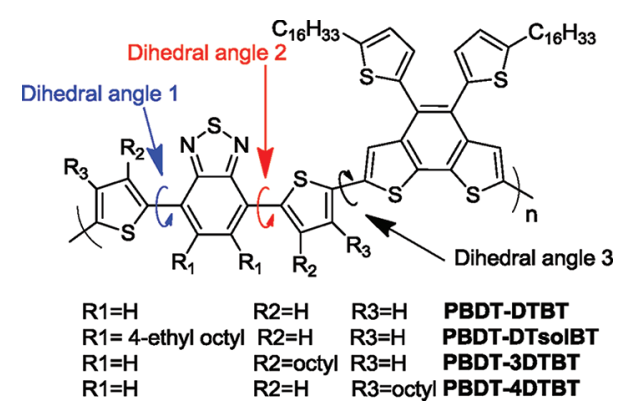

Figure 20. Chemical structures of PBDT-DTBT, PBDT-4DTBT, PBDT-3DTBT, and PBDT-DTsolBT. Reprinted with permission from ref 159. Copyright 2010 American Chemical Society.

These three polymers with alkyl chains attached on DTBT have similar molecular weights (much higher than that of PBDT-DTBT without alkyl chains on DTBT), thereby minimizing the potential complication from the influence of different molecular weights. Thus, all observed differences in properties (optical, electrochemical, and photovoltaic) can be ascribed to the difference in where these side chains were placed. They quantitatively measured the steric hindrance introduced by these alkyl chains by calculating the dihedral angles between two thienyl groups with the center BT unit as well as with the donor BDT. There is only a slight increase of the dihedral angle between the 4-substituted thienyl group and the BDT unit in PBDT4DTBT when compared with the original PBDT-DTBT, indicating a minimum steric hindrance introduced by the 4DTBT. Moreover, the DFT calculation showed that the electron density is delocalized in the HOMO of PBDT-4DTBT, similar to that of PBDT-DTBT. This results in an almost negligible difference between the HOMO energy level of PBDT-DTBT and that of PBDT-4DTBT. On the other hand, moving these alkyl chains away from the vicinity of $\mathrm{BDT}$ unit in the case of PBDT-3DTBT and PBDT-DTsolBT decreases the steric hindrance between substituted DTBT and BDT unit, recovering small numbers on the dihedral angle 3 . However, greater steric hindrance is formed between the thienyl groups and the center BT unit, as shown by a dramatic numerical increase in the dihedral angles 1 and 2. This severe steric hindrance essentially breaks the conjugation at the linkages between these thienyl groups and the $\mathrm{BT}$, thereby rendering large band gaps for these two polymers (2.21 eV for PBDT-3DTBT and $2.48 \mathrm{eV}$ for PBDT-DTsolBT).

The thorough investigation of this library of structurally related polymers clearly indicates that attaching alkyl chains on the 4-positions of these thienyl groups (i.e., 4DTBT) only introduces minimum steric hindrance into the related $\mathrm{D}-\mathrm{A}$ polymer. Therefore, PBDT-4DTBT maintains almost identical band gap and energy levels when compared with those of PBDTDTBT. However, these additional side chains offer a high molecular weight and excellent solubility of PBDT-4DTBT, the latter leading to a more uniform mixture with $\mathrm{PC}_{61} \mathrm{BM}$ with better control on the film morphology. All these features of PBDT-4DTBT contribute to a noticeably enhanced efficiency (up to $2.2 \%$ ) of PBDT-4DTBT-based BHJ cells, significantly higher than that of PBDT-DTBT-based devices (0.7\%).

2.5.2. Shape and Length. Even when the side chains are "properly" anchored on the conjugated backbone, the length and shape of these side chains also have a noticeable (sometimes substantial) impact on the properties of resulting conjugated polymers. Gadisa et al. completed a comparative investigation on the photovoltaic properties of $\mathrm{BHJ}$ devices based on a series of poly(3-alkylthiophene)s of butyl (P3BT), pentyl (P3PT), and hexyl (P3HT). ${ }^{200}$ FF of $0.529,0.624$, and 0.675 were obtained from solar cells based on P3BT:PC ${ }_{61} \mathrm{BM}$ (1:0.8), P3PT:PC ${ }_{61} \mathrm{BM} \quad(1: 1)$, and P3HT:PC ${ }_{61} \mathrm{BM}$ (1:1), respectively. Bipolar measurements made by field-effect transistors showed a decrease in the hole mobility and an increase in the electron mobility with increasing alkyl chain length, which is attributed to the an increase in the degree of phase separation. The longer side chains facilitate the clustering of $\mathrm{PC}_{61} \mathrm{BM}$ molecules and establish fast electron-percolation pathways, leading to improved electron mobility. Since holes and electrons exhibit well-balanced mobilities in the case of P3HT:PC ${ }_{61} \mathrm{BM}$, a better fill factor was observed.

In another study, Egbe et al. grafted different side chains to the backbone of a series of anthracene-containing poly $(p$-phenyleneethynylene)-alt-poly ( $p$-phenylenevinylene) (PPE-PPV) copolymers to tune the $\pi-\pi$ stacking ability of the materials (Figure 21). ${ }^{201}$ Polymers with octyloxy substitution close to the AnE units $(a b, a d, a e)$ arrange in a stacked manner, whereas asymmetric $(c c)$ or branched side chain substitution $(b b, b a)$ near the AnE unit yields less organized or even amorphous polymers. The best performance of $3.14 \%$ was achieved from $\mathrm{BHJ}$ devices based on $a b$ ANE-PV which shows both stacking ability and biggest $\pi-\pi$ stacking distance of $0.386 \mathrm{~nm}$ as opposed to $0.380 \mathrm{~nm}$ for the other polymers in this series. Lower efficiency values were obtained for the $\mathrm{BHJ}$ devices based on amorphous polymers $b a$ and $b b$, due to a high miscibility of components in the active layer resulting in insufficient percolation paths for the 

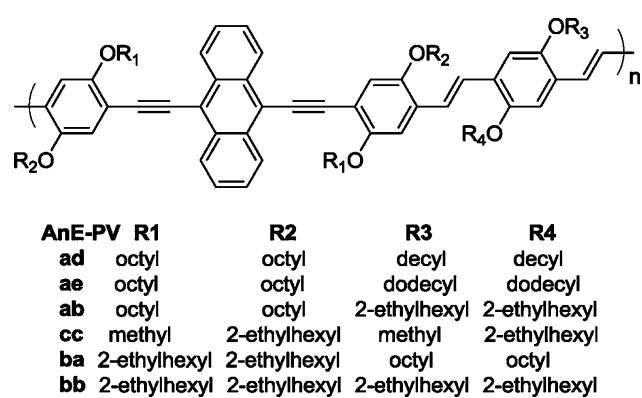

Figure 21. Chemical structures of PPE-PPV with different alkyl side chains. Reprinted with permission from ref 201. Copyright 2010 American Chemical Society.

photogenerated charges. Moreover, $\mathrm{BHJ}$ devices based on ad and ae with higher side chain density (number of carbons) exhibited lower photovoltages and fill factors and thus lower photovoltaic performance when compared with those of $a b$ based $\mathrm{BHJ}$ devices. The authors believed that high density side chains dilute the concentration of the light absorbing conjugated species per volume unit and reduce the amount of light absorbed by the active layer. High density side chains also reduce the interfacial area between the DONOR polymer and the $\mathrm{PC}_{61} \mathrm{BM}$, leading to a strong phase separation and concomitant poor PV performance. Finally, a large $V_{\text {oc }}$ change from $\sim 0.65 \mathrm{~V}$ to $\sim 0.90 \mathrm{~V}$ was observed, which is likely influenced by the shape and size of these side chains. However, the relationship between the $V_{\text {oc }}$ and the side chains (shape and size) was not further investigated in the report.

The first quantitative analysis of the influence from the size of these side chains on photovoltaic properties of polymerfullerene solar cells was carried out by You and co-workers. ${ }^{50}$ In their report, six polymers with an identical polymer backbone (PNDT-DTBT) but different side chains (i.e., size and branching) were synthesized and investigated (Figure 22a). In good solvent and at high temperature, all polymer chains are completely solvated with minimum intermolecular interactions, which leads to almost identical UV-vis absorptions due to the identical backbone of PNDT-DTBT. However, BHJ solar cells employ the polymer: $\mathrm{PC}_{61} \mathrm{BM}$ blend at the solid state where the intermolecular interactions (i.e., between polymers and between the polymer and the $\mathrm{PC}_{61} \mathrm{BM}$ molecules) play a crucial role. Since these seemingly subtle differences in the polymer structures (size and branching of these side chains) affect the intermolecular interactions in the solid state, the observed $V_{\text {oc }}$ and $J_{\text {sc }}$ of these polymer-based $\mathrm{BHJ}$ devices can vary as much as $100 \%$. Consequently, the overall efficiency of these solar cells has shown a significant variation as much as 2.5 -fold (from $1.20 \%$ to $3.36 \%$ ). More importantly, the observed $V_{\text {oc }}$ change was quantitatively correlated with a pre-exponential dark current term, $J_{\text {so }}$, which accounts for the intermolecular interactions in the polymer $/ \mathrm{PC}_{61} \mathrm{BM}$ blends. There is excellent agreement between the experimentally observed $V_{\text {oc }}$ values and the calculated ones using the following theoretical equation (Table 7), a clear indication of the viability and effectiveness of this simulation for $V_{\text {oc }}$ :

$$
V_{\mathrm{oc}} \approx \frac{n k T}{q} \ln \left(\frac{J_{\mathrm{sc}}}{J_{\mathrm{so}}}\right)+\frac{\Delta E_{\mathrm{DA}}}{2 q}
$$

where $q$ is the fundamental charge, $n$ is the diode ideality factor, and $\Delta E_{\mathrm{DA}}$ is the energy difference between the LUMO level of the ACCEPTOR and the HOMO level of the DONOR.

Specifically, the polymer with the long and branched side chains $(\mathrm{C} 10,6-\mathrm{C} 6,2)$ displayed the highest $V_{\text {oc }}$ of $0.81 \mathrm{~V}$ in its $\mathrm{BHJ}$ cells. As the long branched chains were systematically converted to short linear chains-until the extreme of the polymer C8C8-the measured $V_{\text {oc }}$ gradually decreased to a minimum of $0.41 \mathrm{~V}$ (Table 7). From the XRD spectrum, the very weak (010) peak intensity in the C10,6-C6,2 polymer indicates a weak $\pi$-overlapping among individual conjugated polymer chains which results in weak intermolecular interaction (Figure 22b). This weak intermolecular interaction leads to a small $J_{\text {so }}$ that is beneficial to the $V_{\text {oc }}$ (see above equation). On the other hand, short and straight side chains would promote the a

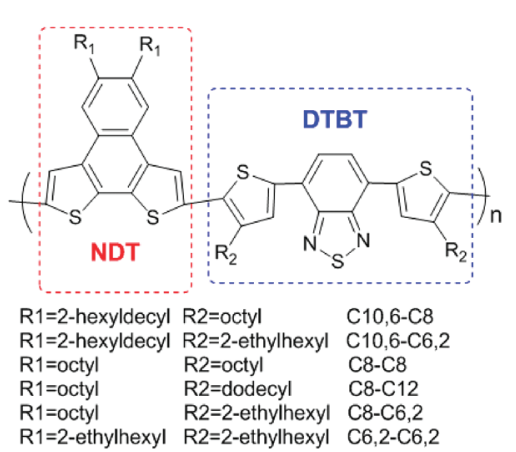

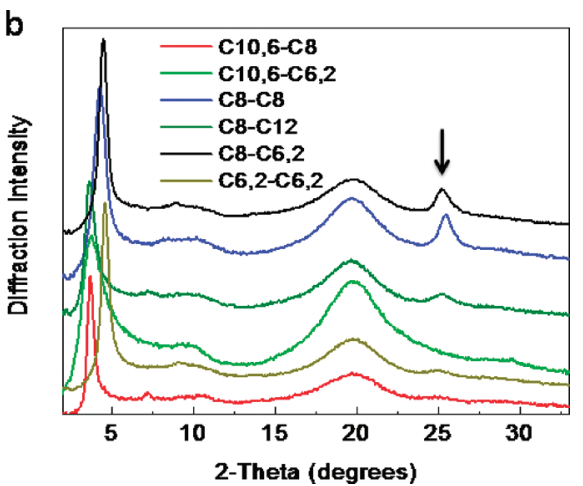

Figure 22. (a) Chemical structures of six polymers based on the PNDT-DTBT backbone. (b) XRD spectra of conjugated polymers:PC ${ }_{61} \mathrm{BM}(1: 1)$ blends in thin films (arrows indicating (010) peaks). ${ }^{50}$

Table 7. Measured and Calculated Performance Parameters for All Devices of PNDT-DTBT Series ${ }^{50}$

\begin{tabular}{lccccccc}
\multicolumn{1}{c}{ polymer } & $J_{\mathrm{so}}\left(\mathrm{mA} / \mathrm{cm}^{2}\right)$ & HOMO $(\mathrm{eV})$ & $V_{\text {oc }}(\mathrm{V}) \mathrm{cal}$ & $V_{\text {oc }}(\mathrm{V})$ exp & $J_{\mathrm{sc}}\left(\mathrm{mA} / \mathrm{cm}^{2}\right)$ & $F F$ & PCE $(\%)$ \\
C10,6-C8 & 148 & -5.32 & 0.60 & 0.59 & 0.98 & 0.46 \\
C10,6-C6,2 & 3.38 & -5.33 & 0.83 & 0.81 & 5.62 & 0.44 \\
C8-C8 & 399 & -5.13 & 0.39 & 0.41 & 6.97 & 0.42 \\
C8-C12 & 254 & -5.27 & 0.53 & 0.52 & 5.88 & 0.42 \\
C8-C6,2 & 68.8 & -5.30 & 0.60 & 0.59 & 10.93 & 0.46 \\
C6,2-C6,2 & 22.6 & -5.34 & 0.70 & 0.69 & 10.67 & 0.46
\end{tabular}


intermolecular interaction, as confirmed by the highly intense (010) peak. This improved intermolecular interaction (represented by a large $J_{\text {so }}$ ) renders a small optical band gap and better charge transport, which should increase the $J_{\mathrm{sc}}$ (though at the expense of $\left.V_{o c}\right)$. The short and branched side chains $(\mathrm{C} 6,2-\mathrm{C} 6,2)$ strike a desirable balance between $V_{\mathrm{oc}}$ and $J_{\mathrm{sc}}$ to reach the optimum efficiency via an appropriate $J_{\text {so }}$. Therefore the C6,2-C6,2 polymer based $\mathrm{BHJ}$ cells exhibited the highest efficiency of $3.36 \%$ in this study with a $V_{\text {oc }}$ of $0.69 \mathrm{~V}$ and a $J_{\text {sc }}$ of $10.67 \mathrm{~mA} / \mathrm{cm}^{2}$.

A similar impact of these side chains has also been observed by $\mathrm{Yu}$ and co-workers on a series of low-band-gap polymers with identical conjugated backbone of poly(thieno[3,4- $b$ ]thiophene-benzodithiophene) (Figure 23). ${ }^{74,194,202}$ The first

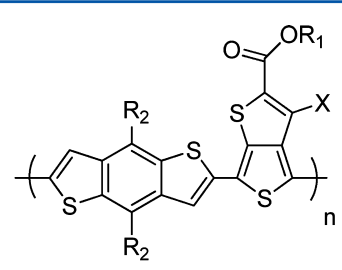

PTB1: $X=H, R 1=$ n-dodecyl, $\quad$ R2 = n-octyloxy PTB2: $X=\mathrm{H}, \mathrm{R} 1=$ 2-ethylhexyl, R2 = n-octyloxy PTB3: $X=H, R 1=2$-ethylhexyl, R2 = n-octyl

PTB4: $X=F, R 1=$-octyl $\quad$ R2 = 2-ethylhexyloxy

PTB5: $X=H, R 1=$ n-octyl, $\quad$ R2 = 2-ethylhexyloxy

PTB6: $X=H, R 1=2$-butyloctyl, R2 = n-octyloxy

PTB7: $X=F, R 1=2$-ethylhexyl, R2 = 2-ethylhexyloxy

Figure 23. Chemical structures of polymers PTB1-PTB7. ${ }^{202}$

six polymers (PTB1 to PTB6) have similar weight-averaged molecular weights between 19.3 and $25.0 \mathrm{~kg} / \mathrm{mol}$ with a relatively narrow polydispersity index (PDI) between 1.25 and 1.50 , indicating that the changes in monomer structures did not lead to significant changes in the polymerization reaction. A clear relationship between properties and structure was observed from the careful study of these six polymers. Generally, the branched side chain grafted polymers (PTB2 through PTB6) show larger $V_{\text {oc }}$ in their related BHJ devices than that of PTB1 with only straight side chains, partly due to lower HOMO energy levels of these polymers of branched side chains. However, too bulky side chains reduce the miscibility of polymer with $\mathrm{PC}_{61} \mathrm{BM}$, leading to excessive phase separation between polymer chains and $\mathrm{PC}_{61} \mathrm{BM}$ molecules and thereby reducing the interfacial areas for charge separation in PTB5- or PTB6-based solar cells. The related smaller currents lead to the diminished solar cell performances in the case of PTB5 or PTB6.

To further understand the effect of side chains on the performance of solar cells based on the PTB series, both GIWAXS and GISAXS were employed to investigate the film morphology of these six polymers and their blends with $\mathrm{PC}_{61} \mathrm{BM} / \mathrm{PC}_{71} \mathrm{BM}$, along with $\mathrm{PTB} 7$ which shows an impressive efficiency as high as $7.4 \%$ of its $\mathrm{BHJ}$ cells. ${ }^{202}$ Both the $\pi-\pi$ stacking interactions in the polymer domains and $\mathrm{PC}_{61} \mathrm{BM} / \mathrm{PC}_{71} \mathrm{BM}$ incorporation into these domains are very sensitive to the structure of the side chains attached to the TT or the BnDT subunits of the PTB polymers. The branched side chains attached on the BnDT unit cause an increase in the $\pi-\pi$ stacking spacing in thin films and a decrease in the efficiency of related $\mathrm{BHJ}$ devices, while the branched side chain attached on the TT unit does not interfere with the $\pi-\pi$ stacking spacing in the film and enhances the device efficiency. On the other hand, linear alkyl side chains occupy less space than branched alkyl side chains, resulting in a $\pi-\pi$ stacking distance of $3.65 \AA$ for PTB1 vs $3.89 \AA$ for PTB5. A striking relationship between the fill factor $(F F)$ of related $\mathrm{BHJ}$ devices and the $\pi-\pi$ stacking distances of the seven PTB polymers was also revealed, which indicates that a closer $\pi-\pi$ stacking distance in the polymer film gives a larger FF of its corresponding $\mathrm{BHJ}$ device. This behavior was ascribed to the fact that the PTB polymers with the strongest $\pi-\pi$ stacking should have the most crystalline polymer domains and bind most strongly to the anode interfacial layer, facilitating electronic communication across the interface.

The studies on PTB polymers also reveal that devices based on the fluorinated polymers (PTB4 and PTB7) show larger $V_{\text {oc }}$ than those of other PTB polymers, mainly because the electron-withdrawing nature of these fluorine atoms leads to observed lower HOMO energy levels of PTB4 and PTB7. Moreover, the comparison of PTB2 and PTB3 discloses that replacing the octyloxy side chains with octyl side chains improves the $V_{\text {oc }}$ of related $\mathrm{BHJ}$ devices from $0.6 \mathrm{~V}$ of PTB2 to $0.74 \mathrm{~V}$ in the case of PTB3. These alkoxy groups anchored on $\mathrm{BnDT}$ ring are strongly electron-donating, which can raise the HOMO energy level of resulting polymers and lead to the observed reduction in $V_{\text {oc }}$. The differences between alkyl chains and alkoxy side chains will be further discussed in the next section.

2.5.3. Alkoxy vs Alkyl. Compared with alkyl groups, alkoxy groups are more electron-donating, which usually raise up the HOMO energy level of related conjugated polymers when they are attached with alkoxy side chains. Shi et al. studied a series of poly(thiophene)s with alkoxy side chains. ${ }^{203}$ Table 8 compares

Table 8. Optical and Electronic Properties of P3HT, P3DOT, and POT-co-DOT

\begin{tabular}{|c|c|c|c|c|c|}
\hline \multirow[b]{2}{*}{ polymer } & \multicolumn{2}{|c|}{$\lambda_{\max }(\mathrm{nm})$} & \multirow[b]{2}{*}{$\begin{array}{c}E_{\mathrm{g}}^{\mathrm{opt}} \\
(\mathrm{eV})\end{array}$} & \multirow[b]{2}{*}{$\begin{array}{c}\mathrm{HOMO} \\
(\mathrm{eV})\end{array}$} & \multirow[b]{2}{*}{$\begin{array}{c}\text { LUMO } \\
(\mathrm{eV})\end{array}$} \\
\hline & $\begin{array}{c}\mathrm{CHCl}_{3} \\
\text { soln }\end{array}$ & film & & & \\
\hline P3HT & 425 & 514 & 1.92 & -4.75 & -2.83 \\
\hline P3DOT & 565 & 624 & 1.60 & -4.47 & -2.87 \\
\hline POT-co-DOT & 538 & 621 & 1.64 & -4.55 & -2.91 \\
\hline
\end{tabular}

the optical and electronic properties of regioregular P3HT, regioregular poly(3-decyloxythiophene-2,5-diyl) (P3DOT), and regioregular copolymer poly(3-octylthiophene-2,5-diyl-co3-decyloxythiophene-2,5-diyl) (POT-co-DOT). P3DOT demonstrates an optical absorption maximum at longer wavelength than that of the P3HT. This can be attributed to both the electrondonating effect of the alkoxy group and the more coplanar backbone of the P3DOT than that of the P3HT (because of the smaller size of $\mathrm{O}$ than that of $\mathrm{CH}_{2}$ ). It is not surprising that when the alkyl chains are only partially replaced by alkoxy groups in the case of POT-co-DOT, the HOMO energy level and band gap of this regioregular copolymer are in between those of P3DOT and P3HT. Similar effect of the electron-donating alkoxy group was also reported by Hou et al. on conjugated polymers with benzo$[1,2-b: 3,4-b]$ dithiophene (BnDT) and 4,7-dithiophen-2,1,3benzothiadiazole (DTBT) units. $^{204}$

When the steric hindrance is not a primary concern, employing alkyl chains rather than alkoxy chains will lower the HOMO energy level of resulting polymers and increase the $V_{\text {oc }}$ of related $\mathrm{BHJ}$ solar cells. This was best illustrated by the studies on PBDTTT series (structures shown in Figure 24). ${ }^{74,205}$ The HOMO level of the original PBDTTT-E was successfully reduced by replacing the alkoxy group on the carbonyl of the 


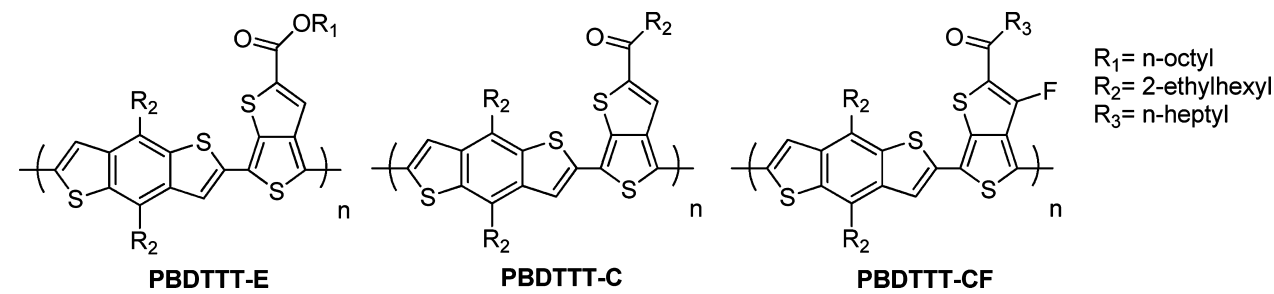

Figure 24. Chemical structures of PBDTTT-E, PBDTTT-C and PBDTTT-CF. ${ }^{74}$ Reprinted with permission from ref 74. Copyright 2009 Nature Publishing Group.

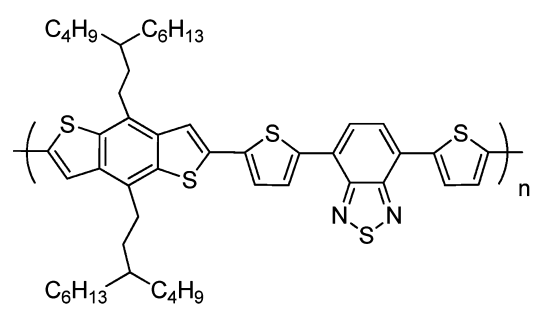

PBnDT-DTBT

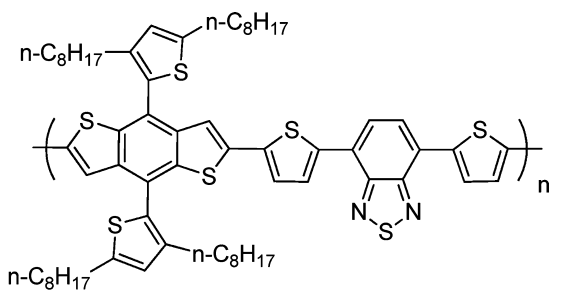

PBDTT-DTBT

Figure 25. Chemical structures of PBnDT-DTBT and PBDTT-DTBT.
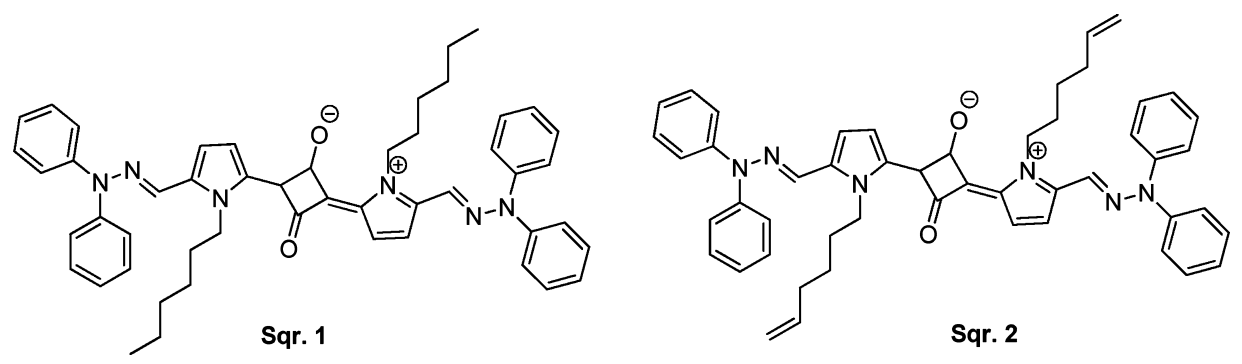

Figure 26. Chemical structures of squaraine 1 and squaraine $2 .^{207}$

thieno[3,4-b]thiophene unit with an alkyl side chain (hereafter referred to as PBDTTT-C). Because of its low HOMO level, a $V_{\text {oc }}$ of $0.70 \mathrm{~V}$ was obtained in the device based on PBDTTT-C, $0.12 \mathrm{~V}$ higher than that of the PBDTTT-E/PC $\mathrm{PC}_{71} \mathrm{BM}$-based device. Interestingly, the substitution of the alkoxy by the alkyl group almost has no influence on the band gap for this kind of polymer, implying a complete delocalization of electronic states in low-band-gap polymers based on quinoid structures. Therefore, devices based on PBDTTT-C maintain a high $J_{\text {sc }}$ of $14.7 \mathrm{~mA} / \mathrm{cm}^{2}$, with an overall PCE reaching $6.58 \%$. Further structural modification was accomplished by substituting the hydrogen atom on the thienothiophene with a fluorine (as discussed in section 2.4), which converted the PBDTTT-C into PBDTTT-CF. As expected, the introduction of fluorine further lowered both the HOMO and LUMO levels, resulting in a similar band gap when compared with those of other PBDTTT-based polymers. Thus, the $V_{\text {oc }}$ of devices based on PBDTTT-CF can be further increased to $0.76 \mathrm{~V}$. Combined with a high $J_{\mathrm{sc}}$ and a fill factor $(F F)$, a very impressive average PCE of $7.38 \%$ was achieved in the PBDTTT-CF-based BHJ cells. ${ }^{74}$ The highest measured PCE is $7.73 \%$, which is the highest efficiency value for polymer solar cells as reported in the literature.

2.5.4. Other Side Chains. Adding additional aromatic units (not fused) to the conjugated backbone as part of the side chains has also been explored. For example, Yang and coworkers incorporated additional thienylene units to the original PBnDT-DTBT (Figure 25). ${ }^{6}$ The resulting polymer PBDTT-
DTBT-based solar cells exhibited a high $V_{\text {oc }}$ of $0.92 \mathrm{~V}$ and a high $J_{\mathrm{sc}}$ of $10.7 \mathrm{~mA} / \mathrm{cm}^{2}$, which are almost $0.1 \mathrm{~V}$ and $3 \mathrm{~mA} / \mathrm{cm}^{2}$ larger than those of PBnDT-DTBT-based solar cells. ${ }^{206}$ Consequently, the overall efficiency increased from $3.85 \%$ of PBnDT-DTBT-based devices to $5.66 \%$ of PBDTT-based ones. Interestingly, since both PBDTT-DTBT and PBnDT-DTBT exhibited similar HOMO levels and band gaps, the improved $V_{\text {oc }}$ and $J_{\text {sc }}$ of PBDTT-DTBT-based devices cannot be simply attributed to a lower HOMO level or a smaller band gap introduced by these thienylene groups. It is plausible that these side chains with bulky thienylene groups decrease the intermolecular interaction between polymer and fullerene derivatives, leading to an enhanced $V_{\text {oc }}$. Also, it is likely that an improved carrier transport introduced by these thienylene groups helps increase the $J_{\text {sc }}$.

Lastly, Bangis et al. reported characterization of $\mathrm{BHJ}$ solar cells based on two new squaraine dyes, substituted at the pyrrolic nitrogen with $n$-hexyl (squaraine 1) or $n$-hexenyl (squaraine 2) chains (Figure 26). ${ }^{207}$ Squaraine 2-based devices invariably outperform those based on hexyl-substituted squaraine 1 . This performance improvement predominantly arises from the $J_{\text {sc }}$ enhancement. To further understand the property differences between squaraine $\mathbf{1}$ and squaraine 2 , the crystal structures of these two dyes were investigated. The data reveal that the $n$-alkenyl substituent affords a more compact solid-state structure, enhancing charge mobility (thin film transistor hole mobility is increased by $\sim 5$ times) and hence increasing $J_{\text {sc }}$. 
Although this report investigated only the side-chain effect on small molecules, it implies a new structural strategy of conjugated polymer to enhance charge transport efficiency via noncovalent alkenyl-phenyl contacts by incorporating alkenyl side chains to the polymer backbone.

\section{OUTLOOK AND CHALLENGES}

3.1. Maximum Efficiency Reachable with Polymer: Fullerene BHJ Solar Cell. Tremendous progress has been made in the past 16 years in the field of polymer solar cells, particularly in the design and synthesis of novel conjugated polymers as discussed in previous sections. The record high efficiency has been constantly updated in the past 3 years by the synergistic efforts between the academic researchers (e.g., design and synthesis of new polymers) and companies (e.g., device optimizations). Furthermore, the design and synthesis of these novel polymers would not have been possible without a deeper understanding of the governing physical principles, ${ }^{33,208,209}$ device physics, $^{31,51,210}$ and morphology investigation and control. ${ }^{211-216}$ As a result of the synergy in the community (including both academia and companies), the $J_{\text {sc }}$ can reach as high as $17.3 \mathrm{~mA} / \mathrm{cm}^{2}, 5,217$ the highest $V_{\text {oc }}$ obtained has been over $1 \mathrm{~V}^{41-43}$ and the highest obtained FF has breached $70 \%{ }^{44,45}$ If we could achieve all these impressive values with one system, this champion $\mathrm{BHJ}$ solar cell would offer an unprecedented value of $12 \%$ ! This is the bright future of the exciting field of polymer solar cells and also the goal that numerous researchers strive for. Unfortunately, all these high values are obtained from different polymer-based $\mathrm{BHJ}$ systems, partly due to an intrinsic "tug of war" between $J_{\mathrm{sc}}$ and $V_{\mathrm{oc}}$ as elaborated on in section $1.3^{59}$ and experimentally demonstrated. ${ }^{46}$ A more rigorous model calculation on the ultimate performance of polymer:fullerene $\mathrm{BHJ}$ cells was recently accomplished by Blom and co-workers (ref 218 and references therein). They predicted a maximum power efficiency of $11.7 \%$ for single junction cells and $14.1 \%$ for tandem structures. This is very encouraging, and the community is steadily approaching these numbers: for example, a new record high efficiency of $9.2 \%$ for organic solar cells has been recently reported. ${ }^{9}$

3.2. Even Higher Efficiency Possible? However, if polymer solar cells (and organic solar cells in general) intend to compete with other thin film PV technologies (such as CIGS or CdTe) as a viable economic solution for renewable energy future, higher efficiencies (15-20\%) will be strongly desirable if not required. For example, flexible thin film solar cells based on copper indium gallium (di)selenide (CIGS) can reach an energy conversion efficiency as high as $18.7 \%,{ }^{219}$ and the efficiency of massproduced CIGS thin film modules has breached $13 \% .{ }^{220}$ Can polymer (organic) solar cells achieve similar performances? To answer this challenge, one has to analyze the $J_{s \mathcal{O}} V_{\text {oc }}$ and $F F$ individually, since these three parameters ultimately decide the efficiency of any solar cells. To facilitate the discussion and related recommendations, we collected roughly 200 data sets from different polymer/fullerene $\mathrm{BHJ}$ systems in the literature reports and plotted the $J_{\mathrm{sc}}$ versus the band gap of the polymer (Figure 27) and $V_{\mathrm{oc}}$ versus the HOMO energy level of the polymer (Figure 28). To make the analysis meaningful, we averaged all the experimental values in related intervals in both figures.

- $J_{\text {sc }}$ : Figure 27 clearly shows that a smaller band gap favors a higher short-circuit current. However, this trend reaches its maximum around $1.3 \mathrm{eV}$. Polymers with even smaller band gap than $1.3 \mathrm{eV}$ fail to offer more current as expected from their absorption extending into the near-IR. Two possible reasons

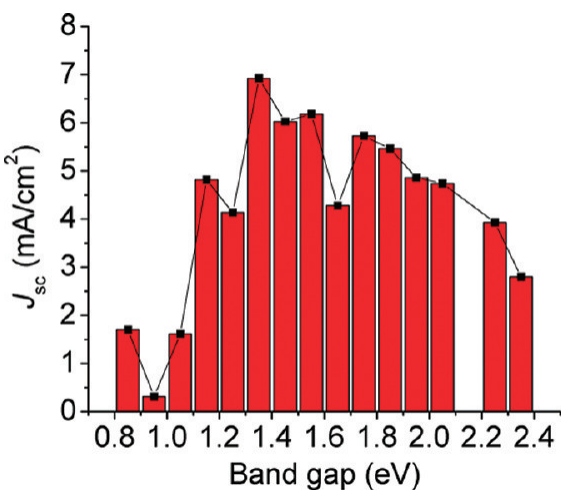

Figure 27. $E_{\mathrm{g}}$ vs $J_{\mathrm{sc}}$ plot. A total of $\sim 200$ data points were taken and summarized with $0.1 \mathrm{eV}$ interval, e.g., $0.80-0.89,0.90-0.99 \mathrm{eV}$.

account for this observation. The first is related with the energy levels of these polymers having extremely small band gaps. Often a very strong acceptor (such as benzobisthiadiazole) was paired with a strong donor to achieve the small band gap via the donor-acceptor low-band-gap approach; however, these strong acceptors could lower the LUMO level below $-3.9 \mathrm{eV}$, leading to an inefficient exciton dissociation when $\mathrm{PC}_{61} \mathrm{BM}$ was used as the electron ACCEPTOR in the BHJ solar cells. The second is the usually small full width at half-maximum (FWHM) of these conjugated polymers, normally on the order of $200 \mathrm{~nm}$. Thus, continuously shifting the absorption of the polymer toward the IR end of the solar spectrum would inevitably diminish its ability to absorb the light in the visible region. In addition, these near-IR/ IR absorbing polymers usually have low absorption coefficients, which exacerbate the light harvesting. On the basis of these analyses, we identify a few potential directions worth of further research:

a. Choosing appropriate structural units in $D-A$ polymers: In order to achieve a narrow band gap, a strong electron-accepting structural unit is required in donor-acceptor copolymers. However, one should develop appropriate "strong" acceptors such that they would bring the LUMO level close to but not lower than the ideal LUMO level (Figure 5). As discussed in section 2.3.2 which is focused on the design of acceptors, the relative easier approach is to fine-tune existing acceptors by attaching substituents (e.g., changing DTBT to DTffBT ${ }^{61}$ ) or changing specific atoms (e.g., switching DTBT to DTPyT ${ }^{107}$ ). A better approach-though more challenging-is to envision new designs of chemical structures. For example, one can certainly benefit from a close look at dyes and pigments since a number of of the recently developed "strong" acceptors were adapted from existing dyes. Equally important in achieving a narrow band gap is the fine-tuning of HOMO levels of these electron-donating structural units, which certainly require deliberation. As indicated in section 2.3.1 which is dedicated to the design of donors, polyaromatic units with fused aromatic rings offer noticeable advantages as donor moieties. The rigid and planar structures of these fused aromatics usually lead to strong $\pi$-interactions, which help improve the hole mobility and decrease the band gap of related conjugated polymers in the solid state. However, appropriate side chains need to be carefully selected to maintain the beneficial polymer-polymer interactions and polymer-PCBM interactions, while still providing enough solubility to the polymer (for high molecular weight and easy processability).

b. Increasing FWHM: Two possible solutions have emerged to increase the FWHM, both of which used random copolymerization to bring more than two monomers into the 
conjugated backbone, though in a slightly different manner. Liang et al. incorporated the pre-quinoid unit of thieno[3,4- $b]$ thiophene (TT) into the polythiophene backbone, basically introducing the low-band-gap character of the TT into the backbone. $^{72}$ Depending upon the feed ratio of the TT vs thiophene, the band gap and the energy level of the random copolymer can be tuned. In an earlier report, $\mathrm{Li}$ and co-workers added another conjugated oligomer (bithienylenevinylene) to the 3-position of the thiophene and polymerized this modified thiophene unit with 3-hexylthiophene and unsubstituted thiophene monomers in a random manner into the biTVPT. ${ }^{21}$ These conjugated side chains add strong absorption from 350 to $480 \mathrm{~nm}$, thereby leading to a broad absorption spectrum from 350 to $650 \mathrm{~nm}$ of these copolymers. Both reports did obtain better performance from these random copolymers than that of the benchmark P3HT in their studies, though the obtained efficiency numbers are still noticeably lower than that of the optimized P3HT-based cell $(\sim 5 \%)$. Nevertheless, considering the effective broadening of the absorption by these approaches, further investigation is still warranted.

c. Making n-type material absorb: Alternatively, one can employ electron-accepting materials that absorb the complementary part of the solar spectrum in regard to the absorption of the electron-donating polymers, thereby broadening the light harvesting of the active layer. The most successful example is the $\mathrm{PC}_{71} \mathrm{BM}$, whose lesser symmetry (compared with $\mathrm{PC}_{61} \mathrm{BM}$ ) renders a much enhanced absorption from 300 to $600 \mathrm{~nm}^{15}$ This strong absorption in the UV-vis region by the $\mathrm{PC}_{71} \mathrm{BM}$ effectively complements the main absorption in the visible to NIR region by these narrow-band-gap polymers (600 to $900 \mathrm{~nm}$ ), offered by these narrow-band-gap polymers, thereby leading to an appreciable increase ( $20 \%$ or more) in the $J_{\text {sc }}$ of related solar cells when compared with that of $\mathrm{PC}_{61} \mathrm{BM}$-based ones. Almost all reported polymer/PCBM-based solar cells with over $7 \%$ efficiency have used $\mathrm{PC}_{71} \mathrm{BM},{ }^{60,62,74,78}$ with only few exceptions. ${ }^{45,61}$ A more elegant solution comes from the design and synthesis of electronaccepting polymers with tunable absorption. Though these polymer:polymer solar cells have not reached high efficiency (highest around $2.5 \%^{222}$ ) as polymer:fullerene solar cells, the full tunability (e.g., energy level and band gap) of these electronaccepting polymers offers a viable approach toward not only a higher $J_{\mathrm{sc}}$ but also a high $V_{\mathrm{oc}}$ in these all polymer solar cells.

d. Improving EQE: In contrast to the internal quantum efficiency (IQE) which already reached $100 \%$ in some recent reports, ${ }^{4}$ the external quantum efficiency (EQE) remains relatively low $(50 \%-80 \%)$, even in these highly efficient polymers/fullerene $\mathrm{BHJ}$ solar cells. For example, the highest reported $J_{\mathrm{sc}}$ of $17.3 \mathrm{~mA} / \mathrm{cm}^{2}$ could have been $30 \mathrm{~mA} / \mathrm{cm}^{2}$ based on its band gap of $1.3 \mathrm{eV}$, if the EQE were $100 \%$ instead of the observed $\sim 55 \%{ }^{5}$ This is mainly due to the low mobility of charge carriers in these polymer:fullerene blends and the intrinsically disordered morphology of the $\mathrm{BHJ}$ cells, which limits the optimal film thickness of the active layer to less than $200 \mathrm{~nm}$. A thicker film would be able to harvest all the light within the film absorption; however, the generated charges after dissociating these excitons would not be able to transverse the thick film and reach the individual electrode before various recombination mechanisms kick in to annihilate these energy carrying charges. Thus further improving the carrier mobilities (both holes and electrons), controlling the morphology, and finding methods to slow down or even eliminate charge recombination should be among research priorities.

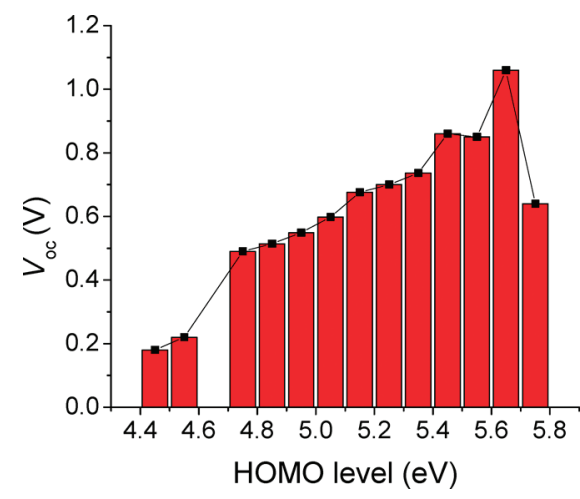

Figure 28. HOMO vs $V_{\text {oc }}$ plot. A total of $\sim 200$ data points were taken and summarized with $0.1 \mathrm{eV}$ interval, e.g., 4.40-4.49, 4.50$4.59 \mathrm{eV}$. Please note that all HOMO energy levels should be negative. In the $\mathrm{Y}$ axis, the "-" sign was omitted for clarity.

- $V_{\text {oc }}$ : A similar trend has been observed for $V_{\text {oc }}$ vs HOMO level (Figure 28). The open-circuit voltage increases as the HOMO energy level lowers, reaching the maximum of $1.02 \mathrm{~V}$ around a HOMO level of $-5.56 \mathrm{eV}$, and then drops. ${ }^{102}$ This observation is not surprising since after years of investigation, it is generally accepted that the $V_{\mathrm{oc}}$ is proportional to the difference between the HOMO of the DONOR and the LUMO of the ACCEPTOR, though recent advances in understanding the origin of the $V_{\mathrm{oc}}$ have provided further insights. ${ }^{4-50,223}$ Thus, a lower HOMO energy level (but not too low) is desirable. As shown in earlier discussion (e.g., section 2.3.1), polyaromatic units with flanking thiophene units are good candidates of such "weak" donors to offer appropriate HOMO levels in D-A conjugated polymers. This is because the electron-donating ability of those units can be fine-tuned by varying fused aromatic units and/or attaching substituents. Moreover, thiophene units are less likely to have steric hindrance with adjacent units than benzene would have. Therefore, having thiophenes as the finish for these polyaromatic units can lead to a more planar backbone with better conjugation. But is achieving a $V_{\text {oc }}$ of $1.1 \mathrm{~V}$ indeed applaudable? If we took $-4.2 \mathrm{eV}$ as the LUMO of the $\mathrm{PC}_{61} \mathrm{BM}$, we would still have lost $0.4 \mathrm{eV}$ from the energy difference $\left(E_{\mathrm{LUMO}}\right.$ (ACCEPTOR) $\left.-E_{\mathrm{HOMO}(\mathrm{DONOR})}\right)$ which was not converted to the $V_{\mathrm{oc}}$. This loss of $0.4 \mathrm{eV}$ or more is typically observed in polymer solar cells. If we consider another source of the voltage loss, the empirical $0.3 \mathrm{eV}$ between the LUMOs of the DONOR polymer and the fullerene, we have lost $\sim 0.7 \mathrm{eV}$ altogether, which could have doubled the $V_{\text {oc }}$ if all contributed to the $V_{\text {oc }}$ ! Therefore, much more work needs to be done on two possible fronts:

a. Further understanding the origin of $V_{\text {oc }}$ and searching for new acceptors: First, is the empirical $0.3 \mathrm{eV}$ required for effective exciton splitting at the interface really necessary? With a recently developed new $\pi$-electron ACCEPTOR (D99'BF), ${ }^{224}$ Heeger and Wudl showed that a $V_{\mathrm{oc}}$ of $1.2 \mathrm{~V}$ could be obtained from the P3HT/D99'BF BHJ solar cell, ${ }^{225}$ as opposed to the usually obtained $0.6 \mathrm{~V}$ in the case of $\mathrm{P} 3 \mathrm{HT} / \mathrm{PC}_{61} \mathrm{BM}$ solar cells. More importantly, these authors demonstrated that electron transfer could still occur even with only $0.12 \mathrm{eV}$ in the LUMOs offset. Apparently, the exciton binding energy could be as small as $0.1 \mathrm{eV}$ (at least in the case of $\mathrm{P} 3 \mathrm{HT}$ ). This exciting discovery points to a potential further increase on the $V_{\text {oc }}$ via designing nonfullerene-based acceptors. However, even in this successful demonstration, a loss of over $0.5 \mathrm{eV}$ was still observed since the difference between the LUMO of D99'BF and the HOMO of 
P3HT was $1.78 \mathrm{eV}$. This leads to the second question: can we minimize the commonly observed loss of $0.4-0.6 \mathrm{eV}$ from the energy level difference between $E_{\text {LUMO(ACCEPTOR) }}$ and $E_{\mathrm{HOMO}(\mathrm{DONOR})}$ ? There have been some suggestions that reducing the electron-phonon coupling of these excitons thereby smaller Stokes shift would help diminish this loss mechanism. ${ }^{226}$ This would call for well-ordered polymers with delocalized excitons. Further, recent advances in further understanding of the $V_{\text {oc }}$ suggest that reducing the electronic coupling between the polymer and the fullerene would increase the $V_{\mathrm{oc}}{ }^{48-50,223}$ Nevertheless, there is still a lot to be done to determine a clearer structureproperty relationship regarding the $V_{\text {oo }}$ so the synthetic chemists will know how to design better materials (both electron-donating and electron-accepting materials).

$b$. Engineering the fullerene: Alternatively, before we find new acceptors that can replace the fullerene on all fronts, we can still modify the structure of this fascinating group of molecules to raise up their LUMO energy levels in order to gain a higher $V_{\text {oc }}$. There have been successful examples such as trimetallic nitride endohedral fullerenes (TNEFs, in particular $\left.\mathrm{Lu}_{3} \mathrm{~N} @ \mathrm{C} 80\right){ }^{13}$ indene- $\mathrm{C}_{60}$ bisadduct (ICBA), ${ }^{16}$ among others. ${ }^{227}$ The $V_{\text {oc }}$ of related $\mathrm{P} 3 \mathrm{HT}$ :modified fullerene $\mathrm{BHJ}$ cells can be increased as much as $0.26 \mathrm{~V}^{16}$ when compared with $\mathrm{P} 3 \mathrm{HT} / \mathrm{PC}_{61} \mathrm{BM}$ cells because of the raised LUMO energy level of the modified fullerene.

- FF: Unlike silicon solar cell or even dye-sensitized solar cells, both of which give high fill factors $(75 \%-80 \%$ or higher), the polymer solar cells usually only offer a fill factor around $60 \%$. The fill factor is ultimately determined by the series resistance $\left(R_{\mathrm{s}}\right)$ and the shunt resistance $\left(R_{\mathrm{sh}}\right)$ of the devices. Because of the low charge carrier mobilities (especially holes) and the disorded nature of the $\mathrm{BHJ}$ film, BHJ solar cells usually have a relatively high $R_{\mathrm{s}}$ and relatively low $R_{\mathrm{sh}}$. In order to get a high FF, one would require to achieve both a low $R_{s}$ and a high $R_{\mathrm{sh}}$. Research efforts are needed to reach a balanced and rapid charge transport (holes vs electrons), to optimize and control the film morphology into more ordered structure, and to improve all electric contacts.

- Morphology: The full potential of any conjugated polymer for solar cells can only be realized with an optimized morphology. Though there is a general consensus regarding what defines a preferred morphology (i.e., interpenetrating network at nanometer scale), the "ideal" morphology could vary from one polymer/fullerene system to the other. How to control the morphology poses an even bigger challenge, though considerable progress has been made, ${ }^{228}$ particularly the annealing (via thermal or solvent) and the discovery of processing additives. ${ }^{211,213,216}$ The interactions between DONOR polymers, between DONOR polymer and fullerene ACCEPTORS and between fullerene ACCEPTORS all contribute to the formation of the morphology in a thin film. First, the interaction between DONOR polymers is dominated by the $\pi-\pi$ interaction among conjugated backbones, which can bring polymer backbones close enough to form stacked polymer clusters. This stacking is beneficial for charge transport between polymer chains. However, too strong $\pi-\pi$ interactions can lead to the formation of large polymer-rich domains, resulting in a low hole mobility across the entire film due to multiple crosses over grain boundaries. In addition to the conjugated backbone, the side chains can also impact the intermolecular interaction as discussed in section 2.5. Therefore, both conjugated backbone and side chains need to be carefully designed in order to control the polymer-polymer interaction such that these polymers can form desired "channels" to facilitate the charge transport. Second, the polymer-fullerene interactions and their contribution to the morphology are even more complicated. Progress has been made, though. For example, McGehee and co-workers showed that fullerene derivatives were intercalated between the polymer side chains in some polymer:fullerene blends. ${ }^{147,148,229}$ This intercalation is important in determining the optimal polymer:fullerene ratio. For example, in blends where intercalation occurs, fullerenes must fill all available space between the polymer side chains prior to the formation of a pure electron-transporting fullerene phase. This intercalation would also affect some important device characteristics such as mobility, light absorption, photoluminescence, and recombination due to the intimate mixing of the polymer DONORS and fullerene ACCEPTORS in the intercalated phase. In short, we are still in the early stage of fully understanding the morphology of polymer:fullerene blends in thin films. Further development of analytical tools to unveil the "true" morphology of highly efficient BHJ systems, and novel approaches to render the ideal morphology (via chemical design or physical methods), should remain on the top of research priorities.

3.3. Other Pertinent Issues. Though the constitution of the active layer (i.e., polymer and fullerene or other ACCEPTORS) ultimately determine the maximum efficiency achievable with the $\mathrm{BHJ}$ cell, one still needs to solve a number of other issues before reaching the full potential of any given cell. Listed below are a few other active research fronts:

- Interfaces: The interface between organic active layers and these two contact electrodes (cathode and anode) needs to be optimized to facilitate the charge collection and minimize any loss. ${ }^{230,231}$ Metal oxides recently emerged as versatile interface modifiers, such as $\mathrm{NiO},{ }^{232} \mathrm{MoO}_{3}{ }^{233-235}$ and $\mathrm{WO}_{3}{ }^{236,237}$ as the hole transport layer and $\mathrm{TiO}_{x}^{37,238}$ and $\mathrm{ZnO}^{239-242}$ as the electron transport layer.

- Device engineering: Progress has been made in the inverted cells (to increase the air stability), ${ }^{243}$ applying light trapping for better light harvesting, ${ }^{244}$ and using tandem structure ${ }^{245}$ to increase the overall efficiency of polymer solar cells.

In addition, to achieve the commercial viability, the community still needs to work on the following issues:

- Transparent contact electrode (TCO): ITO has been the standard TCO for polymer solar cells. However, the physical nature (brittleness) and the high price associated with ITO prevent a large-scale production of polymer solar cells based on this particular material. Carbon nanotubes, graphenes, ${ }^{246-254}$ and metal nanowires ${ }^{255,256}$ have been proposed, and respectable results have been obtained.

- Stability: Significant progress has been made; for example, Konarka has shown a lifetime of 3 years for their polymer solar cells. $^{257}$

All these challenges (also opportunities) compose the major part of the rather long wish list for the research community of polymer (organic) solar cells. This is a tall order; however, if we could achieve these goals via collaborative efforts, the payoff would be huge-single junction polymer solar cells with $15 \%$ efficiency would be within reach (for example, a band gap of $1.3 \mathrm{eV}$ with an EQE of $80 \%$, a $V_{\text {oc }}$ of $0.8 \mathrm{~V}$, and a FF of 0.75$)$ !

\section{AUTHOR INFORMATION}

\section{Corresponding Author}

*E-mail: wyou@unc.edu. 


\section{BIOGRAPHIES}

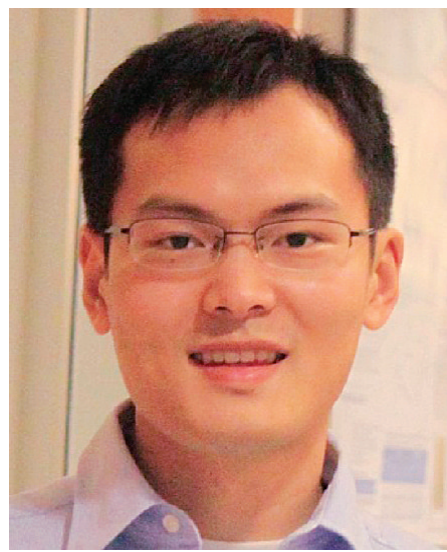

Huaxing Zhou obtained his B.S. degree in polymer chemistry from the University of Science and Technology of China in 2007. He recently received his Ph.D. degree from the department of Chemistry at the University of North Carolina at Chapel Hill under the direction of Prof. Wei You (2011). His Ph.D. research was focused on the rational design of conjugated polymers for organic solar cells. He is currently a postdoctoral fellow in the research group of Prof. Jeremiah A. Johnson at Massachusetts Institute of Technology.

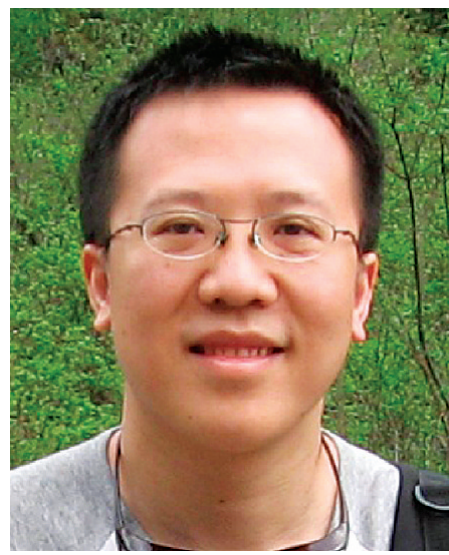

Liqiang Yang is currently a $\mathrm{PhD}$ candidate under the guidance of Prof. Wei You at the University of North Carolina at Chapel Hill. He received his B.S. degree in material sciences and engineering at Xi'an Jiaotong University in 2004 and obtained an M.S. degree in material engineering at the University of Wisconsin-Milwaukee in 2007. His current research focus is the fundamental understanding the structureproperties relationships of novel polymers for organic solar cells.

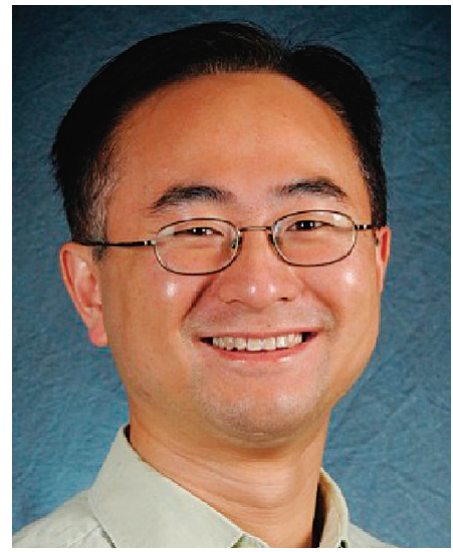

Wei You was born in a small village outside of Chuzhou in Anhui Province of China and grew up in Hefei, the provincial capital of
Anhui. After receiving a B.S. degree in Polymer Chemistry from University of Science and Technology of China in 1999, he attended the graduate program of chemistry at the University of Chicago, where he obtained his Ph.D. in 2004 under the guidance of Professor Luping $\mathrm{Yu}$. He then moved west and finished his postdoctoral training at Stanford University in 2006 with Professor Zhenan Bao. In July 2006, he joined the University of North Carolina at Chapel Hill as an Assistant Professor in Chemistry. Professor You's research interests focus on the development of novel multifunctional materials for a variety of applications, including organic solar cells, molecular electronics, and spintronics.

\section{ACKNOWLEDGMENTS}

The authors want to thank past and present members of the You group (Dr. Shengqiang Xiao, Dr. Paul G. Hoertz, Dr. Samuel C. Price, Andrew Stuart, Rycel Uy, Wentao Li, among others) for their contributions. We gratefully acknowledge financial support (past and present) from the University of North Carolina at Chapel Hill, a DuPont Young Professor Award, Office of Naval Research (Grants N000140911016 and N000141110235), and a NSF CAREER Award (DMR0954280).

\section{REFERENCES}

(1) Bijleveld, J. C.; Zoombelt, A. P.; Mathijssen, S. G. J.; Wienk, M. M.; Turbiez, M.; de Leeuw, D. M.; Janssen, R. A. J. J. Am. Chem. Soc. 2009, 131 (46), 16616-16617.

(2) Lewis, N. S. Science (Washington, DC, U. S.) 2007, 315 (5813), $798-801$

(3) Yu, G.; Gao, J.; Hummelen, J. C.; Wudl, F.; Heeger, A. J. Science (Washington, DC, U. S.) 1995, 270 (5243), 1789-1791.

(4) Park, S. H.; Roy, A.; Beaupre, S.; Cho, S.; Coates, N.; Moon, J. S.; Moses, D.; Leclerc, M.; Lee, K.; Heeger, A. J. Nature Photonics 2009, 3 (5), 297-302.

(5) Coffin, R. C.; Peet, J.; Rogers, J.; Bazan, G. C. Nature Chem. 2009, 1 (8), 657-661.

(6) Huo, L.; Hou, J.; Zhang, S.; Chen, H.-Y.; Yang, Y. Angew. Chem., Int. Ed. 2010, 49 (8), 1500-1503.

(7) Xiao, S.; Price, S. C.; Zhou, H.; You, W. ACS Symp. Ser. 2010, $1034,71-80$.

(8) Kirchmeyer, S.; Reuter, K. J. Mater. Chem. 2005, 15 (21), 20772088.

(9) Service, R. F. Science (Washington, DC, U. S.) 2011, 332 (6027), 293.

(10) Cheng, Y.-J.; Yang, S.-H.; Hsu, C.-S. Chem. Rev. (Washington, DC, U. S.) 2009, 109 (11), 5868-5923.

(11) Chen, J.; Cao, Y. Acc. Chem. Res. 2009, 42 (11), 1709-1718.

(12) Facchetti, A. Chem. Mater. 2010, 23 (3), 733-758.

(13) Ross, R. B.; Cardona, C. M.; Guldi, D. M.; Sankaranarayanan, S. G.; Reese, M. O.; Kopidakis, N.; Peet, J.; Walker, B.; Bazan, G. C.; Van Keuren, E.; Holloway, B. C.; Drees, M. Nature Mater. 2009, 8 (3), 208-212.

(14) Lenes, M.; Wetzelaer, G.-J. A. H.; Kooistra, F. B.; Veenstra, S. C.; Hummelen, J. C.; Blom, P. W. M. Adv. Mater. 2008, 20 (11), 2116-2119.

(15) Wienk, M. M.; Kroon, J. M.; Verhees, W. J. H.; Knol, J.; Hummelen, J. C.; van Hal, P. A.; Janssen, R. A. J. Angew. Chem., Int. Ed. 2003, 42 (29), 3371-3375.

(16) He, Y.; Chen, H.-Y.; Hou, J.; Li, Y. J. Am. Chem. Soc. 2010, 132 (4), 1377-1382.

(17) Zhao, G.; He, Y.; Li, Y. Adv. Mater. 2010, 22 (39), 4355-4358.

(18) Matsuo, Y.; Sato, Y.; Niinomi, T.; Soga, I.; Tanaka, H.; Nakamura, E. J. Am. Chem. Soc. 2009, 131 (44), 16048-16050.

(19) Sariciftci, N. S.; Smilowitz, L.; Heeger, A. J.; Wudl, F. Science (Washington, DC, U. S.) 1992, 258 (5087), 1474-1476. 
(20) Murata, M.; Morinaka, Y.; Murata, Y.; Yoshikawa, O.; Sagawa, T.; Yoshikawa, S. Chem. Commun. (Cambridge, U. K.) 2011, 47 (26), 7335-7337.

(21) Thompson, B. C.; Fréchet, J. M. J. Angew. Chem., Int. Ed. 2008, 47 (1), 58-77.

(22) Kroon, R.; Lenes, M.; Hummelen, J. C.; Blom, P. W. M.; de Boer, B. Polym. Rev. (Philadelphia, PA, U. S.) 2008, 48 (3), 531-582. (23) Kippelen, B.; Bredas, J.-L. Energy Environ. Sci. 2009, 2 (3), 251261.

(24) Helgesen, M.; Sondergaard, R.; Krebs, F. C. J. Mater. Chem. 2010, 20 (1), 36-60.

(25) Delgado, J. L.; Bouit, P.-A.; Filippone, S.; Herranz, M. A.; Martin, N. Chem. Commun. (Cambridge, U. K.) 2010, 46 (27), 48534865.

(26) Heeger, A. J. Chem. Soc. Rev. 2010, 39 (7), 2354-2371.

(27) Dennler, G.; Scharber, M. C.; Brabec, C. J. Adv. Mater. 2009, 21 (13), 1323-1338.

(28) Günes, S.; Neugebauer, H.; Sariciftci, N. S. Chem. Rev. (Washington, DC, U. S.) 2007, 107 (4), 1324-1338.

(29) Hains, A. W.; Liang, Z.; Woodhouse, M. A.; Gregg, B. A. Chem. Rev. (Washington, DC, U. S.) 2010, 110 (11), 6689-6735.

(30) Po, R.; Maggini, M.; Camaioni, N. J. Phys. Chem. C 2009, 114 (2), 695-706.

(31) Blom, P. W. M.; Mihailetchi, V. D.; Koster, L. J. A.; Markov, D. E. Adv. Mater. 2007, 19 (12), 1551-1566.

(32) Krebs, F. C.; Tromholt, T.; Jorgensen, M. Nanoscale 2010, 2 (6), 873-886.

(33) Brédas, J.-L.; Norton, J. E.; Cornil, J.; Coropceanu, V. Acc. Chem. Res. 2009, 42 (11), 1691-1699.

(34) Shaheen, S. E.; Brabec, C. J.; Sariciftci, N. S.; Padinger, F.; Fromherz, T.; Hummelen, J. C. Appl. Phys. Lett. 2001, 78 (6), 841843.

(35) Brabec, C. J.; Shaheen, S. E.; Winder, C.; Sariciftci, N. S.; Denk, P. Appl. Phys. Lett. 2002, 80 (7), 1288-1290.

(36) Reyes-Reyes, M.; Kim, K.; Carroll, D. L. Appl. Phys. Lett. 2005, $87(8), 3-6$.

(37) Kim, J. Y.; Kim, S. H.; Lee, H. H.; Lee, K.; Ma, W. L.; Gong, X.; Heeger, A. J. Adv. Mater. 2006, 18 (5), 572-576.

(38) Ma, W. L.; Yang, C. Y.; Gong, X.; Lee, K.; Heeger, A. J. Adv. Funct. Mater. 2005, 15 (10), 1617-1622.

(39) Li, G.; Shrotriya, V.; Huang, J. S.; Yao, Y.; Moriarty, T.; Emery, K.; Yang, Y. Nature Mater. 2005, 4 (11), 864-868.

(40) Kim, Y.; Cook, S.; Tuladhar, S. M.; Choulis, S. A.; Nelson, J.; Durrant, J. R.; Bradley, D. D. C.; Giles, M.; McCulloch, I.; Ha, C.-S.; Ree, M. Nature Mater. 2006, 5 (3), 197-203.

(41) Gadisa, A.; Mammo, W.; Andersson, L. M.; Admassie, S.; Zhang, F.; Andersson, M. R.; Inganäs, O. Adv. Funct. Mater. 2007, 17 (18), $3836-3842$.

(42) Zhang, F.; Jespersen, K. G.; Björström, C.; Svensson, M.; Andersson, M. R.; Sundström, V.; Magnusson, K.; Moons, E.; Yartsev, A.; Inganäs, O. Adv. Funct. Mater. 2006, 16 (5), 667-674.

(43) Zheng, Q.; Jung, B. J.; Sun, J.; Katz, H. E. J. Am. Chem. Soc. 2010, 132 (15), 5394-5404.

(44) Zoombelt, A. P.; Mathijssen, S. G. J.; Turbiez, M. G. R.; Wienk, M. M.; Janssen, R. A. J. J. Mater. Chem. 2010, 20 (11), 2240-2246.

(45) Price, S. C.; Stuart, A. C.; Yang, L.; Zhou, H.; You, W. J. Am. Chem. Soc. 2011, 133 (12), 4625-4631.

(46) Zhou, H.; Yang, L.; Liu, S.; You, W. Macromolecules 2010, 43 (24), 10390-10396.

(47) Scharber, M. C.; Mühlbacher, D.; Koppe, M.; Denk, P.; Waldauf, C.; Heeger, A. J.; Brabec, C. J. Adv. Mater. 2006, 18 (6), 789-794.

(48) Perez, M. D.; Borek, C.; Forrest, S. R.; Thompson, M. E. J. Am. Chem. Soc. 2009, 131 (26), 9281-9286.

(49) Vandewal, K.; Tvingstedt, K.; Gadisa, A.; Inganas, O.; Manca, J. V. Nature Mater. 2009, 8 (11), 904-909.

(50) Yang, L.; Zhou, H.; You, W. J. Phys. Chem. C 2010, 114 (39), 16793-16800.

(51) Moliton, A.; Nunzi, J.-M. Polym. Int. 2006, 55 (6), 583-600.
(52) http://www.pveducation.org/pvcdrom/.

(53) Mauer, R.; Kastler, M.; Laquai, F. Adv. Funct. Mater. 2010, 20 (13), 2085-2092.

(54) Kim, Y.; Nelson, J.; Durrant, J. R.; Bradley, D. D. C.; Heo, K.; Park, J.; Kim, H.; McCulloch, I.; Heeney, M.; Ree, M.; Ha, C.-S. Soft Matter 2007, 3 (1), 117-121.

(55) Roncali, J. Chem. Rev. (Washington, DC, U. S.) 1997, 97 (1), 173-205.

(56) Havinga, E. E.; ten Hoeve, W.; Wynberg, H. Synth. Met. 1993, 55 (1), 299-306.

(57) Ajayaghosh, A. Chem. Soc. Rev. 2003, 32 (4), 181-191.

(58) Zhang, Q. T.; Tour, J. M. J. Am. Chem. Soc. 1998, 120 (22), $5355-5362$.

(59) Zhou, H.; Yang, L.; Stoneking, S.; You, W. ACS Appl. Mater. Interfaces 2010, 2 (5), 1377-1383.

(60) Chu, T.-Y.; Lu, J.; Beaupré, S.; Zhang, Y.; Pouliot, J.-R. m.; Wakim, S.; Zhou, J.; Leclerc, M.; Li, Z.; Ding, J.; Tao, Y. J. Am. Chem. Soc. 2011,133 (12), 4250-4253.

(61) Zhou, H.; Yang, L.; Stuart, A. C.; Price, S. C.; Liu, S.; You, W. Angew. Chem., Int. Ed. 2011, 50 (13), 2995-2998.

(62) Amb, C. M.; Chen, S.; Graham, K. R.; Subbiah, J.; Small, C. E.; So, F.; Reynolds, J. R. J. Am. Chem. Soc. 2011, 133 (26), 10062-10065.

(63) Su, M.-S.; Kuo, C.-Y.; Yuan, M.-C.; Jeng, U. S.; Su, C.-J.; Wei, K.-H. Adv. Mater. 2011, 23 (29), 3315-3319.

(64) Wudl, F.; Kobayashi, M.; Heeger, A. J. J. Org. Chem. 1984, 49 (18), 3382-3384.

(65) Pomerantz, M.; Chalonergill, B.; Harding, L. O.; Tseng, J. J.; Pomerantz, W. J. J. Chem. Soc., Chem. Commun. 1992, 22, 1672-1673.

(66) Hong, S. Y.; Marynick, D. S. Macromolecules 1992, 25 (18), $4652-4657$.

(67) Sotzing, G. A.; Lee, K. H. Macromolecules 2002, 35 (19), 72817286.

(68) Qin, Y.; Kim, J. Y.; Frisbie, C. D.; Hillmyer, M. A. Macromolecules 2008, 41 (15), 5563-5570.

(69) Hou, J. H.; Park, M. H.; Zhang, S. Q.; Yao, Y.; Chen, L. M.; Li, J. H.; Yang, Y. Macromolecules 2008, 41 (16), 6012-6018.

(70) Wienk, M. M.; Turbiez, M. G. R.; Struijk, M. P.; Fonrodona, M.; Janssen, R. A. J. Appl. Phys. Lett. 2006, 88 (15), 153511-153513.

(71) Zhang, F.; Mammo, W.; Andersson, L. M.; Admassie, S.; Andersson, M. R.; Inganäs, O. Adv. Mater. 2006, 18 (16), 2169-2173.

(72) Liang, Y. Y.; Xiao, S. Q.; Feng, D. Q.; Yu, L. P. J. Phys. Chem. C 2008, 112 (21), 7866-7871.

(73) Kleinhenz, N.; Yang, L.; Zhou, H.; Price, S. C.; You, W. Macromolecules 2011, 44 (4), 872-877.

(74) Chen, H.-Y.; Hou, J.; Zhang, S.; Liang, Y.; Yang, G.; Yang, Y.; Yu, L.; Wu, Y.; Li, G. Nature Photonics 2009, 3 (11), 649-653.

(75) Huang, Y.; Hou, L.; Zhang, S.; Guo, X.; Han, C. C.; Li, Y.; Hou, J. Chem. Commun. (Cambridge, U. K.) 2011, 47 (31), 8904-8906.

(76) Son, H. J.; Wang, W.; Xu, T.; Liang, Y.; Wu, Y.; Li, G.; Yu, L. J. Am. Chem. Soc. 2011, 133 (6), 1885-1894.

(77) He, F.; Wang, W.; Chen, W.; Xu, T.; Darling, S. B.; Strzalka, J.; Liu, Y.; Yu, L. J. Am. Chem. Soc. 2011, 133 (10), 3284-3287.

(78) Liang, Y.; Xu, Z.; Xia, J.; Tsai, S.-T.; Wu, Y.; Li, G.; Ray, C.; Yu, L. Adv. Mater. 2010, 22 (20), E135-E138.

(79) Li, Y.; Zou, Y. Adv. Mater. 2008, 20 (15), 2952-2958.

(80) Huang, F.; Chen, K.-S.; Yip, H.-L.; Hau, S. K.; Acton, O.; Zhang, Y.; Luo, J.; Jen, A. K. Y. J. Am. Chem. Soc. 2009, 131 (39), 1388613887.

(81) Duan, C.; Chen, K.-S.; Huang, F.; Yip, H.-L.; Liu, S.; Zhang, J.; Jen, A. K. Y.; Cao, Y. Chem. Mater. 2010, 22 (23), 6444-6452.

(82) Cravino, A.; Sariciftci, N. S. J. Mater. Chem. 2002, 12 (7), 19311943.

(83) Giacalone, F.; Martín, N. Chem. Rev. (Washington, DC, U. S.) 2006, 106 (12), 5136-5190.

(84) Ramos, A. M.; Rispens, M. T.; van Duren, J. K. J.; Hummelen, J. C.; Janssen, R. A. J. J. Am. Chem. Soc. 2001, 123 (27), 6714-6715.

(85) Yang, C.; Li, H.; Sun, Q.; Qiao, J.; Li, Y.; Li, Y.; Zhu, D. Sol. Energy Mater. Sol. Cells 2005, 85 (2), 241-249. 
(86) Tan, Z. a.; Hou, J.; He, Y.; Zhou, E.; Yang, C.; Li, Y. Macromolecules 2007, 40 (6), 1868-1873.

(87) Martín, N.; Sánchez, L.; Herranz, M. a. Á.; Illescas, B.; Guldi, D. M. Acc. Chem. Res. 2007, 40 (10), 1015-1024.

(88) Hirayama, D.; Takimiya, K.; Aso, Y.; Otsubo, T.; Hasobe, T.; Yamada, H.; Imahori, H.; Fukuzumi, S.; Sakata, Y. J. Am. Chem. Soc. 2002, 124 (4), 532-533.

(89) Miyanishi, S.; Zhang, Y.; Tajima, K.; Hashimoto, K. Chem. Commun. (Cambridge, U. K.) 2010, 46 (36), 6723-6725.

(90) Cravino, A.; Sariciftci, N. S. Nature Mater. 2003, 2 (6), 360361.

(91) Roncali, J. Adv. Energy Mater. 2011, 1 (2), 147-160.

(92) Svensson, M.; Zhang, F.; Veenstra, S. C.; Verhees, W. J. H.; Hummelen, J. C.; Kroon, J. M.; Inganäs, O.; Andersson, M. R. Adv. Mater. 2003, 15 (12), 988-991.

(93) Peet, J.; Kim, J. Y.; Coates, N. E.; Ma, W. L.; Moses, D.; Heeger, A. J.; Bazan, G. C. Nature Mater. 2007, 6 (7), 497-500.

(94) Price, S. C.; Stuart, A. C.; You, W. Macromolecules 2010, 43 (2), 797-804.

(95) Svensson, M. Synth. Met. 2003, 135-136, 137-138.

(96) Hsu, S. L.-C.; Lin, Y.-C.; Lee, R.-F.; Sivakumar, C.; Chen, J.-S.; Chou, W.-Y. J. Polym. Sci., Part A: Polym. Chem. 2009, 47 (20), 53365343.

(97) Kreyenschmidt, M.; Klaerner, G.; Fuhrer, T.; Ashenhurst, J.; Karg, S.; Chen, W. D.; Lee, V. Y.; Scott, J. C.; Miller, R. D. Macromolecules 1998, 31 (4), 1099-1103.

(98) Yohannes, T.; Zhang, F.; Svensson, M.; Hummelen, J. C.; Andersson, M. R.; Inganäs, O. Thin Solid Films 2004, 449 (1-2), 152157.

(99) InganÄs, O.; Zhang, F.; Andersson, M. R. Acc. Chem. Res. 2009, 42 (11), 1731-1739.

(100) Yang, R.; Tian, R.; Yan, J.; Zhang, Y.; Yang, J.; Hou, Q.; Yang, W.; Zhang, C.; Cao, Y. Macromolecules 2005, 38 (2), 244-253.

(101) Janietz, S.; Krueger, H.; Schleiermacher, H.-F.; Würfel, U.; Niggemann, M. Macromol. Chem. Phys. 2009, 210 (18), 1493-1503.

(102) Li, W.; Qin, R.; Zhou, Y.; Andersson, M.; Li, F.; Zhang, C.; Li, B.; Liu, Z.; Bo, Z.; Zhang, F. Polymer 2010, 51 (14), 3031-3038.

(103) Zhou, E.; Cong, J.; Yamakawa, S.; Wei, Q.; Nakamura, M.; Tajima, K.; Yang, C.; Hashimoto, K. Macromolecules 2010, 43 (6), $2873-2879$.

(104) Mühlbacher, D.; Scharber, M.; Morana, M.; Zhu, Z.; Waller, D.; Gaudiana, R.; Brabec, C. Adv. Mater. 2006, 18 (21), 2884-2889.

(105) Moulé, A. J.; Tsami, A.; Bünnagel, T. W.; Forster, M.; Kronenberg, N. M.; Scharber, M.; Koppe, M.; Morana, M.; Brabec, C. J.; Meerholz, K.; Scherf, U. Chem. Mater. 2008, 20 (12), 4045-4050.

(106) Bijleveld, J. C.; Shahid, M.; Gilot, J.; Wienk, M. M.; Janssen, R. A. J. Adv. Funct. Mater. 2009, 19 (20), 3262-3270.

(107) Zhou, H.; Yang, L.; Price, S. C.; Knight, K. J.; You, W. Angew. Chem., Int. Ed. 2010, 49 (43), 7992-7995.

(108) Kudla, C. J.; Dolfen, D.; Schottler, K. J.; Koenen, J.-M.; Breusov, D.; Allard, S.; Scherf, U. Macromolecules 2010, 43 (18), 7864-7867.

(109) Wang, E.; Wang, L.; Lan, L.; Luo, C.; Zhuang, W.; Peng, J.; Cao, Y. Appl. Phys. Lett. 2008, 92 (3), 033307-033310.

(110) Zhou, E.; Wei, Q.; Yamakawa, S.; Zhang, Y.; Tajima, K.; Yang, C.; Hashimoto, K. Macromolecules 2009, 43 (2), 821-826.

(111) Allard, N.; Aïch, R. d. B.; Gendron, D.; Boudreault, P.-L. T.; Tessier, C.; Alem, S.; Tse, S.-C.; Tao, Y.; Leclerc, M. Macromolecules 2010, 43 (5), 2328-2333.

(112) Scharber, M. C.; Koppe, M.; Gao, J.; Cordella, F.; Loi, M. A.; Denk, P.; Morana, M.; Egelhaaf, H.-J.; Forberich, K.; Dennler, G.; Gaudiana, R.; Waller, D.; Zhu, Z.; Shi, X.; Brabec, C. J. Adv. Mater. 2010, 22 (3), 367-370.

(113) Morana, M.; Azimi, H.; Dennler, G.; Egelhaaf, H.-J.; Scharber, M.; Forberich, K.; Hauch, J.; Gaudiana, R.; Waller, D.; Zhu, Z.; Hingerl, K.; van Bavel, S. S.; Loos, J.; Brabec, C. J. Adv. Funct. Mater. 2010, 20 (7), 1180-1188.
(114) Veldman, D.; ipek, O. z.; Meskers, S. C. J.; Sweelssen, J. r.; Koetse, M. M.; Veenstra, S. C.; Kroon, J. M.; Bavel, S. S. v.; Loos, J.; Janssen, R. A. J. J. Am. Chem. Soc. 2008, 130 (24), 7721-7735.

(115) Boudreault, P.-L. T.; Michaud, A.; Leclerc, M. Macromol. Rapid Commun. 2007, 28 (22), 2176-2179.

(116) Zhou, E.; Nakamura, M.; Nishizawa, T.; Zhang, Y.; Wei, Q.; Tajima, K.; Yang, C.; Hashimoto, K. Macromolecules 2008, 41 (22), 8302-8305.

(117) Liu, J.; Zhang, R.; Sauvé, G. v.; Kowalewski, T.; McCullough, R. D. J. Am. Chem. Soc. 2008, 130 (39), 13167-13176.

(118) Zhou, E.; Yamakawa, S.; Tajima, K.; Yang, C.; Hashimoto, K. Chem. Mater. 2009, 21 (17), 4055-4061.

(119) Morin, J.-F.; Leclerc, M.; Adès, D.; Siove, A. Macromol. Rapid Commun. 2005, 26 (10), 761-778.

(120) Drolet, N.; Morin, J. F.; Leclerc, N.; Wakim, S.; Tao, Y.; Leclerc, M. Adv. Funct. Mater. 2005, 15 (10), 1671-1682.

(121) Blouin, N.; Leclerc, M. Acc. Chem. Res. 2008, 41 (9), 11101119.

(122) Chen, C.-P.; Chan, S.-H.; Chao, T.-C.; Ting, C.; Ko, B.-T. J. Am. Chem. Soc. 2008, 130 (38), 12828-12833.

(123) Roncali, J. Macromol. Rapid Commun. 2007, 28 (17), 17611775.

(124) Brédas, J. L.; Calbert, J. P.; da Silva Filho, D. A.; Cornil, J. Proc. Natl. Acad. Sci. U. S. A. 2002, 99 (9), 5804-5809.

(125) Ando, S.; Nishida, J.-i.; Tada, H.; Inoue, Y.; Tokito, S.; Yamashita, Y. J. Am. Chem. Soc. 2005, 127 (15), 5336-5337.

(126) Baek, N. S.; Hau, S. K.; Yip, H.-L.; Acton, O.; Chen, K.-S.; Jen, A. K. Y. Chem. Mater. 2008, 20 (18), 5734-5736.

(127) Wu, J.-S.; Cheng, Y.-J.; Dubosc, M.; Hsieh, C.-H.; Chang, C.-Y.; Hsu, C.-S. Chem. Commun. (Cambridge, U. K.) 2010, 46 (19), 3259-3261.

(128) Song, S.; Jin, Y.; Kim, S. H.; Moon, J.; Kim, K.; Kim, J. Y.; Park, S. H.; Lee, K.; Suh, H. Macromolecules 2008, 41 (20), 7296-7305.

(129) Chen, Y.-C.; Yu, C.-Y.; Fan, Y.-L.; Hung, L.-I.; Chen, C.-P.; Ting, C. Chem. Commun. (Cambridge, U. K.) 2010, 46 (35), 65036505.

(130) Hale, G. D.; Oldenburg, S. J.; Halas, N. J. Appl. Phys. Lett. 1997, 71 (11), 1483-1485.

(131) Cumpston, B. H.; Jensen, K. F. Synth. Met. 1995, 73 (3), 195199.

(132) Wang, J.-Y.; Hau, S. K.; Yip, H.-L.; Davies, J. A.; Chen, K.-S.; Zhang, Y.; Sun, Y.; Jen, A. K. Y. Chem. Mater. 2011, 23 (3), 765-767.

(133) Chen, C. H.; Cheng, Y. J.; Dubosc, M.; Hsieh, C. H.; Chu, C. C.; Hsu, C. S. Chem.-Asian J. 2010, 5 (12), 2483-92.

(134) Xia, Y.; Su, X.; He, Z.; Ren, X.; Wu, H.; Cao, Y.; Fan, D. Macromol. Rapid Commun. 2010, 31 (14), 1287-1292.

(135) Lee, T. W.; Kang, N. S.; Yu, J. W.; Hoang, M. H.; Kim, K. H.; Jin, J.-I.; Choi, D. H. J. Polym. Sci., Part A: Polym. Chem. 2010, 48 (24), $5921-5929$.

(136) Zhou, E.; Yamakawa, S.; Zhang, Y.; Tajima, K.; Yang, C.; Hashimoto, K. J. Mater. Chem. 2009, 19 (41), 7730-7737.

(137) Lu, J.; Liang, F.; Drolet, N.; Ding, J.; Tao, Y.; Movileanu, R. Chem. Commun. (Cambridge, U. K.) 2008, 44 (42), 5315-5317.

(138) Yu, C.-Y.; Chen, C.-P.; Chan, S.-H.; Hwang, G.-W.; Ting, C. Chem. Mater. 2009, 21 (14), 3262-3269.

(139) Xiao, S.; Stuart, A. C.; Liu, S.; Zhou, H.; You, W. Adv. Funct. Mater. 2010, 20 (4), 635-643.

(140) Coropceanu, V.; Kwon, O.; Wex, B.; Kaafarani, B. R.; Gruhn, N. E.; Durivage, J. C.; Neckers, D. C.; Brédas, J.-L. Chem.-Eur. J. 2006, 12 (7), 2073-2080.

(141) Xiao, S.; Zhou, H.; You, W. Macromolecules 2008, 41 (15), $5688-5696$.

(142) Osaka, I.; Abe, T.; Shinamura, S.; Miyazaki, E.; Takimiya, K. J. Am. Chem. Soc. 2010, 132 (14), 5000-5001.

(143) Laquindanum, J. G.; Katz, H. E.; Lovinger, A. J. J. Am. Chem. Soc. 1998, 120 (4), 664-672.

(144) Jiang, Y.; Okamoto, T.; Becerril, H. A.; Hong, S.; Tang, M. L.; Mayer, A. C.; Parmer, J. E.; McGehee, M. D.; Bao, Z. Macromolecules 2010, 43 (15), 6361-6367. 
(145) Umeda, R.; Fukuda, H.; Miki, K.; Rahman, S. M. A.; Sonoda, M.; Tobe, Y. C. R. Chim. 2009, 12 (3-4), 378-384.

(146) Loser, S.; Bruns, C. J.; Miyauchi, H.; Ortiz, R. o. P.; Facchetti, A.; Stupp, S. I.; Marks, T. J. J. Am. Chem. Soc. 2011, 133 (21), 81428145.

(147) Mayer, A. C.; Toney, M. F.; Scully, S. R.; Rivnay, J.; Brabec, C. J.; Scharber, M.; Koppe, M.; Heeney, M.; McCulloch, I.; McGehee, M. D. Adv. Funct. Mater. 2009, 19 (8), 1173-1179.

(148) Cates, N. C.; Gysel, R.; Dahl, J. E. P.; Sellinger, A.; McGehee, M. D. Chem. Mater. 2010, 22 (11), 3543-3548.

(149) Xiao, S.; Stuart, A. C.; Liu, S.; You, W. ACS Appl. Mater. Interfaces 2009, 1 (7), 1613-1621.

(150) Osaka, I.; Abe, T.; Shinamura, S.; Takimiya, K. J. Am. Chem. Soc. 2011, 133 (17), 6852-6860.

(151) Shinamura, S.; Osaka, I.; Miyazaki, E.; Nakao, A.; Yamagishi, M.; Takeya, J.; Takimiya, K. J. Am. Chem. Soc. 2011, 133 (13), 5024-5035.

(152) Rieger, R.; Beckmann, D.; Pisula, W.; Steffen, W.; Kastler, M.; Müllen, K. Adv. Mater. 2010, 22 (1), 83-86.

(153) Rieger, R.; Beckmann, D.; Mavrinskiy, A.; Kastler, M.; Müllen, K. Chem. Mater. 2010, 22 (18), 5314-5318.

(154) Hou, J.; Chen, H.-Y.; Zhang, S.; Li, G.; Yang, Y. J. Am. Chem. Soc. 2008, 130 (48), 16144-16145.

(155) Blouin, N.; Michaud, A.; Leclerc, M. Adv. Mater. 2007, 19 (17), 2295-2300.

(156) Blouin, N.; Michaud, A.; Gendron, D.; Wakim, S.; Blair, E.; Neagu-Plesu, R.; Belletete, M.; Durocher, G.; Tao, Y.; Leclerc, M. J. Am. Chem. Soc. 2008, 130 (2), 732-742.

(157) Slooff, L. H.; Veenstra, S. C.; Kroon, J. M.; Moet, D. J. D.; Sweelssen, J.; Koetse, M. M. Appl. Phys. Lett. 2007, 90 (14), 143506.

(158) Kline, R. J.; McGehee, M. D.; Kadnikova, E. N.; Liu, J.; Fréchet, J. M. J.; Toney, M. F. Macromolecules 2005, 38 (8), 33123319.

(159) Zhou, H.; Yang, L.; Xiao, S.; Liu, S.; You, W. Macromolecules 2010, 43 (2), 811-820.

(160) Wang, X.; Perzon, E.; Mammo, W.; Oswald, F.; Admassie, S.; Persson, N.-K.; Langa, F.; Andersson, M. R.; Inganaes, O. Thin Solid Films 2006, 511-512 (1), 576-580.

(161) Tsai, J.-H.; Chueh, C.-C.; Lai, M.-H.; Wang, C.-F.; Chen, W.-C.; Ko, B.-T.; Ting, C. Macromolecules 2009, 42 (6), 1897-1905.

(162) Lee, J.-Y.; Shin, W.-S.; Haw, J.-R.; Moon, D.-K. J. Mater. Chem. 2009, 19 (28), 4938-4945.

(163) Padhy, H.; Huang, J.-H.; Sahu, D.; Patra, D.; Kekuda, D.; Chu, C.-W.; Lin, H.-C. J. Polym. Sci., Part A: Polym. Chem. 2010, 48 (21), $4823-4834$

(164) Yang, R.; Tian, R.; Hou, Q.; Yang, W.; Cao, Y. Macromolecules 2003, 36 (20), 7453-7460.

(165) Hou, J.; Chen, T. L.; Zhang, S.; Yang, Y. J. Phys. Chem. C 2009, 113 (4), 1601-1605.

(166) Jung, I. H.; Kim, H.; Park, M.-J.; Kim, B.; Park, J.-H.; Jeong, E.; Woo, H. Y.; Yoo, S.; Shim, H.-K. J. Polym. Sci., Part A: Polym. Chem. 2010, 48 (6), 1423-1432.

(167) Li, Z.; Ding, J.; Song, N.; Lu, J.; Tao, Y. J. Am. Chem. Soc. 2010, 132 (38), 13160-13161.

(168) Wang, E.; Ma, Z.; Zhang, Z.; Henriksson, P.; Inganas, O.; Zhang, F.; Andersson, M. R. Chem. Commun. (Cambridge, U. K.) 2011, 47 (17), 4908-4910.

(169) Bijleveld, J. C.; Gevaerts, V. S.; Di, N. D.; Turbiez, M.; Mathijssen, S. G. J.; de, L. D. M.; Wienk, M. M.; Janssen, R. A. J. Adv. Mater. 2010, 22 (35), E242-E246.

(170) Liu, B.; Zou, Y.; Peng, B.; Zhao, B.; Huang, K.; He, Y.; Pan, C. Polym. Chem. 2011, 2 (5), 1156-1162.

(171) Mei, J.; Graham, K. R.; Stalder, R.; Reynolds, J. R. Org. Lett. 2010, 12 (4), 660-663.

(172) Wienk, M. M.; Turbiez, M.; Gilot, J.; Janssen, R. A. J. Adv. Mater. 2008, 20 (13), 2556-2560.

(173) Zou, Y.; Gendron, D.; Badrou-Aïch, R. d.; Najari, A.; Tao, Y.; Leclerc, M. Macromolecules 2009, 42 (8), 2891-2894.
(174) Huo, L.; Hou, J.; Chen, H.-Y.; Zhang, S.; Jiang, Y.; Chen, T. L.; Yang, Y. Macromolecules 2009, 42 (17), 6564-6571.

(175) Woo, C. H.; Beaujuge, P. M.; Holcombe, T. W.; Lee, O. P.; Frechet, J. M. J. J. Am. Chem. Soc. 2010, 132 (44), 15547-15549.

(176) Bronstein, H.; Chen, Z.; Ashraf, R. S.; Zhang, W.; Du, J.; Durrant, J. R.; Shakya, T. P.; Song, K.; Watkins, S. E.; Geerts, Y.; Wienk, M. M.; Janssen, R. A. J.; Anthopoulos, T.; Sirringhaus, H.; Heeney, M.; McCulloch, I. J. Am. Chem. Soc. 2011, 133 (10), 32723275.

(177) Zou, Y.; Najari, A.; Berrouard, P.; Beaupre, S.; Reda, A. B.; Tao, Y.; Leclerc, M. J. Am. Chem. Soc. 2010, 132 (15), 5330-5331.

(178) Zhang, Y.; Hau, S. K.; Yip, H.-L.; Sun, Y.; Acton, O.; Jen, A. K. Y. Chem. Mater. 2010, 22 (9), 2696-2698.

(179) Zhang, G.; Fu, Y.; Zhang, Q.; Xie, Z. Chem. Commun. (Cambridge, U. K.) 2010, 46 (27), 4997-4999.

(180) Piliego, C.; Holcombe, T. W.; Douglas, J. D.; Woo, C. H.; Beaujuge, P. M.; Frechet, J. M. J. J. Am. Chem. Soc. 2010, 132 (22), 7595-7597.

(181) Li, Z.; Tsang, S.-W.; Du, X.; Scoles, L.; Robertson, G.; Zhang, Y.; Toll, F.; Tao, Y.; Lu, J.; Ding, J. Adv. Funct. Mater. 2011, 21 (17), $3331-3336$

(182) Bundgaard, E.; Krebs, F. C. Macromolecules 2006, 39 (8), 2823-2831.

(183) Perzon, E.; Wang, X.; Zhang, F.; Mammo, W.; Delgado, J. L.; de la Cruz, P.; Inganäs, O.; Langa, F.; Andersson, M. R. Synth. Met. 2005, 154 (1-3), 53-56.

(184) Wang, X.; Perzon, E.; Delgado, J. L.; de la Cruz, P.; Zhang, F.; Langa, F.; Andersson, M.; Inganas, O. Appl. Phys. Lett. 2004, 85 (21), 5081-5083.

(185) Zhang, F.; Bijleveld, J.; Perzon, E.; Tvingstedt, K.; Barrau, S.; Inganas, O.; Andersson, M. R. J. Mater. Chem. 2008, 18 (45), 54685474.

(186) Gendron, D.; Morin, P.-O.; Najari, A.; Leclerc, M. Macromol. Rapid Commun. 2010, 31 (12), 1090-1094.

(187) Brédas, J. L.; Heeger, A. J. Chem. Phys. Lett. 1994, 217 (5-6), 507-512.

(188) Helbig, M.; Hörhold, H.-H. Makromol. Chem. 1993, 194 (6), $1607-1618$.

(189) Greenham, N. C.; Moratti, S. C.; Bradley, D. D. C.; Friend, R. H.; Holmes, A. B. Nature (London, U. K.) 1993, 365 (6447), 628630.

(190) Wong, S.; Ma, H.; Jen, A. K. Y.; Barto, R.; Frank, C. W. Macromolecules 2003, 36 (21), 8001-8007.

(191) Reichenbacher, K.; Suss, H. I.; Hulliger, J. Chem. Soc. Rev. 2005, 34 (1), 22-30.

(192) Pagliaro, M.; Ciriminna, R. J. Mater. Chem. 2005, 15 (47), 4981-4991.

(193) Wang, Y.; Parkin, S. R.; Gierschner, J.; Watson, M. D. Org. Lett. 2008, 10 (15), 3307-3310.

(194) Liang, Y.; Feng, D.; Wu, Y.; Tsai, S.-T.; Li, G.; Ray, C.; Yu, L. J. Am. Chem. Soc. 2009, 131 (22), 7792-7799.

(195) Liang, Y.; Yu, L. Acc. Chem. Res. 2010, 43 (9), 1227-1236.

(196) Cho, S.; Seo, J. H.; Kim, S. H.; Song, S.; Jin, Y.; Lee, K.; Suh, H.; Heeger, A. J. Appl. Phys. Lett. 2008, 93 (26), 263301-263303.

(197) Jayakannan, M.; Van Hal, P. A.; Janssen, R. A. J. J. Polym. Sci., Part A: Polym. Chem. 2002, 40 (2), 251-261.

(198) Karikomi, M.; Kitamura, C.; Tanaka, S.; Yamashita, Y. J. Am. Chem. Soc. 2002, 117 (25), 6791-6792.

(199) Wang, E.; Wang, M.; Wang, L.; Duan, C.; Zhang, J.; Cai, W.; He, C.; Wu, H.; Cao, Y. Macromolecules 2009, 42 (13), 4410-4415.

(200) Gadisa, A.; Oosterbaan, W. D.; Vandewal, K.; Bolsée, J.-C.; Bertho, S.; D'Haen, J.; Lutsen, L.; Vanderzande, D.; Manca, J. V. Adv. Funct. Mater. 2009, 19 (20), 3300-3306.

(201) Egbe, D. A. M.; Türk, S.; Rathgeber, S.; Kühnlenz, F.; Jadhav, R.; Wild, A.; Birckner, E.; Adam, G.; Pivrikas, A.; Cimrova, V.; Knör, G. n.; Sariciftci, N. S.; Hoppe, H. Macromolecules 2010, 43 (3), 12611269. 
(202) Szarko, J. M.; Guo, J.; Liang, Y.; Lee, B.; Rolczynski, B. S.; Strzalka, J.; Xu, T.; Loser, S.; Marks, T. J.; Yu, L.; Chen, L. X. Adv. Mater. 2010, 22 (48), 5468-5472.

(203) Shi, C. J.; Yao, Y.; Yang, Y.; Pei, Q. B. J. Am. Chem. Soc. 2006, 128 (27), 8980-8986.

(204) Hou, J.; Chen, H.-Y.; Zhang, S.; Yang, Y. J. Phys. Chem. C 2009, 113 (50), 21202-21207.

(205) Hou, J.; Chen, H.-Y.; Zhang, S.; Chen, R. I.; Yang, Y.; Wu, Y.;

Li, G. J. Am. Chem. Soc. 2009, 131 (43), 15586-15587.

(206) Price, S. C.; Stuart, A. C.; You, W. Macromolecules 2010, 43 (10), 4609-4612.

(207) Bagnis, D.; Beverina, L.; Huang, H.; Silvestri, F.; Yao, Y.; Yan, H.; Pagani, G. A.; Marks, T. J.; Facchetti, A. J. Am. Chem. Soc. 2010, 132 (12), 4074-4075.

(208) Clarke, T. M.; Durrant, J. R. Chem. Rev. (Washington, DC, U. S.) 2010, 110 (11), 6736-6767.

(209) Zhu, X. Y.; Yang, Q.; Muntwiler, M. Acc. Chem. Res. 2009, 42 (11), 1779-1787.

(210) Deibel, C.; Dyakonov, V. Rep. Prog. Phys. 2010, 73 (9), 096401.

(211) Peet, J.; Heeger, A. J.; Bazan, G. C. Acc. Chem. Res. 2009, 42 (11), 1700-1708.

(212) Peet, J.; Senatore, M. L.; Heeger, A. J.; Bazan, G. C. Adv. Mater. 2009, 21 (14-15), 1521-1527.

(213) Moulé, A. J.; Meerholz, K. Adv. Funct. Mater. 2009, 19 (19), 3028-3036.

(214) van Bavel, S.; Veenstra, S.; Loos, J. Macromol. Rapid Commun. 2010, 31 (21), 1835-1845.

(215) Groves, C.; Reid, O. G.; Ginger, D. S. Acc. Chem. Res. 2010, 43 (5), 612-620.

(216) Chen, L.-M.; Hong, Z.; Li, G.; Yang, Y. Adv. Mater. 2009, 21 (14-15), 1434-1449.

(217) Huo, L.; Zhang, S.; Guo, X.; Xu, F.; Li, Y.; Hou, J. Angew. Chem., Int. Ed. 2011, 50 (41), 9697-9702.

(218) Kotlarski, J. D.; Blom, P. W. M. Appl. Phys. Lett. 2011, 98 (5), $053301-053303$.

(219) http://www.flisom.ch/.

(220) http://www.q-cells.com/en/index.html.

(221) Hou, J.; Tan, Z. a.; Yan, Y.; He, Y.; Yang, C.; Li, Y. J. Am. Chem. Soc. 2006, 128 (14), 4911-4916.

(222) Zhou, E.; Cong, J.; Wei, Q.; Tajima, K.; Yang, C.; Hashimoto, K. Angew. Chem., Int. Ed. 2011, 50 (12), 2799-2803.

(223) Schlenker, C. W.; Thompson, M. E. Chem. Commun. (Cambridge, U. K.) 2011, 47 (13), 3702-3716.

(224) Brunetti, F. G.; Gong, X.; Tong, M.; Heeger, A. J.; Wudl, F. Angew. Chem., Int. Ed. 2010, 49 (3), 532-536.

(225) Gong, X.; Tong, M.; Brunetti, F. G.; Seo, J.; Sun, Y.; Moses, D.; Wudl, F.; Heeger, A. J. Adv. Mater. 2011, 23 (20), 2272-2277.

(226) Street, R. A. Appl. Phys. Lett. 2008, 93 (13), 133308-133311.

(227) Varotto, A.; Treat, N. D.; Jo, J.; Shuttle, C. G.; Batara, N. A.; Brunetti, F. G.; Seo, J. H.; Chabinyc, M. L.; Hawker, C. J.; Heeger, A. J.; Wudl, F. Angew. Chem., Int. Ed. 2011, 50 (22), 5166-5169.

(228) Brabec, C. J.; Heeney, M.; McCulloch, I.; Nelson, J. Chem. Soc. Rev. 2011, 40 (3), 1185-1199.

(229) Cates, N. C.; Gysel, R.; Beiley, Z.; Miller, C. E.; Toney, M. F.; Heeney, M.; McCulloch, I.; McGehee, M. D. Nano Lett. 2009, 9 (12), $4153-4157$.

(230) Steim, R.; Kogler, F. R; Brabec, C. J. J. Mater. Chem. 2010, 20 (13), 2499-2512.

(231) Chen, L.-M.; Xu, Z.; Hong, Z.; Yang, Y. J. Mater. Chem. 2010, 20 (13), 2575-2598.

(232) Irwin, M. D.; Buchholz, D. B.; Hains, A. W.; Chang, R. P. H; Marks, T. J. Proc. Natl. Acad. Sci. U. S. A. 2008, 105 (8), 2783-2787.

(233) Sun, Y.; Takacs, C. J.; Cowan, S. R.; Seo, J. H.; Gong, X.; Roy, A.; Heeger, A. J. Adv. Mater. 2011, 23 (19), 2226-2230.

(234) Subbiah, J.; Kim, D. Y.; Hartel, M.; So, F. Appl. Phys. Lett. 2010, 96 (6), 063303-063306.

(235) Kröger, M.; Hamwi, S.; Meyer, J.; Riedl, T.; Kowalsky, W.; Kahn, A. Appl. Phys. Lett. 2009, 95 (12), 123301-123304.
(236) Tao, C.; Ruan, S. P.; Xie, G. H.; Kong, X. Z.; Shen, L.; Meng, F. X.; Liu, C. X.; Zhang, X. D.; Dong, W.; Chen, W. Y. Appl. Phys. Lett. 2009, 94 (4), 043311-043314.

(237) Meyer, J.; Kroger, M.; Hamwi, S.; Gnam, F.; Riedl, T.; Kowalsky, W.; Kahn, A. Appl. Phys. Lett. 2010, 96 (19), 193302193305.

(238) Hayakawa, A.; Yoshikawa, O.; Fujieda, T.; Uehara, K.; Yoshikawaa, S. Appl. Phys. Lett. 2007, 90 (16), 163517-163520.

(239) Sun, Y.; Seo, J. H.; Takacs, C. J.; Seifter, J.; Heeger, A. J. Adv. Mater. 2011, 23 (14), 1679-1683.

(240) Yip, H.-L.; Hau, S. K.; Baek, N. S.; Ma, H.; Jen, A. K. Y. Adv. Mater. 2008, 20 (12), 2376-2382.

(241) Bulliard, X.; Ihn, S.-G.; Yun, S.; Kim, Y.; Choi, D.; Choi, J.-Y.; Kim, M.; Sim, M.; Park, J.-H.; Choi, W.; Cho, K. Adv. Funct. Mater. 2010, 20 (24), 4381-4387.

(242) Chang, C.-Y.; Wu, C.-E.; Chen, S.-Y.; Cui, C.; Cheng, Y.-J.; Hsu, C.-S.; Wang, Y.-L.; Li, Y. Angew. Chem., Int. Ed. 2011, 50 (40), 9386-9390.

(243) Ameri, T.; Dennler, G.; Waldauf, C.; Azimi, H.; Seemann, A.; Forberich, K.; Hauch, J.; Scharber, M.; Hingerl, K.; Brabec, C. J. Adv. Funct. Mater. 2010, 20 (10), 1592-1598.

(244) Ko, D.-H.; Tumbleston, J. R.; Zhang, L.; Williams, S.; DeSimone, J. M.; Lopez, R.; Samulski, E. T. Nano Lett. 2009, 9 (7), 2742-2746.

(245) Hadipour, A.; de Boer, B.; Blom, P. W. M. Adv. Funct. Mater. 2008, 18 (2), 169-181.

(246) Hu, L.; Hecht, D. S.; Grüner, G. Nano Lett. 2004, 4 (12), 2513-2517.

(247) Wu, Z.; Chen, Z.; Du, X.; Logan, J. M.; Sippel, J.; Nikolou, M.; Kamaras, K.; Reynolds, J. R.; Tanner, D. B.; Hebard, A. F.; Rinzler, A. G. Science (Washington, DC, U. S.) 2004, 305 (5688), 1273-1276.

(248) Zhang, M.; Fang, S.; Zakhidov, A. A.; Lee, S. B.; Aliev, A. E.; Williams, C. D.; Atkinson, K. R.; Baughman, R. H. Science (Washington, DC, U. S.) 2005, 309 (5738), 1215-1219.

(249) Li, J.; Hu, L.; Wang, L.; Zhou, Y.; Grüner, G.; Marks, T. J. Nano Lett. 2006, 6 (11), 2472-2477.

(250) Miller, A. J.; Hatton, R. A.; Silva, S. R. P. Appl. Phys. Lett. 2006, 89 (13), 133117-133120.

(251) Rowell, M. W.; Topinka, M. A.; McGehee, M. D.; Prall, H.-J.; Dennler, G.; Sariciftci, N. S.; Hu, L.; Gruner, G. Appl. Phys. Lett. 2006 88 (23), 233506-233509.

(252) Eda, G.; Fanchini, G.; Chhowalla, M. Nature Nanotechnol. 2008, 3 (5), 270-274.

(253) Kim, K. S.; Zhao, Y.; Jang, H.; Lee, S. Y.; Kim, J. M.; Kim, K. S.; Ahn, J.-H.; Kim, P.; Choi, J.-Y.; Hong, B. H. Nature (London, U. K.) 2009, 457 (7230), 706-710.

(254) Gomez De Arco, L.; Zhang, Y.; Schlenker, C. W.; Ryu, K.; Thompson, M. E.; Zhou, C. ACS Nano 2010, 4 (5), 2865-2873.

(255) Gaynor, W.; Burkhard, G. F.; McGehee, M. D.; Peumans, P. Adv. Mater. 2011, 23 (26), 2905-2910.

(256) Yang, L.; Zhang, T.; Zhou, H.; Price, S. C.; Wiley, B. J.; You, W. ACS Appl. Mater. Interfaces 2011, 3 (10), 4075-4084.

(257) http://www.konarka.com/. 